\title{
Anotação e classificação automática de entidades nomeadas em notícias esportivas em Português Brasileiro
}

\author{
Rodrigo Constantin Ctenas Zaccara
}

\section{DisSERTAÇÃO APRESENTADA}

$\mathrm{AO}$

Instituto DE Matemática e Estatística

$\mathrm{DA}$

Universidade de SÃo Paulo

PARA

OBTENÇÃO DO TÍTULO

$\mathrm{DE}$

Mestre em CiÊnCIAS

Programa: Ciência da Computação

Orientador: Prof. Dr. Marcelo Finger 


\section{Anotação e classificação automática de entidades nomeadas em notícias esportivas em Português Brasileiro}

Esta versão da dissertação contém as correções e alterações sugeridas pela Comissão Julgadora durante a defesa da versão original do trabalho, realizada em 11/07/2012. Uma cópia da versão original está disponível no

Instituto de Matemática e Estatística da Universidade de São Paulo.

Comissão Julgadora:

- Prof. Dr. Marcelo Finger (orientador) - IME-USP

- Prof. Dr. Alfredo Goldman vel Lejbman - IME-USP

- Prof. Ricardo Luis de Azevedo da Rocha - EP-USP 


\section{Resumo}

ZACCARA, R. C. C. Anotação e classificação automática de entidades nomeadas em notícias esportivas em Português Brasileiro. 2012. 72 f. Dissertação (Mestrado) Instituto de Matemática e Estatística, Universidade de São Paulo, São Paulo, 2012.

O objetivo deste trabalho é desenvolver uma plataforma para anotação e classificação automática de entidades nomeadas para notícias escritas em português do Brasil. Para restringir um pouco o escopo do treinamento e análise foram utilizadas notícias esportivas do Campeonato Paulista de 2011 do portal UOL ${ }^{1}$ (Universo Online).

O primeiro artefato desenvolvido desta plataforma foi a ferramenta WebCorpus. Esta tem como principal intuito facilitar o processo de adição de metainformações a palavras através do uso de uma interface rica web, elaborada para deixar o trabalho ágil e simples. Desta forma as entidades nomeadas das notícias são anotadas e classificadas manualmente. A base de dados foi alimentada pela ferramenta de aquisição e extração de conteúdo desenvolvida também para esta plataforma.

O segundo artefato desenvolvido foi o córpus UOLCP2011 (UOL Campeonato Paulista 2011). Este córpus foi anotado e classificado manualmente através do uso da ferramenta WebCorpus utilizando sete tipos de entidades: pessoa, lugar, organização, time, campeonato, estádio e torcida.

Para o desenvolvimento do motor de anotação e classificação automática de entidades nomeadas foram utilizadas três diferentes técnicas: maximização de entropia, índices invertidos e métodos de mesclagem das duas técnicas anteriores. Para cada uma destas foram executados três passos: desenvolvimento do algoritmo, treinamento utilizando técnicas de aprendizado de máquina e análise dos melhores resultados.

Palavras-chave: córpus; entidade nomeada; motor de anotação e classificação; interface rica web; webcorpus; uolcp2011; maximização de entropia; índices invertidos; aprendizado de máquina.

\footnotetext{
${ }^{1}$ http://www.uol.com.br/
} 


\title{
Abstract
}

\author{
ZACCARA, R. C. C. Automatic named entity recognition and classification for
} brazilian portuguese sport news. 2012. 72 f. Dissertação (Mestrado) - Instituto de Matemática e Estatística, Universidade de São Paulo, São Paulo, 2012.

The main target of this research is to develop an automatic named entity classification tool to sport news written in Brazilian Portuguese. To reduce this scope, during training and analysis only sport news about São Paulo Championship of 2011 written by UOL ${ }^{2}$ (Universo Online) was used.

The first artefact developed was the WebCorpus tool, which aims to make easier the process of add meta informations to words, through a rich web interface. Using this, all the corpora news are tagged manually. The database used by this tool was fed by the crawler tool, also developed during this research.

The second artefact developed was the corpora UOLCP2011 (UOL Campeonato Paulista 2011). This corpora was manually tagged using the WebCorpus tool. During this process, seven classification concepts were used: person, place, organization, team, championship, stadium and fans.

To develop the automatic named entity classification tool, three different approaches were analysed: maximum entropy, inverted index and merge tecniques using both. Each approach had three steps: algorithm development, training using machine learning tecniques and best score analysis.

Keywords: corpora; named entity; classification tool; web rich interface; webcorpus; uolcp2011; maximum entropy; inverted index; machine learning.

${ }^{2}$ http://www.uol.com.br/ 


\section{Sumário}

Lista de Figuras $\quad$ vii

Lista de Tabelas $\quad$ ix

1 Introdução $\quad 1$

1.1 Motivação . . . . . . . . . . . . . . . . . . . . 2

1.2 Objetivos . . . . . . . . . . . . . . . . . . . . 2

1.3 Organização do trabalho . . . . . . . . . . . . . . . . . . . . . . 2

2 Bases conceituais 5

2.1 Córpus . . . . . . . . . . . . . . . . . . . 5

$2.1 .1 \quad$ MUC-7 . . . . . . . . . . . . . . . . . 6

2.1.2 CETENFolha . . . . . . . . . . . . . . . 7

2.2 Aquisição e extração de conteúdo . . . . . . . . . . . . . . . . . . . 10

2.3 Aprendizado de máquina . . . . . . . . . . . . . . . . . . . . 10

2.3.1 Maximização de entropia . . . . . . . . . . . . . . . . . . 11

2.3 .2 Índices invertidos . . . . . . . . . . . . . . . . . . . . 11

2.3.3 Transformação guiada por erro . . . . . . . . . . . . . . . 13

2.3.4 Máquina de vetores de suporte . . . . . . . . . . . . . . . . . . . . 14

3 Aquisição e extração de conteúdo $\quad 15$

3.1 Arquitetura . . . . . . . . . . . . . . . . . . 16

3.2 Especialização . . . . . . . . . . . . . . . . . . . . . . . . . . . 17

4 Interface para classificação de conteúdo $\quad 21$

4.1 Arquitetura . . . . . . . . . . . . . . . . . . . . . 23

4.2 Implementação . . . . . . . . . . . . . . . . . . . . . . . . . . . . 24

5 Córpus $\quad 29$

5.1 Regras de anotação . . . . . . . . . . . . . . . . . . . . . 29

5.2 Tipologia do córpus . . . . . . . . . . . . . . . . . . . . . . . . . 30

5.3 Formato . . . . . . . . . . . . . . . . . . . . . 30

5.4 Licença . . . . . . . . . . . . . . . . . . . . . . . . . . . . . 32 
5.5 Estatísticas . . . . . . . . . . . . . . . . . 32

6 Maximização de entropia $\quad 37$

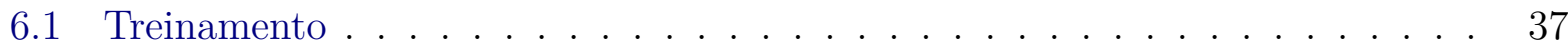

6.2 Análise dos resultados . . . . . . . . . . . . . . . . . . 45

7 Índices invertidos $\quad 51$

7.1 Implementação . . . . . . . . . . . . . . . . . . . . . . . . . 51

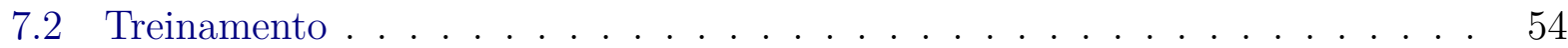

7.3 Análise dos resultados . . . . . . . . . . . . . . . . . 56

8 Método de mesclagem ROdIME $\quad 61$

8.1 Implementação . . . . . . . . . . . . . . . . . . . . . . . . . . . . 61

8.2 Análise dos resultados . . . . . . . . . . . . . . . . . . . . 64

8.3 Comparação com método Carvalho' $12 \ldots \ldots$. . . . . . . . . . . 66

9 Conclusão $\quad 69$

9.1 Trabalhos futuros . . . . . . . . . . . . . . . . . 70

$\begin{array}{ll}\text { Referências Bibliográficas } & 71\end{array}$ 


\section{Lista de Figuras}

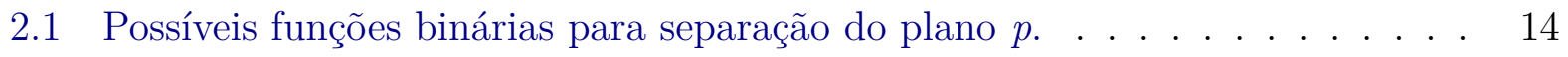

3.1 Em destaque os links que o processo de aquisição de notícias deve escolher entre todos os links da página. . . . . . . . . . . . . . . . . 15

3.2 A área em destaque indica a parte da página que contém o conteúdo da notícia. 16

3.3 Diagrama de classes do serviço de crawler. . . . . . . . . . . . . . . . . 17

3.4 A área clara indica o conteúdo que deve ser descartado no processo de extração de conteúdo. . . . . . . . . . . . . . . . . . . . . . . . . . 19

4.1 Captura de tela da ferramenta WebCorpus durante o processo de classificação. 22

4.2 Captura de tela da primeira versão da ferramenta de classificação de textos. 23

4.3 Estrutura do pacote services . . . . . . . . . . . . . . . . . . . . . 24

4.4 Exemplo de alguns dos recursos localizados para os idiomas: inglês (a esquerda) e português (a direita). . . . . . . . . . . . . . 25

4.5 Estrutura do pacote repository . . . . . . . . . . . . . . . 26

6.1 Resultado dos 36 cenários de teste efetuados para o quinto conjunto de entrada da entidade time. . . . . . . . . . . . . . . . . . . 40

6.2 Resultado dos 36 cenários de teste efetuados para o quinto conjunto de entrada da entidade pessoa. . . . . . . . . . . . . . . . . . . . . . 41

6.3 Resultado dos 36 cenários de teste efetuados para o sexto conjunto de entrada da entidade lugar. . . . . . . . . . . . . . . . . . . . . . .

6.4 Resultado dos 36 cenários de teste efetuados para o quarto conjunto de entrada da entidade campeonato. . . . . . . . . . . . . . .

6.5 Resultado dos 36 cenários de teste efetuados para o sétimo conjunto de entrada da entidade estádio. . . . . . . . . . . . . . . . . . . . . . . 44

6.6 Resultado dos 36 cenários de teste efetuados para o nono conjunto de entrada da entidade organização. . . . . . . . . . . . . . . . . . . .

6.7 Resultado dos 36 cenários de teste efetuados para o oitavo conjunto de entrada para todas as entidades. . . . . . . . . . . . . . . . . . . 46

7.1 Classes do pacote rindex relacionadas ao motor de anotação e classificação. 52

7.2 Classes do pacote rindex relacionadas ao processo de anotação e classificação. 53 
7.3 Resultado do treinamento para o indicador precisão. . . . . . . . . . . . . . 55

7.4 Resultado do treinamento para o indicador cobertura. . . . . . . . . . . . . 55

7.5 Resultado do treinamento para o indicador medida F . . . . . . . . . . . . 56

8.1 Diagrama de classes da implementação do método de mesclagem ROdIME. 62 


\section{Lista de Tabelas}

2.1 Possíveis valores para o atributo TYPE em cada tipo de tag. . . . . . . . . . 7

2.2 Fragmento do arquivo de exemplo do MUC-7. . . . . . . . . . . . 8

2.3 Fragmento completo de uma notícia do córpus CETENFolha versão simples. 9

2.4 Trecho de uma notícia do córpus CETENFolha anotado sintaticamente. . . . 9

2.5 Lista de documentos que serão indexados. . . . . . . . . . . . . . . . . 12

2.6 Índice invertido contendo a relação entre palavra e documento. . . . . . . . . 12

2.7 Índice invertido contendo o identificador do documento e posição da palavra neste. . . . . . . . . . . . . . . . . . . . . . 13

5.1 Classificação segundo os critérios propostos em Sardinha (2004). . . . . . . . 30

5.2 Classificação segundo os critérios propostos em Piperidis (2007). . . . . . . . 31

5.3 Exemplo de documento utilizando o formato XML e anotações de entidades nomeadas. Os elementos do tipo CDATA foram omitidos do início de fim de cada etiqueta para tornar mais clara a estrutura do documento. . . . . . . . 31

5.4 Termos na licença MIT. . . . . . . . . . . . . . . . . . . . 32

5.5 Agrupamento das palavras presentes do córpus separadas por classes de repetições. . . . . . . . . . . . . . . . . . . . . . . . . . . 32

5.6 Agrupamento por repetições de todas as entidades. . . . . . . . . . . . . . 33

5.7 Agrupamento por repetições das entidades do tipo torcida. . . . . . . . . . . 33

5.8 Agrupamento por repetições das entidades do tipo lugar. . . . . . . . . . . . 33

5.9 Agrupamento por repetições das entidades do tipo organização. . . . . . . . . 33

5.10 Agrupamento por repetições das entidades do tipo estádio. . . . . . . . . . . 34

5.11 Agrupamento por repetições das entidades do tipo campeonato. . . . . . . . 34

5.12 Agrupamento por repetições das entidades do tipo pessoa. . . . . . . . . . . 34

5.13 Agrupamento por repetições das entidades do tipo time. . . . . . . . . . . . 35

6.1 Resultado dos melhores parâmetros de treinamento. . . . . . . . . . . . . 46

6.2 Comparação entre os resultados obtidos com o treinamento individual e coletivo utilizando o córpus UOLCP2011. . . . . . . . . . . . . . . 47

6.3 Resultados detalhado da anotação e classificação do modelo individual utilizando o mini córpus. . . . . . . . . . . . . . . . . . . . . 48 
6.4 Resultados detalhado da anotação e classificação do modelo coletivo utilizando o mini córpus. . . . . . . . . . . . . . . . . . . . . . . . . . . . . . . 48

6.5 Comparação entre os resultados obtidos com o treinamento individual e coletivo utilizando o mini córpus. . . . . . . . . . . . . . . . . . . . . . . . 49

7.1 Exemplo do algoritmo de janelas deslizantes com tamanho máximo igual a $2 . \quad 52$

7.2 Comparação dos resultados obtidos entre as implementações de TagSelector utilizando o córpus UOLCP2011. . . . . . . . . . . . . . . . . . 57

7.3 Resultados detalhado da anotação e classificação da heurística baseada em peso utilizando o mini córpus. . . . . . . . . . . . . . . . . . . . . 57

7.4 Resultados detalhado da anotação e classificação da heurística de análise simples utilizando o mini córpus. . . . . . . . . . . . . . . . . . . . . . 58

7.5 Resultados detalhado da anotação e classificação da heurística de análise completa utilizando o mini córpus. . . . . . . . . . . . . . . . . . . . . . . . . 59

7.6 Comparação dos resultados obtidos entre as implementações de TagSelector utilizando o mini córpus. . . . . . . . . . . . . . . . . . . . . . . . . 59

8.1 Comparação entre os resultados obtidos com o córpus UOLCP2011. . . . . . 65

8.2 Resultados detalhado da anotação e classificação do método de mesclagem ROdIME utilizando o mini córpus. . . . . . . . . . . . . . . . . . . . 65

8.3 Comparação entre os resultados obtidos com o mini córpus. . . . . . . . . . . 66

8.4 Comparação entre método de mesclagem ROdIME e Carvalho'12 para anotação e classificação do córpus UOLCP2011. . . . . . . . . . . . . . . . . 67

8.5 Comparação entre método de mesclagem ROdIME e Carvalho'12 para anotação e classificação do mini córpus. . . . . . . . . . . . . . . . . . . . . . . . 67 


\section{Capítulo 1}

\section{Introdução}

Este trabalho tem como intuito a anotação e classificação de entidades nomeadas em conteúdo jornalístico esportivo escrito em português do Brasil. A quantidade de notícias escritas diariamente por grandes portais, jornais e agências é tão grande que inviabiliza qualquer tipo de classificação manual, sendo necessário o desenvolvimento de algoritmos especializados em linguística computacional para resolver esta tarefa. Por este mesmo motivo as técnicas utilizadas neste trabalho centraram seus esforços em notícias esportivas escritas para o Campeonato Paulista de 2011 do portal UOL ${ }^{1}$.

O reconhecimento de entidades nomeadas (REN) é uma subárea de estudo no campo de extração de informação, que tem como objetivo o reconhecimento e a classificação de entidades em categorias pré definidas, tais como: pessoa, organização, lugar, entre outras. Estas categorias podem variar de acordo com objetivo do estudo.

Para que o algoritmo de aprendizado tenha seu desempenho maximizado é importante que a base de treinamento utilizada contenha a maior quantidade possível de palavras e estruturas utilizadas na linguagem. Estas bases recebem o nome de córpus e criá-las com estas características nem sempre é trivial, uma vez que faz parte da linguagem natural a esparsidade dos dados. Segundo a definição da Lei de Zipf, em Manning e Schütze (1999), existem poucas palavras comuns, uma quantidade razoável de palavras com frequência média e muitas palavras com baixa frequência.

Segundo Gasperin e de Lima (2001), a linguagem é um dos aspectos fundamentais do comportamento humano, pois permite a interação entre os indivíduos e a percepção dos conhecimentos. O ser humano compreende e desenvolve de forma natural sentenças na linguagem que aprendeu desde criança.

A linguagem apesar de exercer um papel fundamental na comunicação permite a construção de frases mal formadas ou ambíguas, e nestes cenários a ideia que se quer transmitir nem sempre é a mesma ideia que será recebida. Por exemplo a frase: "pessoas fazem orações por São Paulo" tem dois sentidos diferentes: em um deles as orações são realizadas para o santo São Paulo; e em outra interpretação as orações são realizadas para a cidade de São Paulo

\footnotetext{
${ }^{1}$ http://www.uol.com.br/ . Acesso em julho/2012.
} 
após alguma grande catástrofe. Neste cenário caso algum algoritmo para REN fosse aplicado a entidade São Paulo poderia ser classificada como pessoa ou lugar. O maior problema desta frase, no ponto de vista de classificação, é a falta de informação.

O processo de reconhecimento de classificação de entidades é muito importante para auxiliar a análise semântica de conteúdo, por exemplo, buscando referências, além de diminuir a distância entre humanos e máquinas na interpretação de comandos em linguagem natural.

\subsection{Motivação}

A motivação deste estudo é o desenvolvimento de uma ferramenta para anotação e classificação automática de entidades nomeadas em notícias esportivas. Um possível uso deste, acontece no processo de direcionamento automático de notícias para um determinado nicho. A situação a seguir ilustra um dos problemas envolvidos neste tipo de classificação automática: "exibir notícias relacionadas ao clube São Paulo para seus torcedores". Nem sempre esta tarefa é trivial, pois o termo São Paulo tem uma grande carga de ambiguidade semântica, podendo ser classificado como a cidade, o estado, o time de futebol ou a entidade religiosa.

\subsection{Objetivos}

O objetivo deste trabalho é desenvolver uma plataforma para anotação e classificação automática de entidades nomeadas para notícias escritas em português do Brasil. Os principais artefatos produzidos neste trabalho são: interface rica web para a classificação do córpus de treinamento; córpus anotado e classificado manualmente composto de notícias esportivas; avaliação e testes de diferentes estratégias para a classificação automática baseada em treinamento supervisionado.

\subsection{Organização do trabalho}

O texto está organizado da seguinte forma:

- Capítulo 2, Bases conceituais: exposição e definição de conceitos básicos para entendimento deste trabalho.

- Capítulo 3, Aquisição e extração de conteúdo: explicação detalhada da construção da ferramenta de aquisição e extração de conteúdo para a construção do córpus UOLCP2011.

- Capítulo 4, Interface para classificação de conteúdo: explicação detalhada da construção da interface rica web chamada WebCorpus para adição de metainformações a documentos, além da explicação dos padrões de classificação utilizados no córpus.

- Capítulo 5, Córpus: define o processo de criação do córpus UOLCP2011. 
- Capítulo 6, Maximização de entropia: aborda o desenvolvimento e treinamento do método de anotação e classificação baseado em maximização de entropia.

- Capítulo 7, Índices invertidos: aborda o desenvolvimento e treinamento do método de anotação e classificação baseado em índices invertidos.

- Capítulo 8, Método de mesclagem ROdIME: aborda o desenvolvimento do método de mesclagem dos resultados dos algoritmos de maximização de entropia e índices invertidos. Este capítulo realiza uma comparação entre os resultados dos Capítulos 6 e 7 e o método de mesclagem, que também será comparado com o método proposto em Carvalho (2012).

- Capítulo 9, Conclusão: rápido retrospecto dos resultados obtidos entre as diferentes técnicas e possíveis trabalhos futuros. 


\section{Capítulo 2}

\section{Bases conceituais}

Este capítulo tem como objetivo fornecer algumas definições básicas de conceitos que foram empregados durante o desenvolvimento deste trabalho. A seção 2.1 além de definir estes conceitos também irá mostrar em mais detalhes dois córpus públicos bastante utilizados em pesquisas.

\subsection{Córpus}

Segundo Sardinha (2004) a definição de córpus é dada por: "uma coleção de dados linguísticos, sejam eles textos ou partes de textos escritos ou a transcrição de fala, de uma determinada língua, escolhidos segundo um determinado critério, representando uma amostra desta língua ou uma variedade linguística".

Os córpus de estudo linguístico podem se dividir em dois conjuntos: textos puros ou textos anotados. O primeiro tipo contém texto puro sem nenhum tipo de metainformação, sendo o córpus júris escrito no ano de 534 um exemplo. Já os córpus ${ }^{1}$ anotados trazem metainformações sobre as palavras, sentenças, parágrafos, ou qualquer conjunto que faça sentido para aquela análise. Um exemplo simples é este texto, em que as palavras em itálico representam palavras escritas em outros idiomas e as palavras em negrito, a marcação entre os capítulos. Não existe nenhum tipo de padronização em relação a como as marcações são realizadas ou de seu formato, pois isso varia de acordo com o propósito de cada córpus.

O processo para a criação de um córpus, segundo Candido Jr. (2008), é realizado através das seguintes etapas: projeto, compilação, anotação e uso. O primeiro passo é a definição dos objetivos do córpus. A segunda fase é composta pelo processo de aquisição e extração dos textos definidos no primeiro passo. A terceira etapa somente é obrigatória para córpus anotados, pois esta consiste na anotação dos textos obtidos na fase anterior. Com a execução dos passos anteriores o córpus está pronto para o uso, entre eles, ser a entrada para algoritmos de treinamento em processamento de linguagem natural.

\footnotetext{
${ }^{1}$ Neste trabalho a gráfia adotada para o plural de córpus tem a mesma gráfia do singular.
} 
Em McEnery e Wilson (1996) são descritas as características fundamentais para a elaboração de um córpus para o estudo de linguística computacional:

- Autenticidade: os textos devem estar escritos em linguagem natural, sendo que estes não podem ser escritos exclusivamente para o córpus;

- amostragem e representatividade: os textos devem ter uma amostragem suficiente do idioma para que estes tenham uma representatividade significativa do propósito do córpus;

- formato digital.

Atualmente não existem comitês ou organizações responsáveis por padronizar ou catalogar os córpus, por isso ocorre uma divergência muito grande na forma de realizar anotações nos textos entre córpus de diferentes entidades. Para ilustrar este fato serão apresentados em mais detalhes os córpus: MUC-7² e CETEMFolha ${ }^{3}$.

\subsubsection{MUC-7}

Este córpus foi criado para a sétima edição do evento MUC (Message Understanding Conference Proceedings) em 1997, financiado pela DARPA (Defense Advanced Research Projects Agency). O propósito deste córpus é incentivar a criação e a melhoria de algoritmos na área de extração de informação através de uma competição. Por esta razão o córpus distribuído no MUC-7 não contém anotações referentes a classificação de entidades nomeadas, somente etiquetas estruturais para a divisão do conteúdo.

Para a construção do MUC-7 foram utilizados textos jornalísticos completos com as seguintes temáticas: quedas de aviões; lançamentos de mísseis e foguetes. Todos os textos utilizados na construção deste córpus estão escritos em inglês americano.

Este córpus utiliza SGML (Standard Generalized Markup Language) como linguagem para marcação das etiquetas estruturais, sendo este um padrão definido na norma ISO-8879 em 1996. O padrão SGML é uma evolução do GML (Generalized Markup Language) criado na IBM na década de 60.

O SGML utiliza o conceito de etiquetas para adicionar metainformações ao texto. Estas devem ter um início representado por $<$ valor $>$, sendo valor o nome da etiqueta, e um término representado por $</$ valor $>$. Desta forma o texto que está entre o início e o término ganha as metainformações desta etiqueta, no exemplo do Quadro 1, a palavra São Paulo ganhou a metainformação local.

O padrão proposto no MUC-7 prevê o uso de três tipos de etiquetas para a anotação de entidades: ENAMEX, TIMEX e NUMEX; todas estas obrigatoriamente devem conter

\footnotetext{
${ }^{2}$ http://www.itl.nist.gov/iaui/894.02/related_projects/muc/proceedings/muc_7_toc.html. Acesso em julho/2012.

3 http://www.linguateca.pt/cetenfolha/. Acesso em julho/2012.
} 


$$
\text { Chove em }<\text { local }>\text { São Paulo }</ \text { local }>\text {. }
$$

Quadro 1: Exemplo de texto anotado com etiqueta.

um atributo chamado TYPE que indica a subcategoria da etiqueta. A Tabela 2.1 exibe os possíveis valores deste atributo para cada etiqueta.

\begin{tabular}{|c|c|c|}
\hline Tag & Categoria & Descrição de uso \\
\hline ENAMEX & $\begin{array}{l}\text { LOCATION } \\
\text { ORGANIZATION } \\
\text { PERSON }\end{array}$ & $\begin{array}{l}\text { Nome político ou geográfico de } \\
\text { uma localização } \\
\text { Nome de companhia, órgão gover- } \\
\text { namental ou entidades organiza- } \\
\text { cionais } \\
\text { Nome de pessoa ou família }\end{array}$ \\
\hline NUMEX & $\begin{array}{l}\text { MONEY } \\
\text { PERCENT }\end{array}$ & $\begin{array}{l}\text { Expressão financeira } \\
\text { Dados percentuais }\end{array}$ \\
\hline TIMEX & $\begin{array}{l}\text { DATE } \\
\text { TIME }\end{array}$ & $\begin{array}{l}\text { Expressão completa ou parcial de } \\
\text { data } \\
\text { Expressão completa ou parcial de } \\
\text { horário }\end{array}$ \\
\hline
\end{tabular}

Tabela 2.1: Possíveis valores para o atributo TYPE em cada tipo de tag.

Além das etiquetas utilizadas para a classificação de entidades, o MUC-7 também utilizase de etiquetas estruturais para adicionar metainformações do texto, tais como: referência da fonte, data de publicação, quantidade de palavras, separação de parágrafos e palavras-chave. A Tabela 2.2 contém um fragmento do arquivo de exemplo do MUC-7 ${ }^{4}$.

\subsubsection{CETENFolha}

O córpus CETENFolha (Corpus de Extractos de Textos Electrónicos NILC/Folha de São Paulo) foi desenvolvido no NILC/São Carlos. Sua primeira publicação foi em setembro de 2002. O propósito deste córpus é reunir todas as 365 edições do ano de 1994, incluindo os cadernos não diários, em um total de 25 milhões de palavras. É importante salientar que este córpus não visa substituir o histórico do jornal Folha de São Paulo, por esta razão estão disponíveis somente fragmentos das notícias.

Atualmente o CETENFolha é distribuído como parte do projeto $\mathrm{AC} / \mathrm{DC}^{5}$ (Acesso a

\footnotetext{
4 trecho retirado de http://www.itl.nist.gov/iaui/894.02/related_projects/muc/proceedings/walkthru_ ne_text.html onde o arquivo está disponível na integra. Acesso em julho/2012.

${ }^{5}$ http://www.linguateca.pt/ACDC/. Acesso em julho/2012.
} 


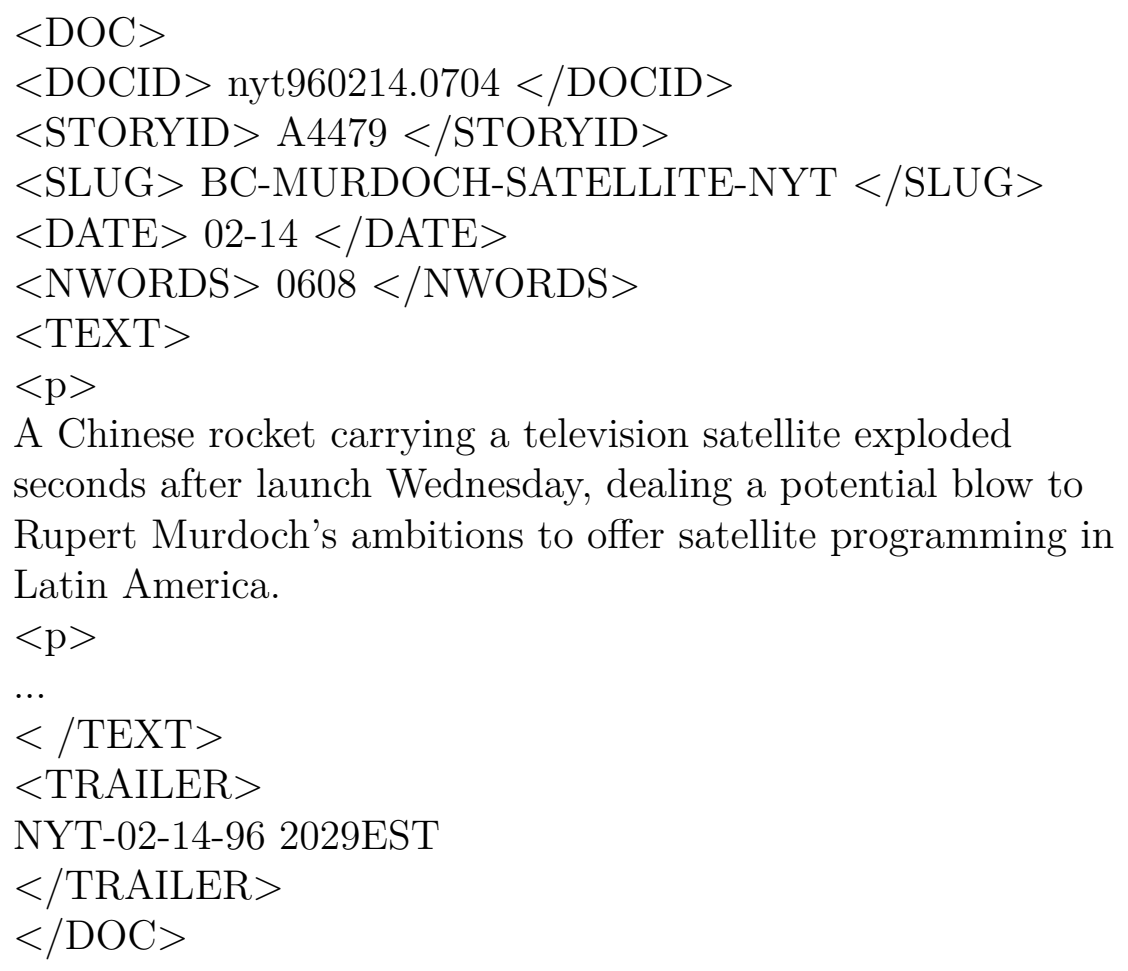

Tabela 2.2: Fragmento do arquivo de exemplo do MUC-7.

córpus/Disponibilização de córpus), iniciado em 1999, com o propósito de ser o ponto único para distribuição de córpus que utilizam a língua portuguesa. Atualmente a junção de todos os córpus do projeto somam 379.793.019 palavras, agrupadas em 16.923.577 frases, entre textos escritos em português de Portugal (PT) e português do Brasil (BR).

O CETENFolha está disponível em dois formatos: simples e com anotações sintáticas, sendo que estas anotações foram realizadas através do projeto PALAVRAS, sem nenhum tipo de revisão humana. Atualmente existem 25.475.272 palavras, em 1.597.807 frases, num total de 34.094 fragmentos de texto.

A versão simples do córpus utiliza o padrão SGML para realizar suas anotações. Existem sete tipos de anotações, listadas a seguir com uma breve descrição de cada: ext, fragmento de uma notícia; s, frase; t, título; a, autor; caixa, metainformações do tipo subtítulo; li, elemento de uma lista; situacao, informação adicional que não faz parte do texto da notícia. A etiqueta ext contém quatro atributos: id, identificador único da notícia; cad, caderno em que a notícia foi publicada; sec, classificação do texto segundo as categorias definidas no CETEMPúblico; sem, semestre de publicação. A Tabela 2.3 exibe um exemplo de fragmento de texto disponível no córpus CETENFolha.

A versão com anotações sintáticas utiliza o padrão PALAVRAS, proposto em Bick (2000). Este dispõe cada uma das unidades do texto em uma linha, e para cada uma destas atribui as seguintes características: lema, categoria gramatical (pos), características morfológicas (temcagr, gen e pessnum) e função sintática (func). A Tabela 2.4 exibe parte do 
$<$ ext id=1 cad="Opinião" sec="opi" sem="94a" $>$

$<\mathrm{s}><\mathrm{t}>\mathrm{PT}$ no governo $</ \mathrm{t}></ \mathrm{s}>$

$<\mathrm{s}><\mathrm{a}>$ Gilberto Dimenstein $</ \mathrm{a}></ \mathrm{s}>$

$<\mathrm{p}>$

$<$ s $>$ BRASÍLIA Pesquisa Datafolha publicada hoje revela um dado supreendente: recusando uma postura radical, a esmagadora maioria $(77 \%)$ dos eleitores quer o PT participando do Governo Fernando Henrique Cardoso . $</ \mathrm{s}>$

$<\mathrm{s}>$ Tem sentido - aliás, muitíssimo sentido . $</ \mathrm{s}>$

$</ \mathrm{p}>$

$<\mathrm{p}>$

$<\mathrm{s}>$ Muito mais do que nos tempos na ditadura, a solidez do PT está, agora, ameaçada $.</ \mathrm{s}>$

$<\mathrm{s}>$ Nem Lula nem o partido ainda encontraram um discurso para se diferenciar . $</ \mathrm{s}>$

$<\mathrm{s}>$ Eles se dizem oposição, mas ainda não informaram o que vão combater . $</ \mathrm{s}>$

$<\mathrm{s}>$ Muitas das prioridades do novo governo coincidem com as prioridades do PT

$.</ \mathrm{s}>$

$</ \mathrm{p}>$

$</$ ext $>$

Tabela 2.3: Fragmento completo de uma notícia do córpus CETENFolha versão simples.

mesmo fragmento da notícia da Tabela 2.3. Para facilitar o entendimento foram removidas as linhas que não continham etiquetas ou pontuação, uma vez que estas não tem nenhum tipo de classificação.

\begin{tabular}{|c|c|c|c|c|c|c|}
\hline Unidade de texto & lema & pos & temcagr & gen & pessnum & func \\
\hline \multirow{3}{*}{$\begin{array}{l}\text { publicada } \\
\text { hoje } \\
\text { revela }\end{array}$} & publicar & $\mathrm{V}$ & PCP & $\mathrm{F}$ & $\mathrm{S}$ & $@ \mathrm{~N}<$ \\
\hline & hoje & ADV & & & & @ADVL> \\
\hline & revelar & $\mathrm{V}$ & $\mathrm{PR}$ & IND & $3 \mathrm{~S}$ & FMV \\
\hline \multirow{5}{*}{$\begin{array}{l}\text { um } \\
\text { dado } \\
\text { supreendente } \\
\text { recusando }\end{array}$} & um & arti & DET & $\mathrm{M}$ & $\mathrm{S}$ & (a) $>\mathrm{N}$ \\
\hline & dar & $\mathrm{V}$ & $\overline{\mathrm{PCP}}$ & $\mathrm{M}$ & $\mathrm{S}$ & $@>N$ \\
\hline & supreendente & DERS & $\mathrm{N}$ & $\mathrm{M}$ & S & @ $<$ SUBJ \\
\hline & recusar & $\mathrm{V}$ & GER & & & @ICL-ADVL> \\
\hline & um & arti & DET & $\mathrm{F}$ & $\mathrm{S}$ & a $>\mathrm{N}$ \\
\hline \multirow{2}{*}{$\begin{array}{l}\text { uma } \\
\text { postura } \\
\text { radical }\end{array}$} & postura & $\mathrm{N}$ & $\mathrm{F}$ & & $\mathrm{S}$ & a $<\mathrm{ACC}$ \\
\hline & radical & ADJ & $\mathrm{F}$ & & S & $@ \mathrm{~N}<$ \\
\hline
\end{tabular}

Tabela 2.4: Trecho de uma notícia do córpus CETENFolha anotado sintaticamente. 


\subsection{Aquisição e extração de conteúdo}

Para a criação do córpus UOLCP2011 foi necessária a implementação de uma ferramenta para adquirir e extrair o conteúdo relevante das notícias hospedadas no portal Universo Online.

Aquisição e extração de conteúdo, ou crawler no inglês, geralmente está associado a conteúdos em páginas da internet. O desenvolvimento deste tipo de processo teve seu início na década de 90, com os sites pioneiros de busca de conteúdo na internet na época, tais como: Excite em 1993, Yahoo! em 1994, Alta Vista em 1995 e por último o Google em 1997.

Segundo Heydon e Najork (1999) e Cho et al. (1998), todo processo de aquisição de conteúdo tem como sua primeira iteração a análise de uma lista pré definida de URLs (seeds). A partir da análise realizada neste conjunto, novas URLs poderão ser obtidas, de forma que estas realimentam o processo de aquisição de conteúdo até que a condição de parada seja atingida. Em alguns crawlers a busca por conteúdo não termina nunca, como o Googlebot, sendo este responsável pela aquisição e extração de todo o conteúdo que alimenta as bases de busca do Google.

\subsection{Aprendizado de máquina}

O estudo do aprendizado de máquina teve seu início na década de 50 com Arthur Lee Samuel, que desenvolveu um algoritmo para ser seu adversário em uma partida do jogo de damas. Segundo Michalski et al. (1985), o aprendizado de máquina é qualquer processo no qual um sistema melhora seu desempenho através da experiência. Desta forma o algoritmo de Samuel aprendia com as jogadas do adversário criando estratégias mais elaboradas para as próximas partidas.

De acordo com Russell e Norvig (1995), o aprendizado de máquina está ligado de forma muito íntima à natureza do problema e definiu três categorias principais: aprendizado supervisionado, não supervisionado e de reforço. O primeiro passo para utilizar estes métodos é a fase de treinamento, que irá construir o modelo "aprendido".

Para realizar o aprendizado supervisionado é necessário que o algoritmo treinado, além do conjunto de entrada, tenha também o resultado esperado para cada entrada. Desta forma o algoritmo irá analisar as características dos dados de entrada avaliando quais são mais relevantes para obter o resultado esperado.

A técnica de aprendizado não supervisionado é similar a técnica de aprendizado supervisionado, porém o algoritmo recebe somente os dados de entrada sem receber o resultado esperado. Assim o algoritmo tentará inferir quais as saídas esperadas.

O método utilizado pelo aprendizado por reforço é a construção de um algoritmo que contém uma base de regras, e seu objetivo é avaliar quais são as melhores combinações destas regras para conseguir alcançar seu objetivo. Assim durante a fase de treinamento é possível submeter o algoritmo a diversas estratégias para resolver o problema desejado. 
Neste trabalho foi utilizado o método de aprendizado supervisionado para a anotação e classificação das entidades nomeadas. As seções 2.3.1, 2.3.2, 2.3.3 e 2.3.4 exibem possíveis implementações deste método. Este trabalho teve como objetivo implementar e analisar as duas primeiras técnicas.

\subsubsection{Maximização de entropia}

Segundo Manning e Schütze (1999) o conceito de maximização de entropia é definido da seguinte forma: "A modelagem de maximização de entropia é um arcabouço para integrar informações de diversas fontes heterogênias para realizar a classificação de algo. Os dados para este problema são descritos através da combinação de diversas características. Estas podem ser sofisticadas a ponto de necessitar de um conhecimento prévio sobre os tipos de informações esperadas para realizar a classificação. Cada característica corresponde a uma restrição no modelo criado. Assim é calculada a entropia máxima que satisfaz todas a restrições apresentadas."

Toda característica é definida por uma função binária que tem como objetivo detectar a presença de um componente que se considera relevante para a classificação que se deseja fazer. A ocorrência destes componentes têm uma distribuição estatística conjunta, sendo que a entropia desta distribuição tem que maximizada respeitando todas a restrições impostas pelo modelo. Alguns exemplos de características aplicadas a palavras: inicia com letra maiúscula, contém números, palavra anterior começa com letra maiúscula.

Segundo Ratnaparkhi (1998) o contexto analisado por uma característica pode ser desde uma única palavra, passando por um conjunto de palavras e em alguns momentos pode ser necessário inclusive informações extras, por exemplo, a classe gramatical de cada uma das palavras.

O método de maximização de entropia além de ser utilizado em tarefas de processamento de linguagem natural também é utilizado para outras áreas tais como: visão computacional, reconstrução de imagens, física estatística, topografia, engenharia, entre outras.

O capítulo 6 descreve em detalhes o treinamento e os resultados obtidos com o uso desta técnica.

\subsection{2 Índices invertidos}

A estratégia de utilizar índices invertidos, também chamados de listas invertidas, é bastante antiga e tem como objetivo realizar buscas de maneira rápida e eficiente. Ao invés de varrer todos os documentos da lista procurando uma determinada palavra, é criada uma estrutura auxiliar durante a inserção do documento na qual cada palavra sabe o documento em que foi escrita. Assim as buscas acontecem nesta estrutura aulixar e indicam os documentos que devem ser devolvidos. As Tabelas 2.5, 2.6 e 2.7 demonstram o funcionamento do mecanismo de índices invertidos. A primeira tabela exibe os documentos que serão inde- 
xados. Para simplificar o exemplo, todas as palavras foram escritas com letras minúsculas e sem acentos.

\begin{tabular}{c|l} 
Documento & Texto \\
\hline 1 & o sao paulo joga hoje \\
2 & hoje esta muito quente \\
3 & palmeiras esta perdendo o jogo \\
4 & o jogo esta quente
\end{tabular}

Tabela 2.5: Lista de documentos que serão indexados.

\begin{tabular}{l|l} 
Palavra & Id. do Texto \\
\hline o & $1,3,4$ \\
sao & 1 \\
paulo & 1 \\
joga & 1 \\
hoje & 1,2 \\
esta & $2,3,4$ \\
muito & 2 \\
quente & 2,4 \\
palmeiras & 3 \\
perdendo & 3 \\
jogo & 3,4
\end{tabular}

Tabela 2.6: Índice invertido contendo a relação entre palavra e documento.

A Tabela 2.6 exibe a estrutura do índice invertido de forma que cada palavra conhece os documentos em que aparece. Desta forma quando a busca pelas palavras "esta" e "quente" for realizada, o resultado final será a intersecção dos resultados obtidos nas buscas dos dois termos. O termo "esta" aparece nos documentos: 2, 3 e 4. Já o termo "quente" esta contido em: 2 e 4. Assim o resultado desta busca será os documentos 2 e 4. Este tipo de índice invertido não consegue realizar consultas por frases, por exemplo "esta quente", uma vez que este só mapeia a relação "contido em".

Os índices invertidos podem ser utilizados para resolver este tipo de problema, desde que sua estrutura interna passe a armazenar a posição da palavra dentro do documento. A Tabela 2.7 exibe uma base criada utilizando os mesmos documentos presentes na Tabela 2.5. Para realizar a busca pela frase "esta quente", o algoritmo ao invés de realizar somente a interseccção dos resultados deve avaliar nestes documentos se existe ocorrência para a palavra "esta" com posição $n$ e a palavra "quente" com posição igual a $n+1$. Assim o documento 2 não contempla esta regra, uma vez que a palavra "esta" ocupa a posição 1 e a palavra "quente" ocupa a posição 3. Já o documento 4 obedece ambas as restrições, com as palavras nas posições 2 e 3 respectivamente.

Os conceitos dos exemplos acima estão descritos em mais detalhes em Zobel e Moffat (2006) e Knuth (1998). O capítulo 7 descreve em detalhes o treinamento e os resultados obtidos com o uso deste método. 


\begin{tabular}{l|l} 
Palavra & Par: $\{$ Id. do Texto, posição $\}$ \\
\hline o & $\{1,0\},\{3,3\},\{4,0\}$ \\
sao & $\{1,1\},\{3,1\}$ \\
paulo & $\{1,2\}$ \\
joga & $\{1,3\}$ \\
hoje & $\{1,4\},\{2,0\}$ \\
esta & $\{2,1\},\{3,1\},\{4,2\}$ \\
muito & $\{2,2\}$ \\
quente & $\{2,3\},\{4,3\}$ \\
palmeiras & $\{3,0\}$ \\
perdendo & $\{3,2\}$ \\
jogo & $\{3,4\},\{4,1\}$
\end{tabular}

Tabela 2.7: Índice invertido contendo o identificador do documento e posição da palavra neste.

\subsubsection{Transformação guiada por erro}

O método de transformação guiada por erro (TBL - Transformation Based error-driver Learning) foi definido em Brill (1992), sendo um método voltado as tarefas de processamento de linguagem natural. Este tem como ideia principal gerar uma lista ordenada de regras para corrigir possíveis erros de anotação e classificação feitos através de uma classificação inicial, realizada por outro sistema, chamado de classificador base (BLS - Baseline System). Estas regras são definidas durante a fase de treinamento utilizando-se de formatos previamente definidos na inicialização do algoritmo.

Segundo Milidíu et al. (2006), a fase de treinamento do algoritmo de transformação guiada por erro é definida através dos passos abaixo:

1. Realizar anotação e classificação inicial do texto sem marcações com o classificador base.

2. Comparar os resultados obtidos no passo 1 com o texto anotado e definir novas regras para correção utilizando os formatos de regras de entrada. Cada nova regra criada para corrigir uma situação pode gerar problemas para outros cenários.

3. Após a definição de todas as regras é calculado um peso para cada uma, sendo este a quantidade de correções menos a quantidade de novos erros gerados. Se nenhuma regra atingir o objetivo mínimo de correção o algoritmo é parado.

4. A regra com melhor resultado é escolhida e armazenada na lista ordenada de regras para correção. Assim o texto é reclassificado utilizando-a.

5. Repetir processo iniciando do passo 2. 


\subsubsection{Máquina de vetores de suporte}

O método de máquinas de vetores de suporte (SVM - Support Vector Machines) foi definido em Vapnik (1998), sendo este baseado na teoria de aprendizado estatístico. Este modelo utiliza-se de de propriedades geométricas para mapear cada uma de suas entradas em uma coordenada $(x, y)$ contida no hiperplano $p$. Após este mapeamento é aplicada uma função binária que define se este ponto pertence ou não a determinada classe. A figura 2.1 exibe de forma gráfica o mapeamento desta função ao hiperplano $p$.
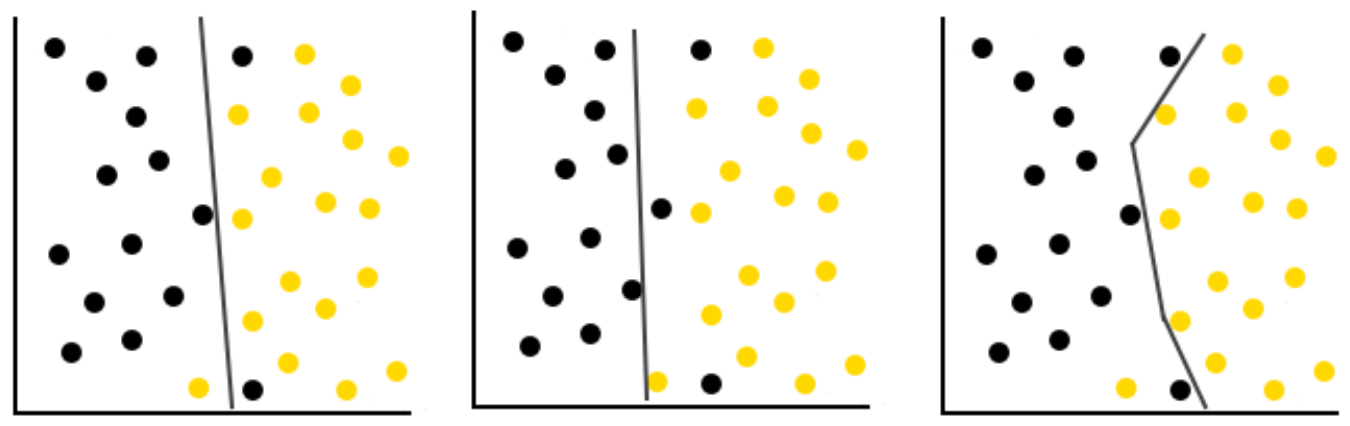

Figura 2.1: Possíveis funções binárias para separação do plano p.

Apesar do método de máquinas de vetores de suporte utilizar funções de classificação binárias, diversos estudos utilizam a combinação de funções para obter resultados de classificação utilizando múltiplas classes. Em Milidíu et al. (2006) é proposta a estratégia "um contra um", que visa o confronto de todas a classes, somando um ponto a cada classificação positiva, no final a classe que tiver mais pontos é a vencedora. 


\section{Capítulo 3}

\section{Aquisição e extração de conteúdo}

A técnica de aquisição de conteúdo utilizada neste trabalho visa a obtenção de $U R L s$ para notícias, de forma a descartar qualquer outro tipo de link. A Figura 3.1 ilustra quais links foram escolhidos como potenciais notícias em uma listagem.

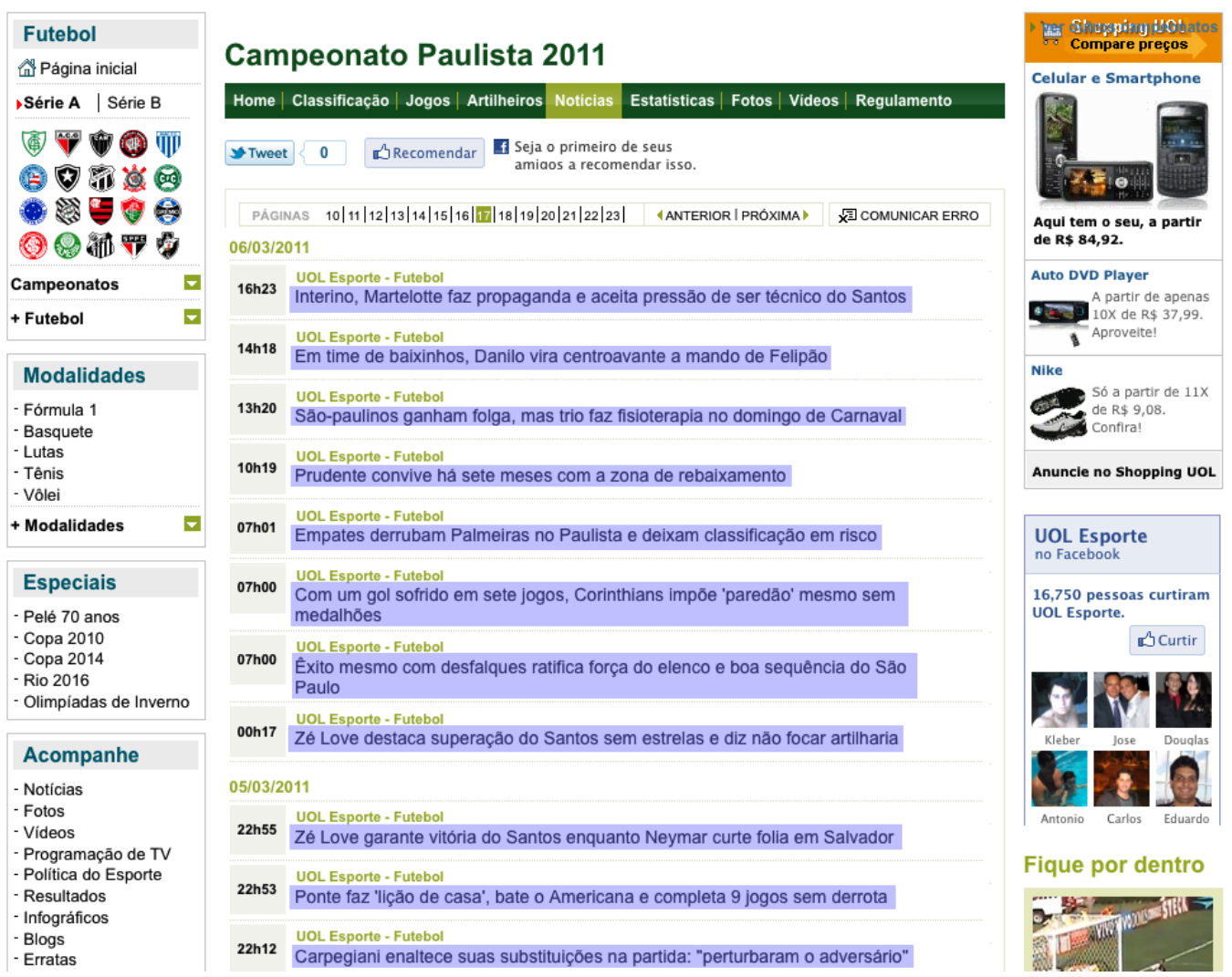

Figura 3.1: Em destaque os links que o processo de aquisição de notícias deve escolher entre todos os links da página.

As URLs encontradas na fase de aquisição são encaminhadas para o processo de extração de conteúdo, que tem como objetivo validar se o conteúdo realmente é uma notícia e extrair seus principais dados.

A técnica de extração de conteúdo no processo de crawling deste trabalho visa reconhecer a área onde os seguintes elementos estão presentes: título, data e hora de criação ou 
atualização e o corpo da notícia. Se todos estes elementos estiverem presentes o conteúdo é classificado como uma notícia. A Figura 3.2 exibe em destaque a área que contém todos os elementos necessários para esta classificação.

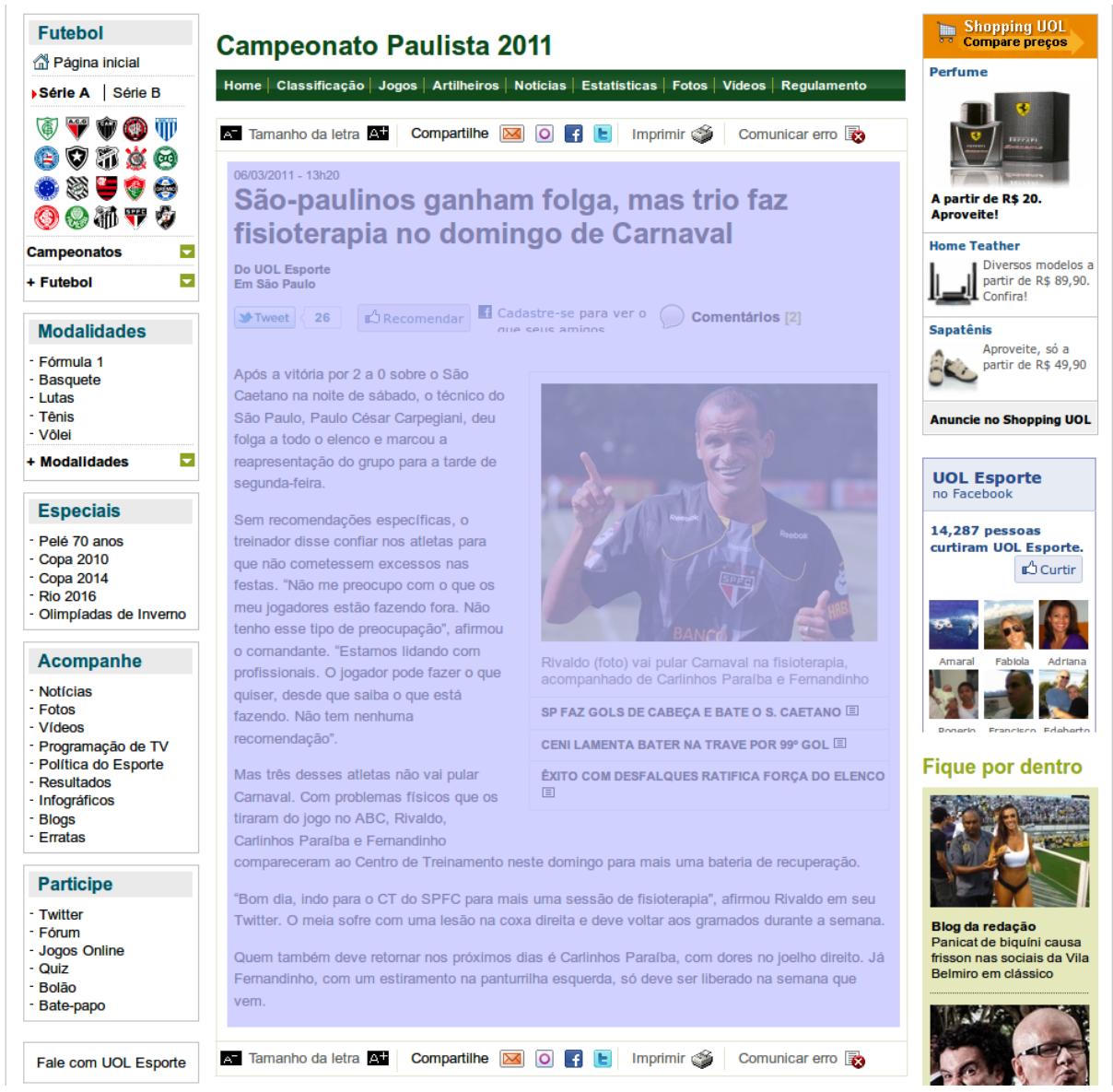

Figura 3.2: A área em destaque indica a parte da página que contém o conteúdo da notícia.

\subsection{Arquitetura}

Todo o processo de aquisição e extração de conteúdo foi elaborado para ser facilmente expandido e especializado de forma a oferecer uma interface simples para comunicação com outros serviços.

O diagrama de classes da Figura 3.3 exibe todas as interfaces e classes do pacote crawler, neste existem quatro entidades. A seguir uma pequena descrição destas entidades:

- Crawler: entidade responsável por encontrar novas URLs e extrair os conteúdos relevantes. Estas regras podem ser diferentes dependendo do propósito do córpus, por esta razão esta entidade é uma interface;

- CrawlerDocument: entidade responsável por transportar os valores extraídos pelo método Crawler.extract e enviá-los para o ContentRepository.save; 


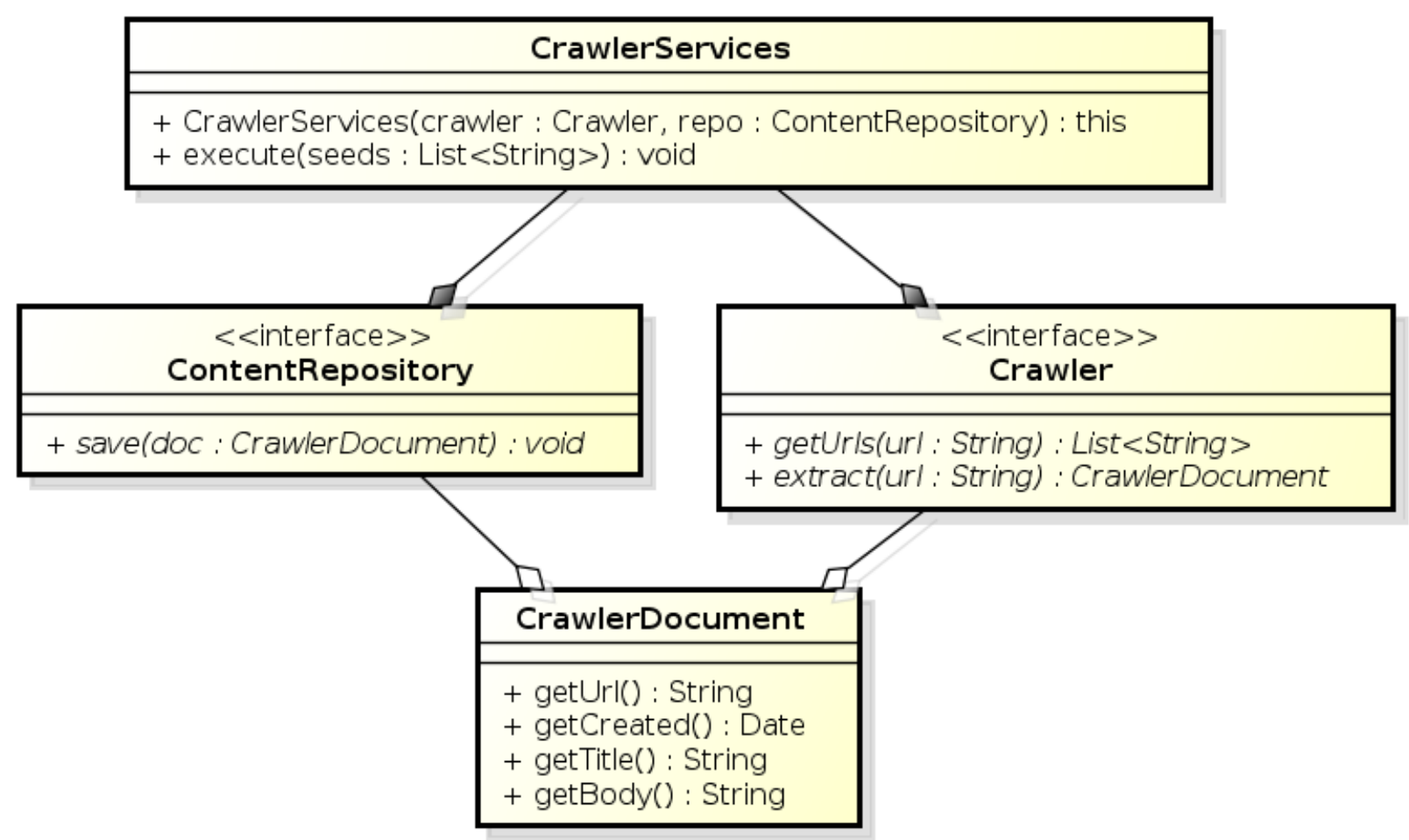

powered by Astah ais

Figura 3.3: Diagrama de classes do serviço de crawler.

- ContentRepository: entidade responsável por armazenar os conteúdos capturados e deixá-los disponíveis para a classificação através do WebCorpus, mais detalhes no capitulo 4;

- CrawlerServices: entidade responsável pelo ciclo de vida do processo de aquisição e extração de conteúdo.

A implementação da classe CrawlerServices utiliza o padrão de projeto injeção de dependência, definido por Fowler (2004). O uso deste torna o sistema simples de ser especializado, uma vez que todas as dependências externas necessárias para o ciclo de vida desta classe são definidas por quem constrói o serviço. O construtor da classe CrawlerServices recebe uma implementação das interfaces Crawler e ContentRepository.

\subsection{Especialização}

Para validar a arquitetura proposta no Capítulo 3.1, de aquisição e extração de conteúdo, foi criada uma implementação cujo objetivo é coletar notícias esportivas de um determinado portal da internet brasileira. O pacote crawler, descrito na Figura 3.3, necessita da implementação das interfaces: Crawler e ContentRepositoty.

Para auxiliar no processamento de conteúdo HTML foi utilizada a biblioteca HTML Parser $^{1}$. Seu principal uso foi transformar o conteúdo de uma página HTML em uma árvore

\footnotetext{
${ }^{1}$ http://htmlparser.sourceforge.net/ . Acesso em julho/2012.
} 
navegável de elementos e entidades.

O primeiro passo foi a implementação da interface Crawler, que possui duas responsabilidades: adquirir novos links e extrair o conjunto de dados necessários para classificar o conteúdo como uma notícia. A implementação desta interface foi realizada na classe $W e b$ Crawler.

O processo de aquisição de links tem seu início baseado em um conjunto pré definido de URLs. A primeira implementação deste processo era bastante simples, somente extraía das páginas o atributo href das etiquetas do tipo âncora $(a)$ e avaliava se estas apontavam para o mesmo domínio do portal. Esta regra de triagem foi criada pois existem diversas chamadas para sites de parceiros, e estes não fazem parte do escopo da criação deste córpus.

Apesar de ser uma implementação simples, esta não deixava de capturar nenhum conteúdo de notícia, mas acabava sobrecarregando a fase de extração de conteúdo, pois todo conteúdo do portal acabava sendo analisado. Para refinar este modelo, foi realizada a análise das URLs que continham notícia contra as que não continham. Como resultado desta análise foi adicionada mais uma regra de triagem, que diz que toda $U R L$ de notícia deve conter o seguinte padrão "http://...com.br/.../AAAA/MM/DD/...html", sendo AAAA ano, MM mês e DD dia. Após a implementação desta regra o número de links encontrados em uma página passou de 295 para 56, uma redução de $81 \%$ de $U R L s$, comprovando assim a eficácia desta regra.

Com o método de aquisição de URLs pronto, a implementação do processo de extração de conteúdo teve seu início. Este processo tem como característica procurar no conteúdo de uma $U R L$ a existência das seguintes informações: título, data e hora de criação ou atualização e o corpo da notícia.

Antes de realizar qualquer tipo de análise do conteúdo disponível em uma $U R L$ é verificado o valor do header Content-Type, presente em todas as versões do protocolo HTTP. Esta informação fornece qual o tipo de conteúdo está presente na $U R L$ solicitada, sendo que o único valor permitido para esta implementação é o "text/html", caso ocorra qualquer outro valor, a $U R L$ não pode ser classificada como uma notícia.

A implementação do processo de extração de conteúdo teve seu início com uma análise das marcações HTML nas páginas encontradas na fase de aquisição. Felizmente estas páginas continham todas a mesma estrutura, tendo todo o conteúdo relevante para a extração dentro de um elemento div com o valor "conteudo" em seu atributo class. A Figura 3.2 exibe a área do conteúdo deste elemento div.

O primeiro passo foi elaborar uma regra para extração do título. Em sua implementação foi necessário extrair o conteúdo do corpo da etiqueta $h 1$ e remover qualquer outra marcação HTML, como por exemplo, $b$ (negrito) ou $i$ (itálico).

O segundo passo foi a formulação de uma regra para extração de data e hora de criação ou atualização da matéria. Sua implementação foi um pouco mais extensa que a anterior, pois sua regra é definida por: localizar elemento div que tenha o valor "data" no atributo class sendo que este seja filho de um elemento div que contenha o valor "conteudo" no atributo 
class e remover qualquer outra marcação HTML.

O terceiro passo foi a construção da regra para extração do corpo da notícia. A primeira tentativa foi criar uma regra tão simples quanto resgatar o conteúdo do div que contém o valor "texto" dentro do atributo $i d$. Para notícias que não continham elementos como tabelas, imagens ou lista de links relacionados junto ao corpo da notícias esta regra funcionava corretamente, mas este cenário corresponde a cerca de $50 \%$ do conteúdo analisado. Desta forma foi necessária a implementação de uma regra mais sofisticada: buscar o conteúdo de todos as etiquetas de parágrafo $(p)$ que tenham como pai uma tag do tipo div com o valor "texto" em seu atributo $i d$. Desta forma somente os parágrafos com textos válidos são resgatados.

\section{6/03/2011 - 13h20 \\ São-paulinos ganham folga, mas trio faz fisioterapia no domingo de Carnaval}

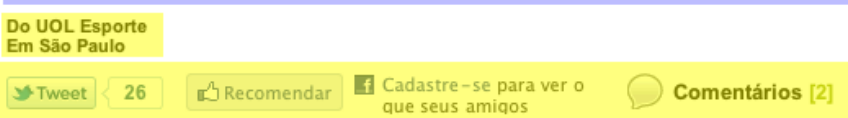

\section{Após a vitória por 2 a 0 sobre o São}

Caetano na noite de sábado, o técnico do São Paulo, Paulo César Carpegiani, deu folga a todo o elenco e marcou a reapresentação do grupo para a tarde de segunda-feira.

Sem recomendaçōes especificas, o treinador disse confiar nos atletas para que não cometessem excessos nas festas. "Não me preocupo com o que os meu jogadores estão fazendo fora. Nāo tenho esse tipo de preocupação", afirmou o comandante. "Estamos lidando com profissionais. O jogador pode fazer o que quiser, desde que saiba o que está fazendo. Nāo tem nenhuma recomendaçāo".

Mas três desses atletas nāo vai pular Carnaval. Com problemas físicos que os tiraram do jogo no $A B C$, Rivaldo, Carlinhos Paraiba e Fernandinho compareceram ao Centro de Treinamento neste domingo para mais uma bateria de recuperação. "Bom dia, indo para o CT do SPFC para mais uma sessão de fisioterapia", afirmou Rivaldo em seu Twitter. O meia sofre com uma lesão na coxa direita e deve voltar aos gramados durante a semana. Quem também deve retornar nos próximos dias é Carlinhos Paraiba, com dores no joelho direito. Já Fernandinho, com um estiramento na panturrilha esquerda, só deve ser liberado na semana que vem.

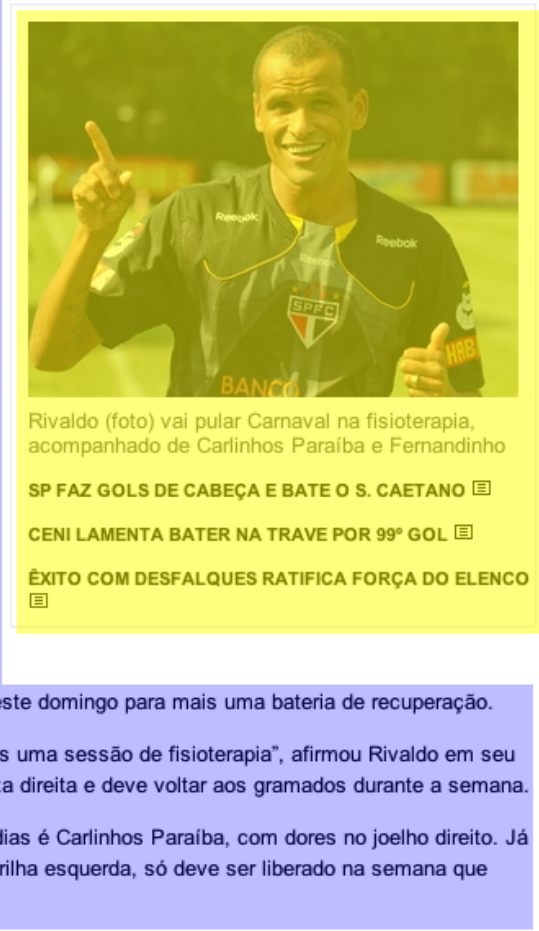

Figura 3.4: A área clara indica o conteúdo que deve ser descartado no processo de extração de conteúdo.

Após realizar diversos testes com esta regra, foi encontrada uma variação deste padrão em $2 \%$ das URLs analisadas. Este novo padrão encontrado é expresso na seguinte regra: buscar as etiquetas de parágrafo $(p)$ que tenham como pai uma tag div que contenham um atributo chamado dir. Este elemento não é especificado em nenhuma das versões do padrão HTML. Desta forma foi criada uma cadeia de regras para extração do título, quando a primeira regra não o encontra, a segunda regra é executada. Caso seja encontrado algum valor para 
o corpo da notícia, todas as etiquetas HTML são removidas, e em seguida é aplicada uma expressão regular para que qualquer quantidade de quebras de linha seguidas por espaço ou não sejam substituídas somente por uma quebra de linha. Com a criação destas regras a implementação da interface Crawler foi concluída. A Figura 3.4 exibe em amarelo as partes do conteúdo da notícia que devem ser excluídos e em lilás o conteúdo que deve ser extraído da notícia.

$\mathrm{Na}$ sequência foi implementada a interface ContentRepository, que tem como responsabilidade armazenar os documentos encontrados no processo de aquisição e extração de conteúdo, através da classe NewsContentRepository. Para simplificar essa implementação, ao invés de criar um mecanismo para armazenamento de conteúdo foi utilizada uma instância da implementação da interface DocumentRepository, que será explicada em mais detalhes no Capítulo 4.2. Nesta interface é definido o método update, que recebe como entrada uma instância da classe Document, deixando a cargo da classe NewsContentRepository somente a transformação da instância de CrawlerDocument para Document.

Com a construção das duas classes: WebCrawler e NewsContentRepository foi possível criar uma implementação de referência para os objetivos deste trabalho, além de validar os conceitos propostos para a arquitetura do módulo de aquisição, extração e persistência de documentos, descritos no Capítulo 3.1. 


\section{Capítulo 4}

\section{Interface para classificação de conteúdo}

A ferramenta WebCorpus tem como principal intuito facilitar o processo de adição de metainformações a documentos através do uso de uma interface rica web. Esta foi elaborada para deixar o trabalho mais ágil e simples. Assim é possível que especialistas de diferentes nichos realizem a anotação e classificação de córpus especializados sem precisar de nenhum conhecimento técnico para realizar esta tarefa.

Outra grande preocupação durante o desenvolvimento foi oferecer uma forma fácil de adaptação e extensão dos recursos de interface. A Figura 4.1 exibe uma captura de tela realizada durante a classificação da notícia exibida na Figura 3.4.

Tanto a ferramenta quanto o código fonte do WebCorpus estão disponíveis no GitHub ${ }^{1}$ utilizando a licença MIT, mais detalhes no Seção 5.4.

O processo de adição de metainformações é realizado através do uso de etiquetas, desta forma o documento após receber suas anotações se torna compatível com o padrão SGML, detalhado na Seção 2.1.1.

As premissas do desenvolvimento do WebCorpus seguem os conceitos abaixo:

- Localização dos recursos de interface, tornando fácil a adaptação a novos idiomas;

- Sistema iterativo de classificação baseado em documentos não classificados;

- Possibilidade de salvar diversas vezes o mesmo documento antes de ir para o próximo, criando assim pontos de recuperação, caso ocorra algum problema de comunicação ou infraestrutura;

- Mecanismo flexível e dinâmico para criação do conjunto de etiquetas.

A primeira implementação da interface de classificação de conteúdo foi pensada para ser algo tão minimalista que não iria fazer parte da lista dos artefatos gerados por este trabalho.

\footnotetext{
${ }^{1}$ https://github.com/rodzac/webcorpus/
} 


\title{
Classificador de Notícias 0.1
}

\author{
Próxima Salvar
}

São-paulinos ganham folga, mas trio faz fisioterapia no domingo de Carnaval

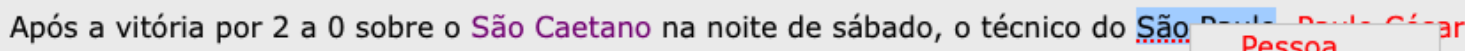
Carpegiani, deu folga a todo o elenco e marcou a reapresentação do grupo para a Lugar -feira.

Sem recomendações específicas, o treinador disse confiar nos atletas para que nãc Organização :essos

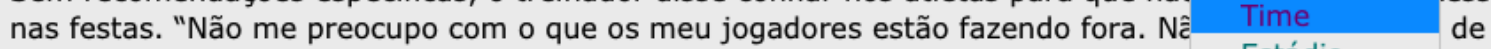
preocupação", afirmou o comandante. "Estamos lidando com profissionais. O jogar Estádio |ue quiser, desde que saiba o que está fazendo. Não tem nenhuma recomendação". Campeonato

Torcida

Mas três desses atletas não vai pular Carnaval. Com problemas físicos que os tirar Remover C, Rivaldo, Carlinhos Paraíba e Fernandinho compareceram ao Centro de Treinamento neste domingo para mais uma bateria de recuperação.

"Bom dia, indo para o CT do SPFC para mais uma sessão de fisioterapia", afirmou Rivaldo em seu Twitter. O meia sofre com uma lesão na coxa direita e deve voltar aos gramados durante a semana.

Quem também deve retornar nos próximos dias é Carlinhos Paraíba, com dores no joelho direito. Já Fernandinho, com um estiramento na panturrilha esquerda, só deve ser liberado na semana que vem.

Figura 4.1: Captura de tela da ferramenta WebCorpus durante o processo de classificação.

Inicialmente esta seria utilizada somente para acelerar o processo de classificação do córpus, sua implementação era composta de uma página HTML com 3 botões e uma grande caixa de texto. Não existia nenhum tipo de repositório de documentos, todo o processo era manual, sendo o primeiro passo colar o conteúdo do documento na caixa de texto. Em seguida marcar o texto que seria classificado e clicar em um dos três botões localizado no topo da página. Este processo adiciona uma etiqueta de entidade em volta do texto selecionado, causando o deslocamento de todo o restante do texto para frente. Após classificar todo o texto era necessário copiá-lo para um editor de texto e salvá-lo. A Figura 4.2 mostra a mesma notícia da Figura 4.1 sendo classificada na interface descrita acima.

Após a realização de alguns testes com esta interface de classificação, foi concluído que o tempo gasto para classificar um texto acabava sendo próximo do tempo gasto para classificar o mesmo texto utilizando um editor de texto comum. Os maiores problemas encontrados foram: deslocamento do texto após cada inserção de etiqueta, o que torna a leitura do texto desconfortável; o tempo gasto percorrendo a tela entre marcar o texto e clicar no botão no topo da tela, ajudando a perder o foco no lugar de onde deveria continuar a leitura. Neste momento a única vantagem em utilizar a interface de classificação era a ausência de possíveis erros de digitação, pois o processo de inserção de etiqueta estava automatizado.

Com base no resultado dos testes realizados, foram implementadas duas novas funcionalidades: trabalhar as anotações com cores ao invés de exibir as etiquetas, eliminando assim o problema do deslocamento; criar um menu com as possibilidades de etiquetas dinamicamente através do clique do botão direito, acabando com o problema do tempo gasto com 


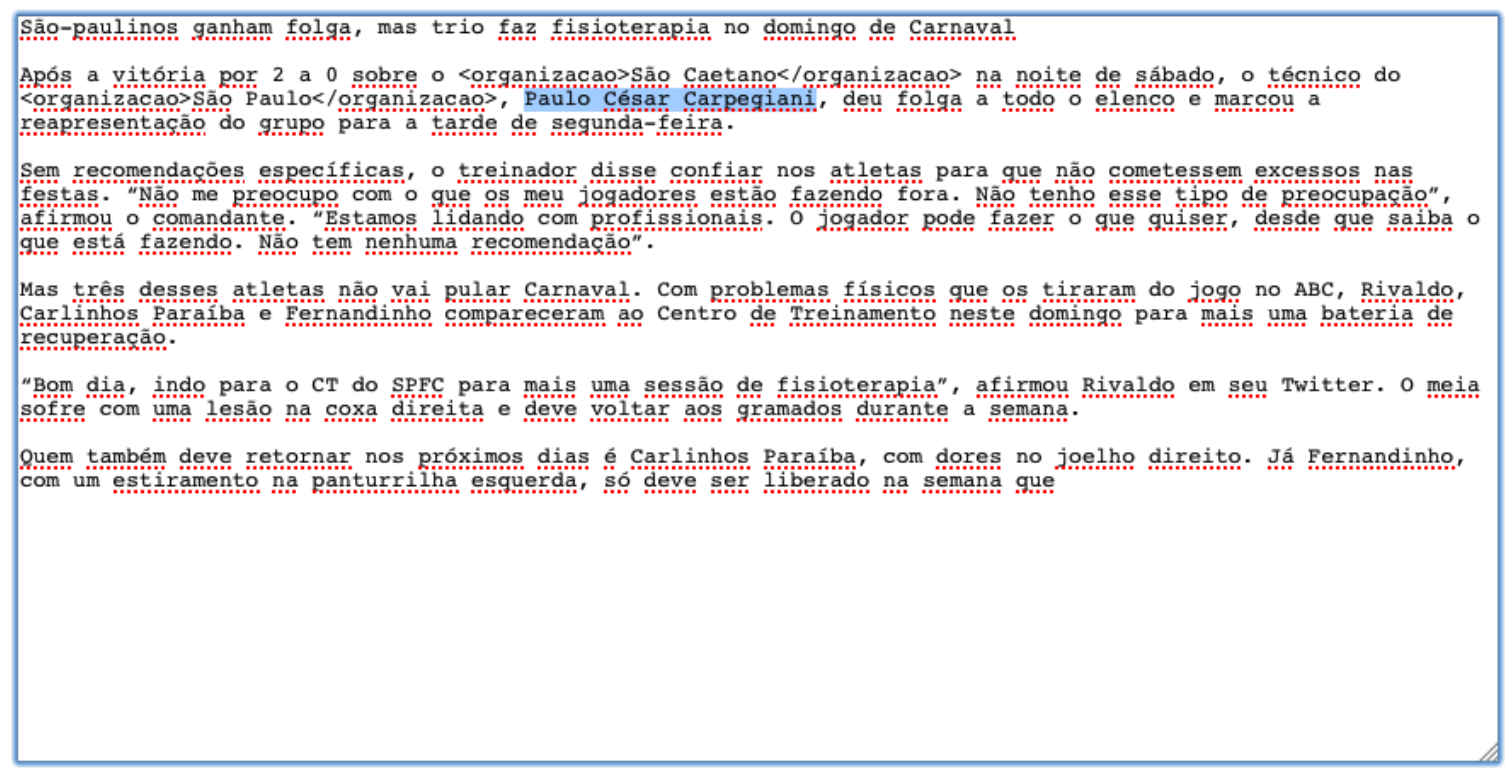

Figura 4.2: Captura de tela da primeira versão da ferramenta de classificação de textos.

o deslocamento do mouse. Os mesmos testes foram realizados após estas implementações e os resultados foram animadores, o tempo gasto para classificar textos caiu para menos da metade.

O próximo passo foi realizar uma análise do tempo gasto entre: encontrar um novo texto ainda não classificado; copiá-lo do editor de texto; colá-lo na área de edição na interface de classificação e após adicionar todas a anotações substituir o texto antigo no editor de textos pelo novo. Todo esse processo realizado de forma manual apesar de simples poderia gerar diversos erros pela quantidade de repetições. A melhor maneira de diminuir este tempo foi a implementação de um repositório de documentos. Este tem como responsabilidade realizar a gerência do ciclo de vida destes documentos, sabendo quais já foram classificados ou não, além de armazenar o conteúdo destes.

O processo de classificação de documentos ficou muito mais simples, de forma que leigos consigam realiza-lo de forma ágil e pouca propenso a erros. A Seção 4.2 descreve em maiores detalhes as técnicas utilizadas para obtenção deste resultado.

\subsection{Arquitetura}

O componente WebCorpus é dividido em duas camadas: apresentação e serviço. A primeira camada é responsável pela interface rica web e por repassar os dados adquiridos do usuário para a camada de serviço; já a segunda tem a responsabilidade de armazenar e resgatar os dados de forma apropriada.

O diagrama de classes da Figura 4.3 exibe todas as interfaces e classes do pacote services, neste existem três entidades. A seguir uma pequena descrição destas entidades: 


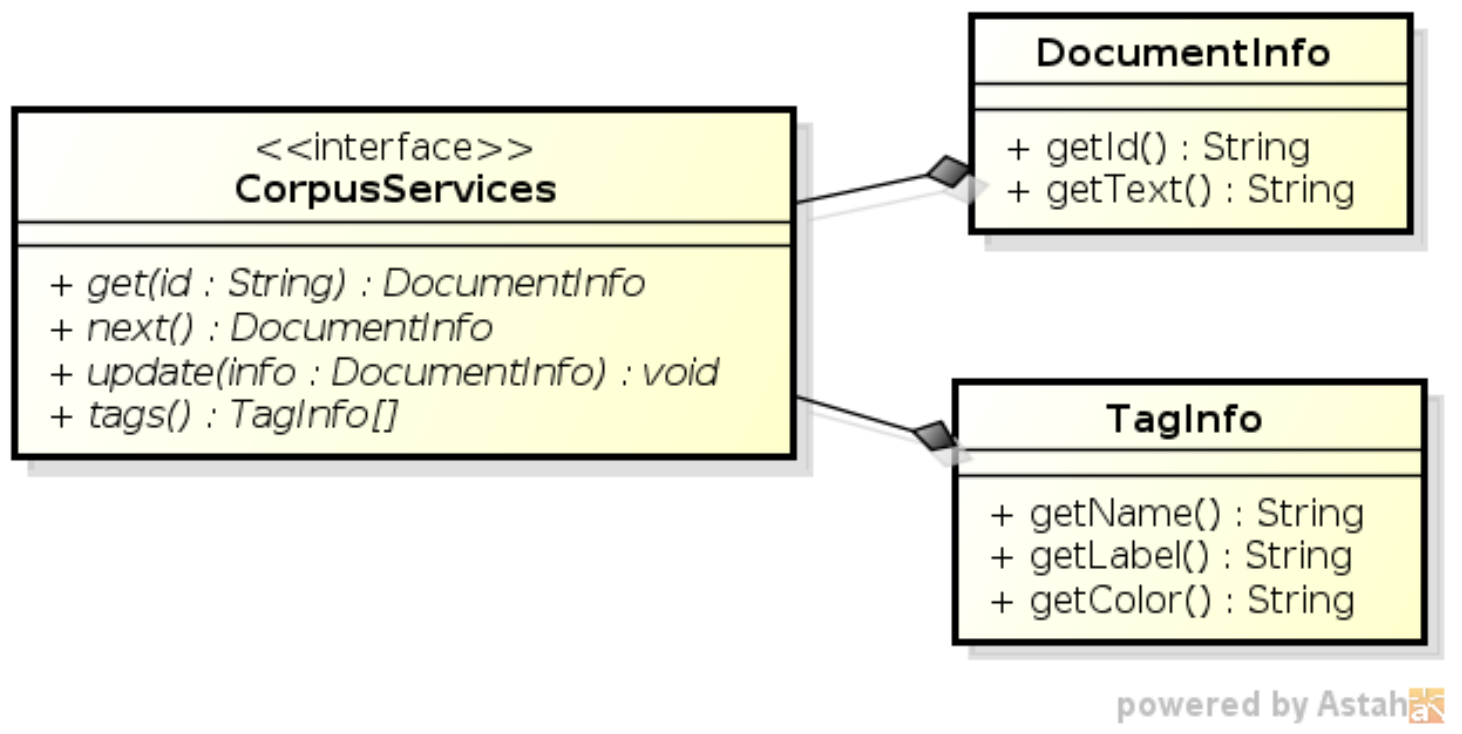

Figura 4.3: Estrutura do pacote services

- DocumentInfo: entidade responsável por transportar os valores dos documentos para classificação na interface web, ou após classificados para a camada de serviço;

- TagInfo: entidade responsável por transportar os valores das etiquetas para a interface rica web;

- CorpusServices: entidade responsável por receber as chamadas da interface rica web e cuidar do ciclo de vida das instâncias de DocumentInfo. Suas operações são: buscar documentar através de seu id, buscar próximo documento não classificado e atualizar o conteúdo do documento após classificação.

Todas a chamadas realizadas à interface CorpusServices são feitas através da classe CorpusServlet, que tem a função de trabalhar como um proxy entre a camada de apresentação e de serviço.

\subsection{Implementação}

Para validar a arquitetura proposta no Seção 4.1, foi criada uma implementação de referência para a camada de apresentação e serviço. Ambas as camadas utilizam o padrão UTF-8 (8-bit Unicode Transformation Format) para a codificação dos caracteres. Esta decisão implicitamente facilita a localização dos recursos da interface rica web, uma vez que o UTF-8 possui uma tabela maior de caracteres que outros conjuntos, tais como: ASCII, ISO-8859-1, CP-1252, entre outros.

A implementação da camada de apresentação foi construída com HTML (HyperText Markup Language), padrão definido pelo W3C (World Wide Web Consortium), como linguagem de definição de elementos e JSP (Java Server Pages), padrão definido pelo JCP 
(Java Community Process) na JSR (Java Service Request) 153, para adicionar informações dinâmicas e metainformações no cabeçalho das requisições.

Outra linguagem utilizada na construção da interface rica web foi o CSS (Cascading Style Sheets), definida pelo W3C, que tem como objetivo realizar a formatação e o estilo dos elementos presentes em uma página HTML. O uso deste tipo de tecnologia facilita a troca de estilo de todos os elementos que compõe a interface gráfica web, através de um único arquivo de folha de estilo.

A processo de localização de recursos, também conhecido como 110n (localization), tem como objetivo traduzir a interface gráfica para o idioma solicitado pelo usuário. Este processo é diferente de internacionalização da interface gráfica, conhecido como i18n (internationalization), pois neste, o posicionamento dos elementos são alterados em função do idioma utilizado. Por exemplo, uma interface gráfica composta por um menu e uma caixa de edição de texto, quando fosse exibida para usuários com o idioma inglês apresentaria o menu do lado esquerdo, enquanto para os usuários do idioma árabe o menu estaria do lado direito, com o texto escrito da direita para esquerda.

A camada de apresentação do WebCorpus foi criada com suporte a localização dos recursos de interface, sua implementação foi realizada através do uso de marcações JSTL (Java Standard Tag Library), padrão definido pelo JCP na JSR 52. A Figura 4.4 mostra o resultado deste trabalho. Atualmente existem traduções disponíveis: português do Brasil (pt_br) e inglês americano (en_us).

\section{\begin{tabular}{l|l} 
News Classifier & Classificador de Notícias \\
0.1
\end{tabular}

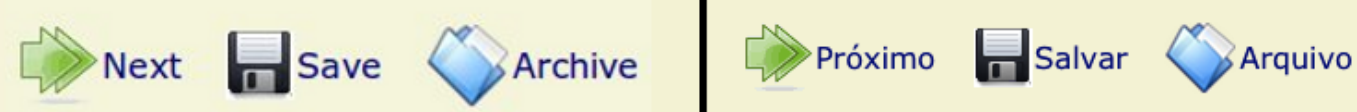

Figura 4.4: Exemplo de alguns dos recursos localizados para os idiomas: inglês (a esquerda) e português (a direita).

A última linguagem utilizada para construção da interface gráfica web foi o JavaScript, sendo este uma implementação do padrão Ecma-262, seu uso tem o intuito de melhorar a experiência do usuário, tornando-a mais simples e objetiva. Para trabalhar com esta linguagem foi utilizado o framework jQuery ${ }^{2}$, que cria uma camada de abstração sobre os principais recursos do JavaScript, deixando assim a execução destas operações transparente em diferentes navegadores.

Além dessa camada de abstração outra vantagem do uso do jQuery é a quantidade de plugins disponíveis. Na construção da interface rica web foi utilizado o plugin Context Menu ${ }^{3}$, que cria um menu contextual ao utilizar o clique do botão direito do mouse. O uso deste tipo de menu ajudou a diminuir o tempo médio de classificação de textos em relação ao uso de menu fixo no topo da caixa de texto, maiores detalhes no capítulo 4.

\footnotetext{
2 http://jquery.com/. Acesso em julho/2012.

${ }^{3}$ http://plugins.jquery.com/project/jquery-contextMenu . Acesso em julho/2012.
} 
A camada de serviço do WebCorpus implementa o modelo proposto na Figura 4.3. A classe SimpleCorpusService é a implementação da interface CorpusServices. Para tornar o sistema simples de ser especializado foi utilizado o padrão de projeto injeção de dependência, definido por Fowler (2004), desta forma todas as dependências externas necessárias para o ciclo de vida desta classe são definidas por quem constrói o serviço. O construtor da classe SimpleCorpusService recebe a implementação das interfaces DocumentRepository e TagRepository.

O diagrama de classes da Figura 4.5 exibe todas as interfaces e classes do pacote repository. Este tem a função de criar uma camada de abstração para acesso aos documentos e etiquetas de classificação. Neste existem cinco entidades, a seguir uma pequena descrição destas entidades:

\begin{tabular}{|c|c|c|}
\hline$<<$ interface $>>$ & Document & \\
\hline DocumentRepository & & $<<$ enum $>>$ \\
\hline $\begin{array}{l}+ \text { get(id: String) : Document } \\
+ \text { update(doc : Document) : Document } \\
+ \text { remove(id: String) : void } \\
+ \text { list(): List<Document> } \\
+ \text { next(): Document }\end{array}$ & $\begin{array}{l}+ \text { getUrl() : String } \\
+ \text { getCreated() : Date } \\
+ \text { getCollected() : Date } \\
+ \text { getText() : String } \\
+ \text { getStatus() : Status }\end{array}$ & $\begin{array}{l}\text { + COLLECTED : Status } \\
\text { + INPROGRESS : Status } \\
\text { + DŌNE : Status }\end{array}$ \\
\hline
\end{tabular}

\begin{tabular}{|c|c|}
\hline $\begin{array}{c}<<\text { interface }>> \\
\text { TagRepository }\end{array}$ & Tag \\
\hline $\begin{array}{l}\text { + list() : List }<\text { Taglnfo }> \\
\text { + remove(id : String) : void } \\
\text { + update(tag : Tag) : Tag }\end{array}$ & $\begin{array}{l}\text { + getName() : String } \\
+ \text { getLabel() : String } \\
+ \text { getColor() : String }\end{array}$ \\
\hline
\end{tabular}

Figura 4.5: Estrutura do pacote repository

- Document: entidade responsável por armazenar os dados presentes nos documentos;

- Status: entidade responsável por definir a máquina de estados da classe Document, tendo os possíveis valores: COLLECTED, documento na fila aguardando por anotações; IN_PROGRESS, documento que está recebendo anotações; DONE, documento já anotado;

- DocumentRepository: entidade responsável por gerenciar o ciclo de vida das instâncias de Document, através dos métodos: get, update, remove e list. O método next devolve o próximo documento não anotado;

- Tag: entidade responsável por armazenar os dados das etiquetas.

- TagRepository: entidade responsável por gerenciar o ciclo de vida das instâncias de Tag, através dos métodos update, remove e list; 
O pacote repository tem duas implementações, sendo uma construída para o $M_{0}$ goDB ${ }^{4}$, que é um repositório de dados no tipo NoSQL (Not only $S Q L$ ) orientado a documentos, e outra para MySQL ${ }^{5}$, um dos mais utilizados SGDBs (Sistema de Gerenciamento de Banco de Dados) relacional. Desta forma foi possível validar o design do pacote repository, uma vez que este conseguiu atender a duas implementações baseadas em diferentes paradigmas.

${ }^{5}$ http://mysql.com/ . Acesso em julho/2012. 


\section{Capítulo 5}

\section{Córpus}

Neste capítulo serão apresentadas informações sobre o córpus UOLCP2011. O conteúdo deste córpus é composto por 100 notícias do Campeonato Paulista de 2011 escritas no portal Universo Online. Todo o processo de anotação e classificação foi realizado manualmente através do uso das ferramentas descritas nos Capítulos 3 e 4 . A classificação das notícias foi realizada utilizando o seguinte conjunto de etiquetas: pessoa, lugar, organização, time, campeonato, torcida e estádio.

\subsection{Regras de anotação}

Antes do processo de anotação dos textos ser iniciado é necessário definir um manual de anotação. Este é composto por um conjunto de regras e padrões para garantir uma classificação uniforme entre os itens classificados. A primeira proposta deste manual foi adicionar metainformações em todas as entidades explicitamente nomeadas, basicamente todos os substantivos próprios, dentro das seguintes categorias: pessoa, lugar ou organização.

Com base nestas regras os nomes de times e campeonatos seriam anotados como organizações; estádios e cidades seriam classificados como lugares. Uma vez que este trabalho tem como principal objetivo a classificação de entidades ambíguas, a definição de categorias muito genéricas poderia dificultar a operação do algoritmo. Logo após a anotação de cinco notícias as categorias foram redivididas da seguinte forma: pessoa, lugar, organização, time, estádio e campeonato. E todos os textos foram anotados novamente.

Após a classificação de mais alguns textos um novo padrão se tornou recorrente, os jogadores têm diversos apelidos, por exemplo, o jogador Kléber do time do Palmeiras tem o apelido de "gladiador", enquanto Valdivia, da mesma equipe, é chamado de "mago". Em ambos os casos não foram utilizados substantivos próprios, e por isso estas entidades não seriam anotadas, o que é um equivoco. Mas a pior falha da regra de classificação de substantivos próprios é na frase "tricolor do Morumbi", que no contexto deveria ser classificada como time, mas com base na regra definida, somente Morumbi seria classificado como lugar. Desta forma o algoritmo de aprendizado supervisionado seria induzido a erros de classificação. 
Com base neste conhecimento adquirido foi criada uma nova regra, em que todas as entidades seriam anotadas independentemente da forma de escrita ou classe gramatical. Com a definição desta nova regra, entidades como "time do Morumbi", "time tricolor" ou "jogadores são paulinos", passariam a ser classificados como time; "treinador tricolor" passaria a ser classificado como pessoa; "assessoria de imprensa corintiana" seria classificada como organização. Assim todos os textos foram classificados novamente.

Novamente após a anotação de algumas notícias outro padrão se fez necessário, por exemplo, a expressão "são paulinos" pode referenciar tanto os jogadores do time São Paulo, como os torcedores deste time. Caso todas as ocorrências de "são paulinos" classificadas remetessem aos jogadores, o algoritmo de classificação seria tendencioso a acreditar que todas as ocorrências de "são paulinos" seriam sobre o time. Para resolver este problema foi criada uma nova categoria chamada torcida e novamente todos os textos foram anotados.

\subsection{Tipologia do córpus}

Da mesma forma que a anotação de textos é um processo muito importante para o estudo da linguística computacional, a classificação do córpus permite que o mesmo possa ser reaproveitado por outros estudos. Atualmente não existe uma entidade responsável por regularizar esta classificação nem tão pouco um consenso da comunidade cientifica. Com este intuito serão apresentadas duas classificações amplamente utilizadas. A primeira é proposta por Sardinha (2004) e a segunda por Giouli e Piperidis (2007), as Tabelas 5.1 e 5.2 exibem as classificações respectivamente.

\begin{tabular}{r|l} 
Critério & Classificação \\
\hline Modo & escrito \\
Tempo & contemporâneo \\
Seleção & estático \\
Conteúdo & especializado \\
Disposição interna & simples \\
Finalidade & treinamento e teste
\end{tabular}

Tabela 5.1: Classificação segundo os critérios propostos em Sardinha (2004).

\subsection{Formato}

O córpus UOLCP2011 está disponível em quatro versões, sendo estas o cruzamento da presença de anotações de entidades nomeadas ou não, e os formatos: texto puro e XML (eXtensible Markup Language). Todas as versões do córpus utilizam o padrão UTF-8 (8-bit Unicode Transformation Format) para a codificação dos caracteres. Quando ocorrer a presença das marcações de entidades nomeadas estas são sempre anotadas utilizando o padrão SGML (Standard Generalized Markup Language). 


\begin{tabular}{r|l} 
Critério & Classificação \\
\hline Modalidade & escrito \\
Tipo de texto & escrito \\
Mídia & conteúdo jornalístico \\
& escrito para internet \\
córpus de língua geral \\
Cobertura da língua \\
Gênero & não fição \\
monolingues \\
Quantidade de línguas \\
Anotação & anotado \\
córpus fechado
\end{tabular}

Tabela 5.2: Classificação segundo os critérios propostos em Piperidis (200\%).

A grande diferença entre os formatos do córpus é que as versões que utilizam o padrão XML contém metainformações sobre o documento, tais como: identificador único do documento (atribudo id da etiqueta document), URL em que o texto foi extraído (etiqueta url) e data em que o documento foi coletado (etiqueta collected). Estas informações são importantes caso seja necessário algum tipo de validação da origem dos documentos. A Tabela 5.3 exibe um documento com anotações de entidades nomeadas utilizando o padrão XML. Já as versões texto puro contém somente o texto. Em ambas as versões do córpus a primeira linha do corpo do texto é o título e cada uma das subsequentes é um parágrafo da notícia.

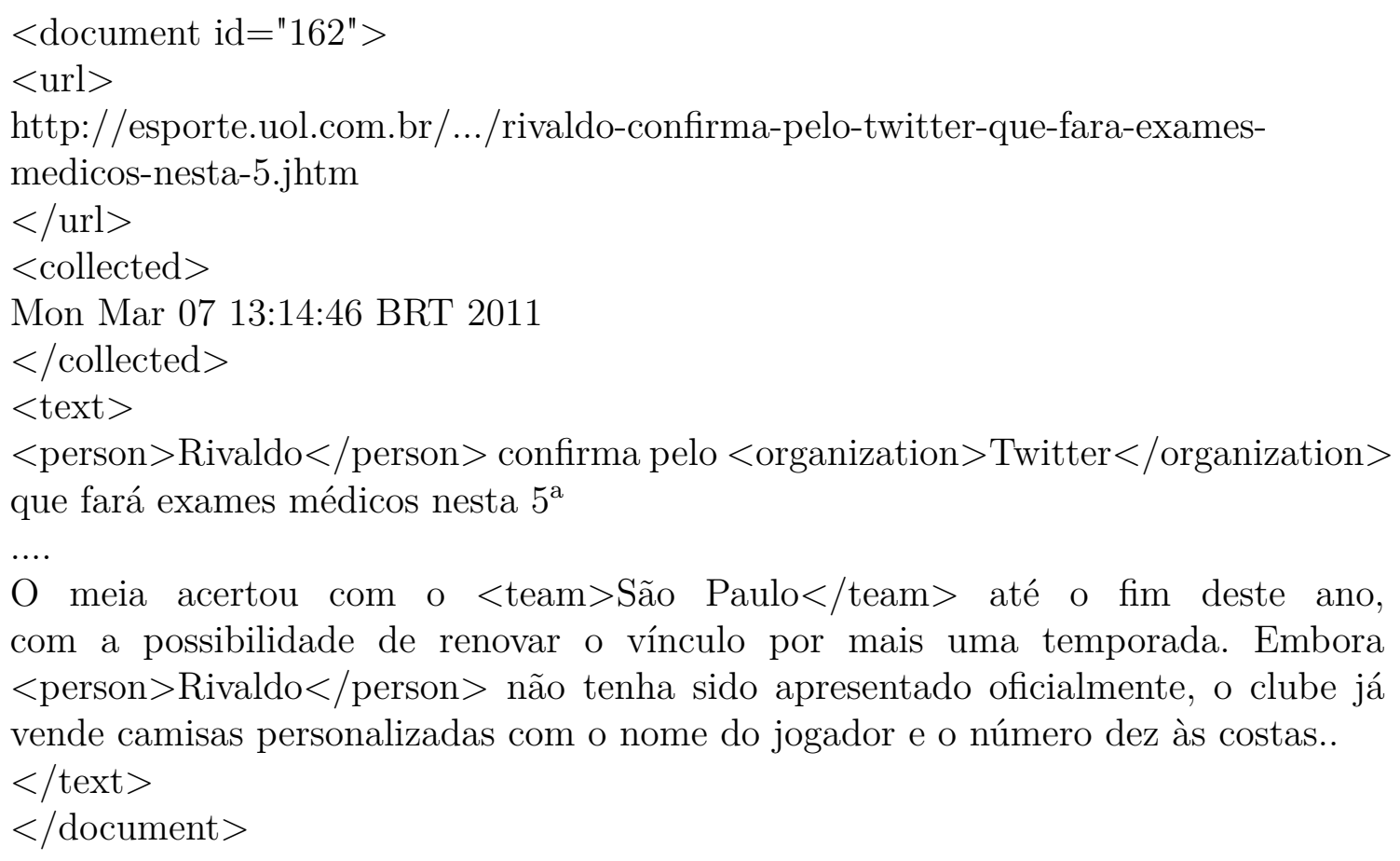

Tabela 5.3: Exemplo de documento utilizando o formato XML e anotações de entidades nomeadas. Os elementos do tipo CDATA foram omitidos do início de fim de cada etiqueta para tornar mais clara a estrutura do documento. 


\subsection{Licença}

O córpus esta disponível em https://github.com/rodzac/UOLCP2011/ utilizando a licença $\mathrm{MIT}^{1}$, sendo esta uma licença permissiva de software livre, na qual permite o reuso em software proprietário desde que o software distribua consigo uma cópia dos termos da licença MIT (texto na integra na Tabela 5.4). Esta licença é compatível com a licença GPL.

THE SOFTWARE IS PROVIDED "AS IS", WITHOUT WARRANTY OF ANY KIND, EXPRESS OR IMPLIED, INCLUDING BUT NOT LIMITED TO THE WARRANTIES OF MERCHANTABILITY, FITNESS FOR A PARTICULAR PURPOSE AND NONINFRINGEMENT. IN NO EVENT SHALL THE AUTHORS OR COPYRIGHT HOLDERS BE LIABLE FOR ANY CLAIM, DAMAGES OR OTHER LIABILITY, WHETHER IN AN ACTION OF CONTRACT, TORT OR OTHERWISE, ARISING FROM, OUT OF OR IN CONNECTION WITH THE SOFTWARE OR THE USE OR OTHER DEALINGS IN THE SOFTWARE.

Tabela 5.4: Termos na licença MIT.

\subsection{Estatísticas}

O córpus UOLCP2011 é composto por 16787 palavras, sendo 2793 únicas. A Tabela 5.5 comprova a distribuição descrita pela Lei de Zipf, definida da seguinte forma por Manning e Schütze (1999): "existem poucas palavras comuns, uma quantidade razoável de palavras com frequência média e muitas palavras com baixa frequência". A lista a seguir apresenta as palavras mais repetidas em ordem decrescente: "o", "a", "de", "do", "e", "no", "para", "que".

\begin{tabular}{c|c} 
Intervalo & Valor \\
\hline 1 & 1477 \\
$2-3$ & 630 \\
$4-10$ & 462 \\
$11-20$ & 120 \\
$21-40$ & 54 \\
$41-60$ & 16 \\
$61-80$ & 12 \\
$81-100$ & 5 \\
$101-200$ & 9 \\
$201-927$ & 8
\end{tabular}

Tabela 5.5: Agrupamento das palavras presentes do córpus separadas por classes de repetições.

Para realizar a anotação das entidades nomeadas foram utilizadas 7 etiquetas diferentes: torcida, lugar, organização, estádio, campeonato, pessoa, time; estas somadas resultam em

\footnotetext{
${ }^{1}$ http://www.opensource.org/licenses/MIT . Acesso em julho/2012.
} 
1886 entidades anotadas, sendo 597 únicas. A Tabela 5.6 apresenta quantidade de etiquetas agrupadas por classes de repetições.

\begin{tabular}{c|c} 
Intervalo & Valor \\
\hline 1 & 343 \\
$2-3$ & 133 \\
$4-9$ & 70 \\
acima de 10 & 41
\end{tabular}

Tabela 5.6: Agrupamento por repetições de todas as entidades.

A etiqueta torcida contém 13 anotações, sendo que destas 11 são únicas. A Tabela 5.7 apresenta quantidade de etiquetas agrupadas por classes de repetições. As etiquetas com mais repetições foram: "torcida corintiana" e "torcida rubro-verde" com 2 ocorrências.

\begin{tabular}{c|c} 
Intervalo & Valor \\
\hline 1 & 9 \\
$2-3$ & 2 \\
$4-9$ & 0 \\
acima de 10 & 0
\end{tabular}

Tabela 5.7: Agrupamento por repetições das entidades do tipo torcida.

A etiqueta lugar contém 93 anotações, sendo que destas 55 entidades únicas. A Tabela 5.8 apresenta quantidade de etiquetas agrupadas por classes de repetições. As etiquetas com mais repetições foram: "Brasília" com 6 ocorrências; "CT da Barra Funda" com 5; "Campinas", "Itápolis", "Barueri", "Presidente Prudente" e "Lins" com 4 ocorrências.

\begin{tabular}{c|c} 
Intervalo & Valor \\
\hline 1 & 36 \\
$2-3$ & 12 \\
$4-9$ & 7 \\
acima de 10 & 0
\end{tabular}

Tabela 5.8: Agrupamento por repetições das entidades do tipo lugar.

A etiqueta organização contém 95 anotações, sendo que destas 45 entidades únicas. A Tabela 5.9 apresenta quantidade de etiquetas agrupadas por classes de repetições. As etiquetas com mais repetições foram: "FPF" com 10 ocorrências; "CBF" com 11.

\begin{tabular}{c|c} 
Intervalo & Valor \\
\hline 1 & 30 \\
$2-3$ & 9 \\
$4-9$ & 4 \\
acima de 10 & 2
\end{tabular}

Tabela 5.9: Agrupamento por repetições das entidades do tipo organização. 
A etiqueta estádio contém 105 anotações, sendo que destas 19 entidades únicas. A Tabela 5.10 apresenta quantidade de etiquetas agrupadas por classes de repetições. As etiquetas com mais repetições foram: "Pacaembu" com 27 ocorrências; "Morumbi" e "Canindé" com 16.

\begin{tabular}{c|c} 
Intervalo & Valor \\
\hline 1 & 5 \\
$2-3$ & 8 \\
$4-9$ & 3 \\
acima de 10 & 3
\end{tabular}

Tabela 5.10: Agrupamento por repetições das entidades do tipo estádio.

A etiqueta campeonato contém 140 anotações, sendo que destas 29 entidades únicas. A Tabela 5.11 apresenta quantidade de etiquetas agrupadas por classes de repetições. As etiquetas com mais repetições foram: "Campeonato Paulista" com 51 ocorrências; "Libertadores" com 18; "Paulistão" com 10.

\begin{tabular}{c|c} 
Intervalo & Valor \\
\hline 1 & 14 \\
$2-3$ & 7 \\
$4-9$ & 5 \\
acima de 10 & 3
\end{tabular}

Tabela 5.11: Agrupamento por repetições das entidades do tipo campeonato.

A etiqueta pessoa contém 716 anotações, sendo que destas 257 entidades únicas. A Tabela 5.12 apresenta quantidade de etiquetas agrupadas por classes de repetições. As etiquetas com mais repetições foram: "Rivaldo" com 36 ocorrências; "Capegiani" e "Fernandinho" com 16; "Rogério Ceni", "Alex Silva" e "Miranda" com 14 ocorrências.

\begin{tabular}{c|c} 
Intervalo & Valor \\
\hline 1 & 148 \\
$2-3$ & 54 \\
$4-9$ & 39 \\
acima de 10 & 16
\end{tabular}

Tabela 5.12: Agrupamento por repetições das entidades do tipo pessoa.

A etiqueta time contém 724 anotações, sendo que destas 171 entidades únicas. A Tabela 5.13 apresenta a quantidade de etiquetas agrupadas por classes de repetições. As etiquetas com mais repetições foram: "Santos" com 67 ocorrências; "São Paulo" com 63; "Palmeiras" com 49; "Corinthians" com 41 ocorrências. 


\begin{tabular}{c|c} 
Intervalo & Valor \\
\hline 1 & 101 \\
$2-3$ & 41 \\
$4-9$ & 12 \\
acima de 10 & 17
\end{tabular}

Tabela 5.13: Agrupamento por repetições das entidades do tipo time. 


\section{Capítulo 6}

\section{Maximização de entropia}

Este capítulo tem como objetivo exibir o processo de treinamento e os resultados alcançados através do uso de maximização de entropia para a tarefa de anotação e classificação de entidades nomeadas.

Para auxiliar o processo de desenvolvimento deste capítulo foi utilizada a biblioteca openNLP ${ }^{1}$, sendo esta um projeto mantido pela Apache Software Foundation e que vem sendo aprimorada por mais de 10 anos. Seu objetivo é prover suporte às tarefas mais comuns necessárias no processamento de linguagem natural, tais como: segmentação de sentenças, separação de palavras, extração de entidades nomeadas, classificação gramatical, entre outras. Neste capítulo as implementações utilizaram as rotinas de extração de entidades nomeadas baseadas no módulo chamado maxent, responsável pelo cálculo de máxima entropia. Toda esta biblioteca é implementada utilizando Java.

\subsection{Treinamento}

Assim como outras ferramentas que utilizam o aprendizado supervisiosado de máquina, para uso do openNLP é necessária uma longa fase de treinamento para ajustar o modelo que deverá ser utilizado. Para esta tarefa é necessário um gabarito, neste caso o córpus anotado apresentado no Capítulo 5 foi utilizado. Para esta fase também são necessários outros dois parâmetros de entrada: quantidade de iterações e quantidade mínima de repetições para corte. Nesta fase de treinamento foram utilizados os valores 100, 150 e 250 para iterações e o intervalo 3 a 5 , incluindo os limites, para o corte.

Também é necessário definir as características que classificarão as entidades. Para todos os testes foram utilizadas as seguintes características: WindowFeature Generator combinados com TokenFeatureGenerator e TokenClassFeatureGenerator; OutcomePriorFeatureGenerator; PreviousMapFeatureGenerator; BigramNameFeatureGenerator e SentenceFeatureGenerator. A escolha deste conjunto visa a classificação em janela da palavra analisada assim como sua classe (texto, número, alfanumérico, inicia com maiúscula, escrito em caixa alta

\footnotetext{
${ }^{1}$ http://opennlp.apache.org/ . Acesso em julho/2012.
} 
entre outras) e posicionamento na frase. Uma vez que a estratégia de janela foi empregada é importante variar o intervalo utilizado. Os valores utilizados nestes testes variam entre 2 e 5, incluindo os limites.

O resultado do treinamento é composto por três indicadores: precisão, cobertura e medida F. Todos os indicadores tem seus resultados contidos no intervalo fechado 0 e 1 . A precisão é calculada através da fórmula 7.1, enquanto o cálculo da cobertura é exibido em 7.2. A medida $\mathrm{F}$ é o resultado da razão ilustrada na função 7.3.

$$
\begin{gathered}
\text { precisão(acertos, entidades anotadas })=\frac{\text { acertos }}{\text { entidades anotadas }} \\
\text { cobertura(acertos, entidades esperadas })=\frac{\text { acertos }}{\text { entidades esperadas }} \\
\text { medidaF }(\text { precisão, cobertura })=\frac{2 * \text { precis } \tilde{a} o * \text { cobertura }}{\text { precisão }+ \text { cobertura }}
\end{gathered}
$$

Durante o treinamento será utilizado o córpus UOLCP2011, quem contém 100 matérias devidamente classificadas utilizando o padrão SGML. Apesar do openNLP utilizar o mesmo padrão, a estrutura das etiquetas de classificação é diferente. Por exemplo: o início da etiqueta pessoa é anotado no córpus como $<$ person $>$, enquanto no openNLP se espera $<$ START:person $>$. Já a etiqueta de término da entidade pessoa é representada por $</$ person $>$ enquanto o openNLP utiliza somente $<$ END $>$, sem repetir o nome da entidade e sem utilizar a barra para indicar o fechamento da etiqueta; outra diferença é que o openNLP espera que o arquivo de entrada tenha todos os tokens separados por espaço. Para realizar estas duas tarefas foi necessário criar uma ferramenta de conversão do padrão do córpus para padrão openNLP.

Para desenvolver o separador de tokens foram utilizados dois outros módulos da própria biblioteca openNLP: SentenceDetector e Tokenizer. O primeiro módulo apresentou diversos problemas com abreviações, de forma que a seguinte frase "na R. Desembargador Paulo Passalacqua" era separada em duas sentenças diferentes. Para resolver problemas deste tipo foi criado um conjunto de expressões regulares, deixando o trabalho de tradução do córpus completamente automático.

Cada bateria de treinamento foi composta por 36 cenários, sendo estes o cruzamento dos valores para janela (intervalo 2 a 5 , inclusive limites), corte (intervalo 3 a 5 , inclusive limites) e iterações (100, 150 e 250). Foram realizadas 8 baterias completas, sendo uma para treinamento individual de cada entidade (pessoa, time, campeonato, lugar, torcida, organização e estádio) e uma bateria para o treinamento coletivo (todas entidades juntas). Assim foram realizados 288 cenários de treinamento.

Cada um destes cenários de treinamento necessita de uma base de treinamento e uma base de validação. O córpus foi dividido em 10 partes iguais de 10 notícias e sempre são utilizadas 9 partes para o treinamento e uma parte para a validação. Desta forma cada 
um dos 288 cenários executa 10 treinamentos diferentes, no total de 2880. Dado este alto volume de informação somente serão exibidos os gráficos dos melhores resultados obtidos. Os gráficos das Figuras 6.1, 6.2, 6.3, 6.4, 6.5 e 6.6 exibem os valores da melhor bateria completa de testes para um conjunto de entrada fixo, composto por 36 execuções.

Nestes gráficos as linhas verticais escuras posicionadas em [12,0] e [24,0] indicam a troca da quantidade de iterações realizadas com valores: 100, 150 e 250. Já as linhas verticais pontilhadas que ocorrem a cada quatro cenários indicam a troca do parâmetro de corte, com valores 3, 4 e 5. Dentro de cada variação do corte foram realizadas variações do tamanho da janela, de 2 a 5. Para descobrir rapidamente os parâmetros de entrada de um cenário são utilizadas as fórmulas: 6.4 para janela, 6.5 para corte e 6.6 para iterações. Desta forma o cenário de treinamento 17 utiliza os parâmetros de entrada: janela 3, corte 4 e 150 iterações.

$$
\begin{gathered}
\text { janela }(x)=\bmod \left(\frac{x}{4}\right)+2 \\
\operatorname{corte}(x)=\bmod \left(\frac{x}{4}\right)+3 \\
\text { iterações }(x)= \begin{cases}x / 12=0, & \text { devolve } 100 \\
x / 12=1, & \text { devolve } 150 \\
x / 12=2, & \text { devolve } 250\end{cases}
\end{gathered}
$$

O gráfico da Figura 6.1 mostra o treinamento da entidade time utilizando o quinto conjunto de entrada. Observa-se que os indicadores pioram conforme a janela aumenta e que a quantidade de iterações realizadas durante o treinamento não melhora a eficiência do modelo gerado. Quanto maior o número de iterações aliado a um corte elevado, pior a acertividade do algoritmo.

Com base nas informações apresentadas no Capítulo 5.5, as etiquetas de time têm uma alta taxa de repetição: Santos tem 67 ocorrências; São Paulo, 63; Palmeiras, 49 e Corinthians 41 ocorrências. Assim o aumento do corte não leva à perda de informações, pois uma grande parte das etiquetas aparece com muita frequência e por este motivo podem aparecer em diferentes contextos, fazendo que repetições da mesma sequência de palavras ocorram pouco. Isto justifica o decréscimo de eficiência quando uma janela maior é utilizada.

Conclui-se que os melhores resultados obtidos são os que utilizam janela igual a 2 e corte igual a 3, sem interferência da quantidade de iterações no resultado. Assim o valor 100 será eleito o melhor por ter um treinamento mais rápido. A escolha deste cenário é mais simples pois com estes parâmetros de entrada todos os indicadores são maximais.

O gráfico da Figura 6.2 mostra o treinamento da entidade pessoa utilizando o quinto conjunto de entrada. Este gráfico tem o comportamento muito diferente do apresentado na Figura 6.1, pois cada indicador tem um comportamento distinto em relação ao outro e por muitas vezes de forma antagônica. O indicador precisão tem resultados piores a medida que a 


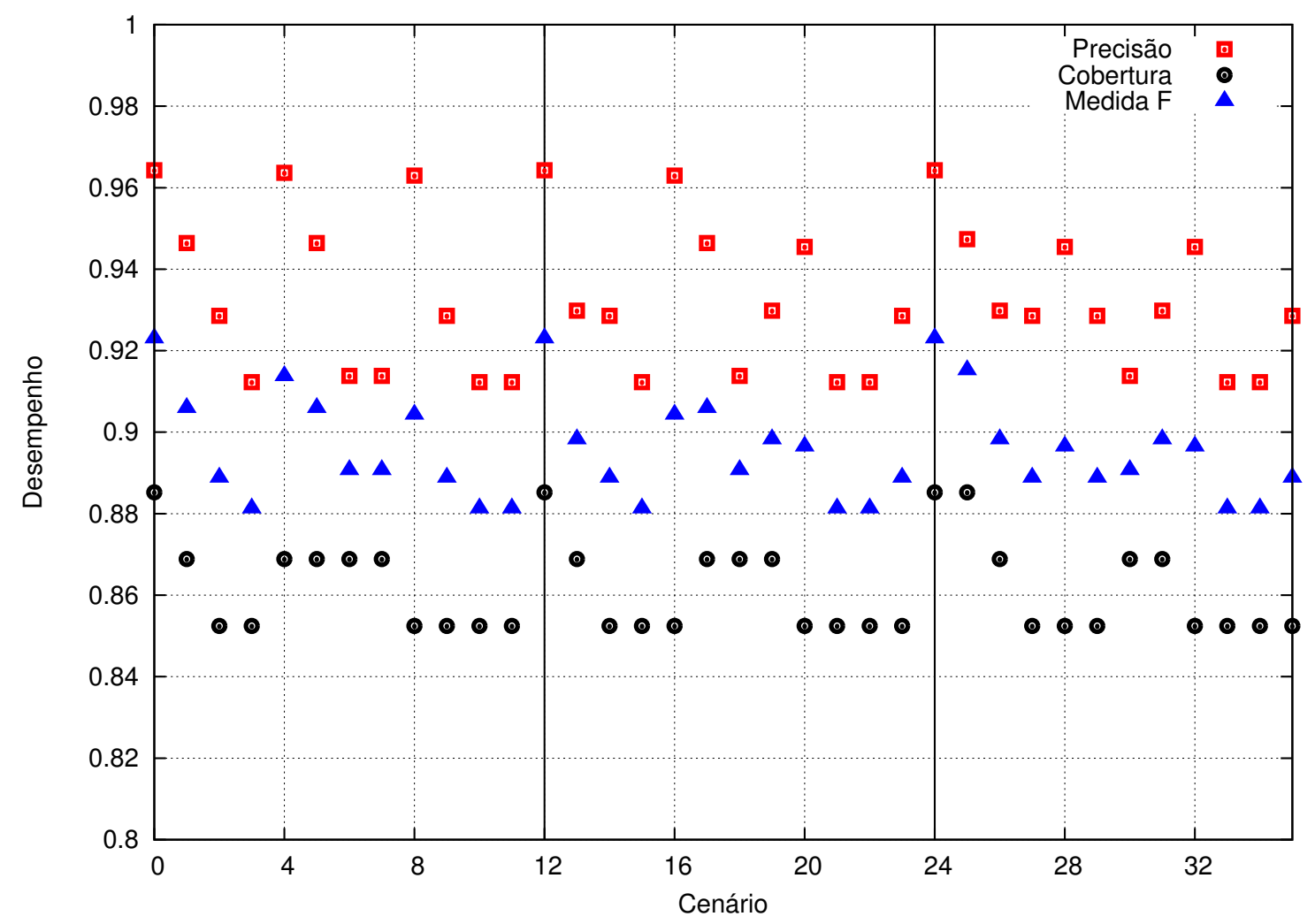

Figura 6.1: Resultado dos 36 cenários de teste efetuados para o quinto conjunto de entrada da entidade time.

janela, corte e iterações crescem. O melhor resultado deste indicador foi obtido utilizando-se janela igual 2, corte igual 3 e 100 iterações. Já o indicador cobertura geralmente tem melhores resultados conforme janela e corte aumentam, e chegam a se aproximar do indicador precisão em alguns momentos. Somente em dois cenários o indicador cobertura superou o indicador precisão: ambos os casos janela e corte têm valor 5 combinados com 150 e 250 iterações.

Confome os dados do Capítulo 5.5, as etiquetas de pessoa tem uma taxa de repetição inferior às de time, mas ainda estão acima da média das demais. "Rivaldo" tem 36 ocorrências, enquanto "Capegiani" e "Fernandinho" tem 16 e "Rogério Ceni", "Alex Silva" e "Miranda" aparecem com 14 ocorrências. Grande parte das entidades anotadas com a etiqueta pessoa tem nomes compostos, o que justifica que o aumento da janela pegue a entidade e seu contexto de forma melhor. Outra informação importante é que quase um terço das entidades aparecem entre uma e três vezes; assim quando o corte é elevado estas entidades são descartadas, ressaltando as características presentes nas entidades que têm um número maior de repetições.

Curiosamente o melhor resultado obtido está em oposição às tendências apresentadas, sendo este o cenário com janela e corte igual a 5 e 100 iterações. O indicador medida F, por se tratar de uma média, teve seu ponto maximal no mesmo cenário que o indicador cobertura. Nesse cenário o indicador de precisão, apesar de não ser maximal, está somente à $3 \%$ do melhor resultado. 


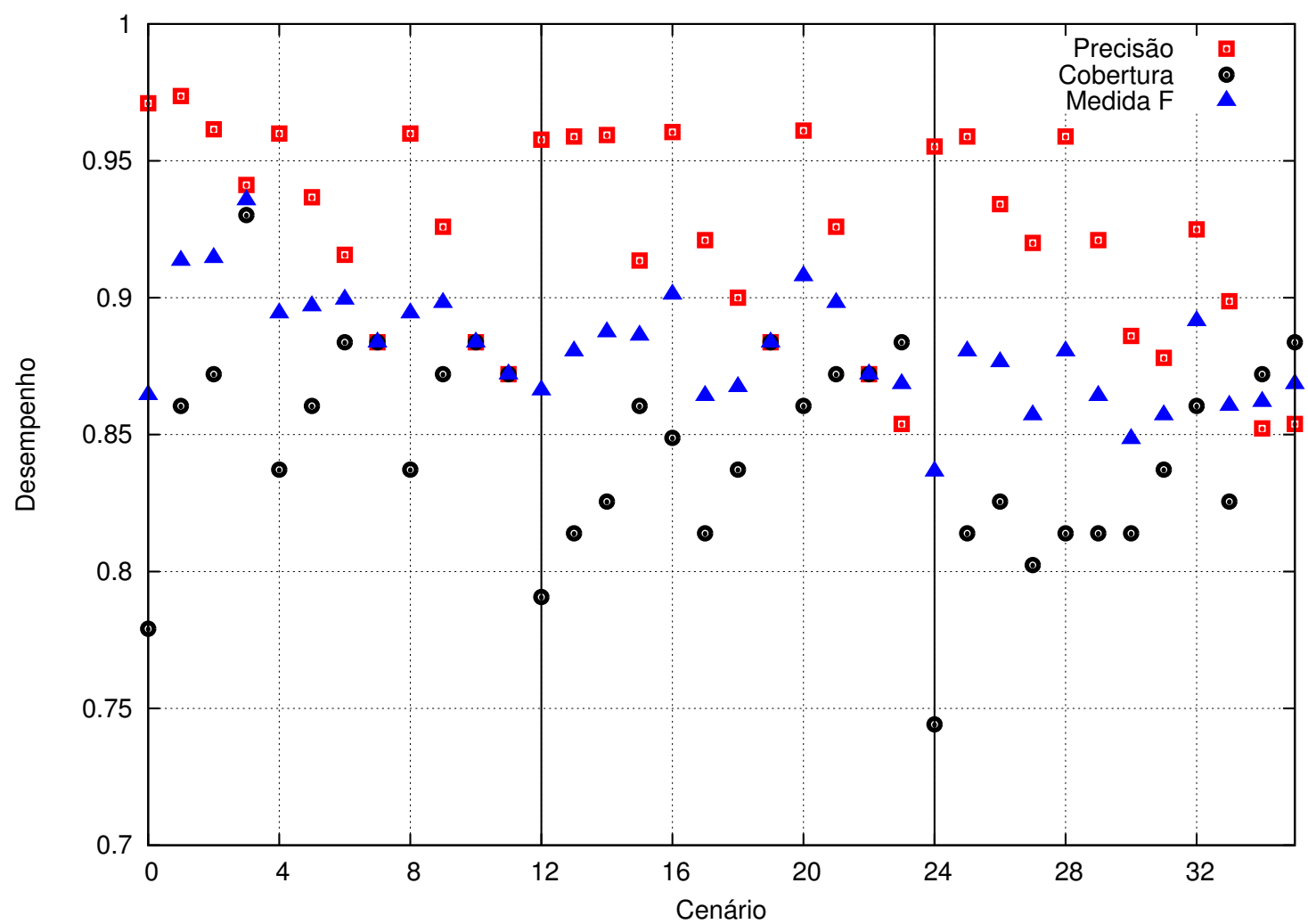

Figura 6.2: Resultado dos 36 cenários de teste efetuados para o quinto conjunto de entrada da entidade pessoa.

O gráfico da Figura 6.3 mostra o treinamento da entidade lugar utilizando o sexto conjunto de entrada. Nele é possível perceber que a maior parte dos resultados maximais ocorre quando o corte é igual a 3 e que a quantidade de iterações realizadas durante o treinamento não melhora a eficiência do modelo gerado. Quando um número maior de iterações é aliado a um corte diferente de 3 a acertividade do algoritmo é pior.

Com base nas informações apresentadas no Capítulo 5.5 as etiquetas de lugar tem uma taxa de repetição baixa. Por exemplo "Brasília" conta com 6 ocorrências; "CT da Barra Funda" com 5; "Campinas", "Itápolis", "Barueri", "Presidente Prudente" e "Lins" com 4 ocorrências. Devido a isto o corte perde muitas informações a cada incremento, pois existem somente 7 entidades que ocorrem mais de 3 vezes.

O melhor resultado obtido é quando se utiliza corte igual a 3, janela igual a 2 e 100 iterações. Como não ocorre interferência do tamanho da janela e quantidade de iterações no resultado foram escolhidos os valores que apresentam o menor tempo de treinamento. A escolha deste cenário é mais simples pois com estes parâmetros de entrada todos os indicadores são maximais.

O gráfico da Figura 6.4 mostra o treinamento da entidade campeonato utilizando o quarto conjunto de entrada. Neste gráfico o indicador precisão atinge ao menos uma vez o valor máximo a cada combinação de corte e iterações com exceção do par corte 5 e 250 iterações. A maior parte dos valores maximais para os indicadores cobertura e medida F são alcançados 


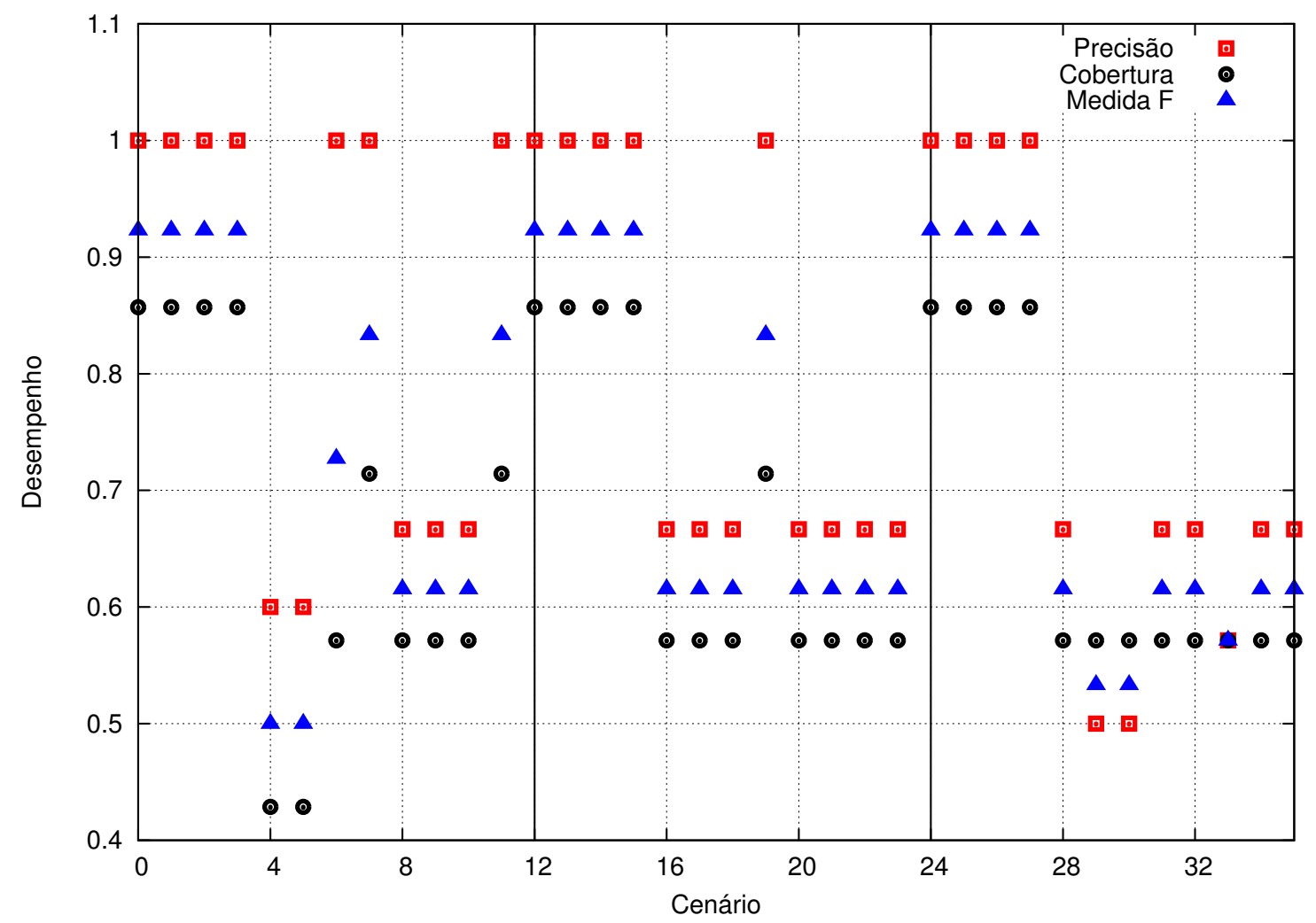

Figura 6.3: Resultado dos 36 cenários de teste efetuados para o sexto conjunto de entrada da entidade lugar.

com corte igual a 4 independente da quantidade de iterações.

Como visto no Capítulo 5.5, as etiquetas de campeonato têm uma taxa de repetição alta: "Campeonato Paulista" aparece em 51 ocorrências; "Libertadores" em 18 e "Paulistão" em 10 ocorrências. Das 140 entidades anotadas com a etiqueta campeonato, 56\% estão no grupo com mais de 10 repetições. Assim com o corte alto as entidades que aparecem pouco são descartadas, reafirmando as características das entidades que aparecem mais, deixando o algoritmo com melhores resultados.

O melhor resultado obtido utiliza corte igual a 4, janela igual a 2 e 100 iterações. Como o tamanho da janela e quantidade de iterações não interferem no resultado, foram escolhidos os valores que apresentam o menor tempo de treinamento. A escolha deste cenário é mais simples pois com estes parâmetros de entrada todos os indicadores são maximais.

O gráfico da Figura 6.5 mostra o treinamento da entidade estádio utilizando o sétimo conjunto de entrada. Nesta gráfico o indicador precisão teve o valor constante máximo em todos as execuções. Já os indicadores cobertura e medida $\mathrm{F}$ tiveram a maior parte dos melhores resultados utilizando corte igual a 4 ou 5 independentemente da quantidade de iterações.

As etiquetas de estádio tem uma taxa de repetição alta, como apresentado no Capítulo 5.5. Das 105 entidades anotadas com a etiqueta estádio, 56\% estão no grupo com mais de 10 repetições, como "Pacaembu" (27 ocorrências), "Morumbi" e "Canindé" (16 ocorrências 


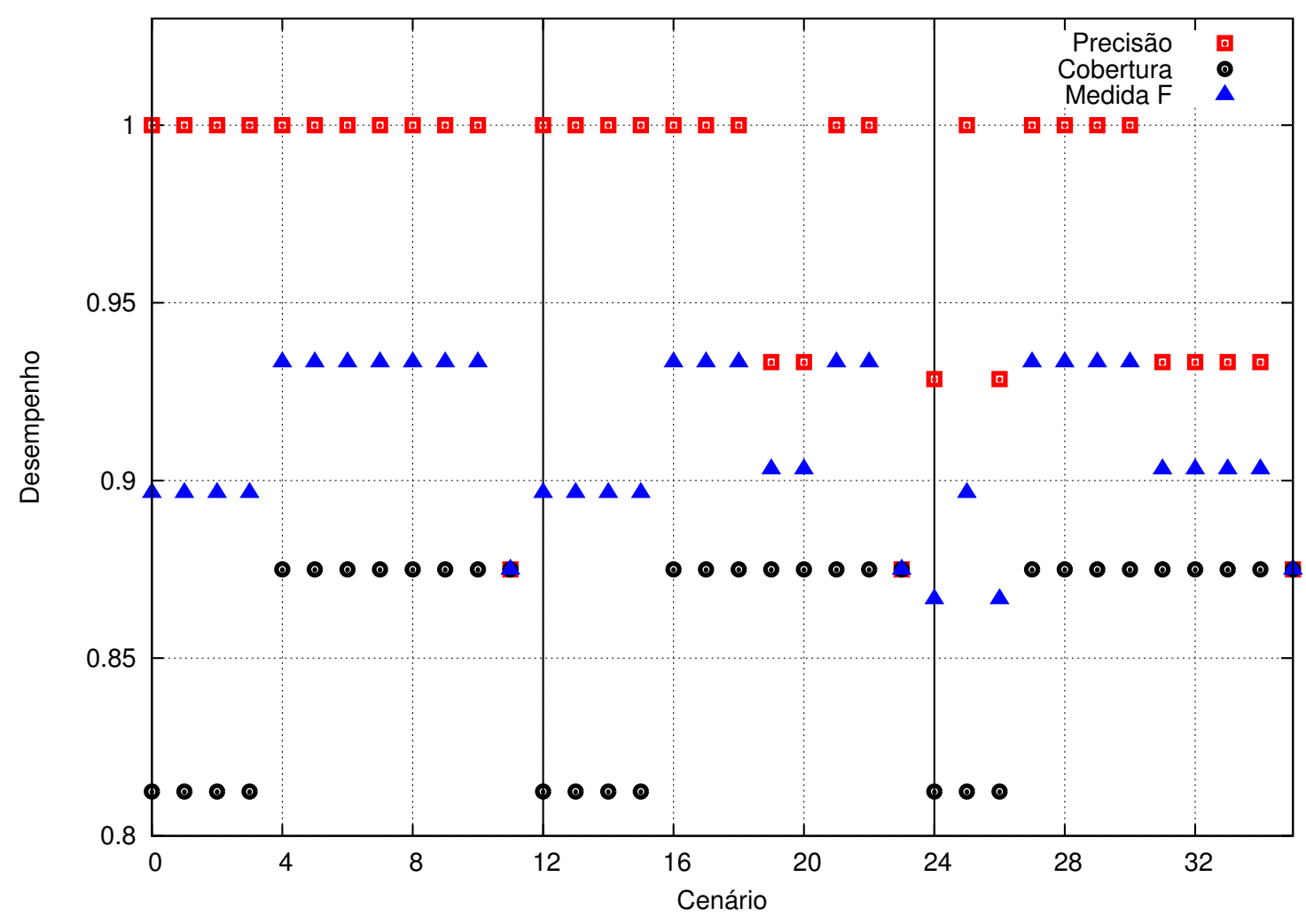

Figura 6.4: Resultado dos 36 cenários de teste efetuados para o quarto conjunto de entrada da entidade campeonato.

cada). Assim com o corte alto as entidades que aparecem pouco são descartadas, reafirmando as características das entidades que aparecem mais, deixando o algoritmo com melhores resultados.

O melhor resultado obtido utiliza corte igual a 4, janela igual a 2 e 100 iterações. Apesar de grande parte dos resultados alcançarem valores maximais, foram eleitos os que têm o treinamento mais rápido. A escolha deste cenário é mais simples pois com estes parâmetros de entrada todos os indicadores são maximais.

O gráfico da Figura 6.6 mostra o treinamento da entidade organização utilizando o nono conjunto de entrada. Neste gráfico o indicador precisão teve o valor máximo em todas as execuções com exceção dos cenários que utilizam corte e janela igual a 5 independente da quantidade de iterações. Já os indicadores cobertura e medida F têm a maior parte dos melhores resultados utilizando corte igual a 4.

Com base nas informações apresentadas no Capítulo 5.5, as etiquetas de organização tem uma taxa de repetição baixa, por exemplo: "FPF" com 10 ocorrências e "CBF" com 11 ocorrências. Mesmo com a baixa taxa de repetição o valor do corte igual a 4 se mostrou mais eficiente que o valor 3 ou 5 .

O melhor resultado obtido utiliza corte igual a 4, janela igual a 2 e 100 iterações. Com base nos mesmo critérios de desempate adotados em estádio e campeonato, foram escolhidos os parâmetros de entrada que tem o treinamento mais rápido. A escolha deste cenário é mais 


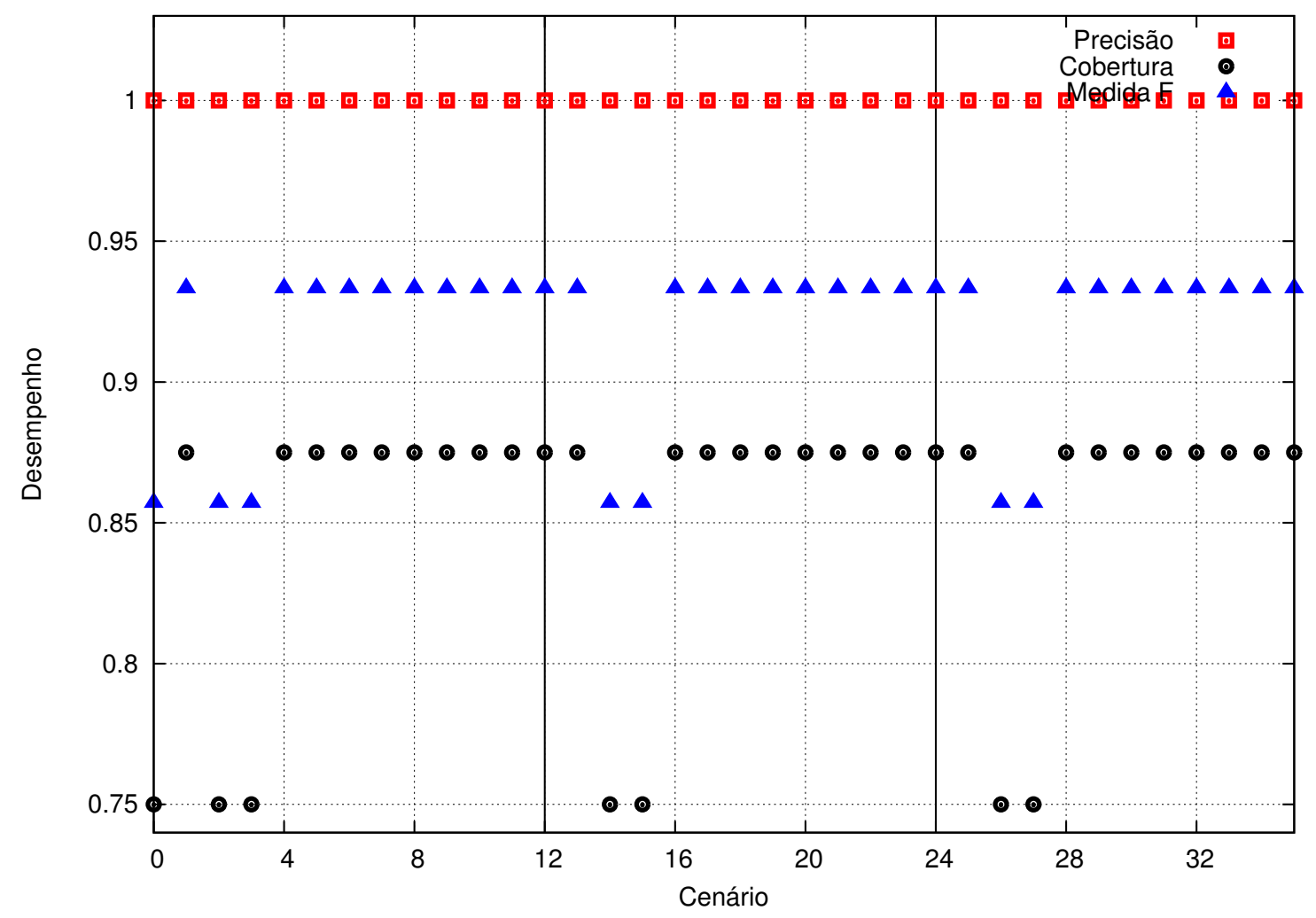

Figura 6.5: Resultado dos 36 cenários de teste efetuados para o sétimo conjunto de entrada da entidade estádio.

simples pois com estes parâmetros de entrada todos os indicadores são maximais.

Os resultados obtidos com o treinamento da entidade torcida não foram significativos devido a baixa frequência destas entidades. A etiqueta torcida contém 13 anotações, sendo 11 entidades únicas. Destas somente "torcida corintiana" e "torcida rubro-verde" tem 2 ocorrências. Todos os experimentos obtiveram resultado 0 para os indicadores precisão e cobertura; -1 para a medida F.

O gráfico da Figura 6.7 mostra o treinamento coletivo das entidades, utilizando o oitavo conjunto de entrada. Neste gráfico todos os indicadores obtiveram melhores resultados com o corte igual a 4, exceto quando foram executadas 150 iterações, que aliado ao o corte igual a 5 foi superior em todos indicadores. Os resultados mais eficientes aconteceram com janelas pequenas, 2 ou 3. Já janelas com valores 4 ou 5 nunca tiveram uma resultado maximal nesta bateria.

Confome os dados do Capítulo 5.5, as etiquetas de entidades nomeadas têm uma taxa de repetição baixa, sendo que somente 41 entidades ocorrem mais de 10 vezes repetidas. $O$ corpus contém 16787 palavras, das quais 1886 são entidades nomeadas, um pouco mais de $11 \%$ do total. Assim valor do corte maior ajuda a remover padrões com baixa recorrência, fixando as características das entidades com mais repetições.

O melhor resultado obtido utiliza corte igual a 5, janela igual a 3 e 150 iterações. A escolha deste cenário é mais simples pois nestes valores escolhidos todos os índices avaliados 


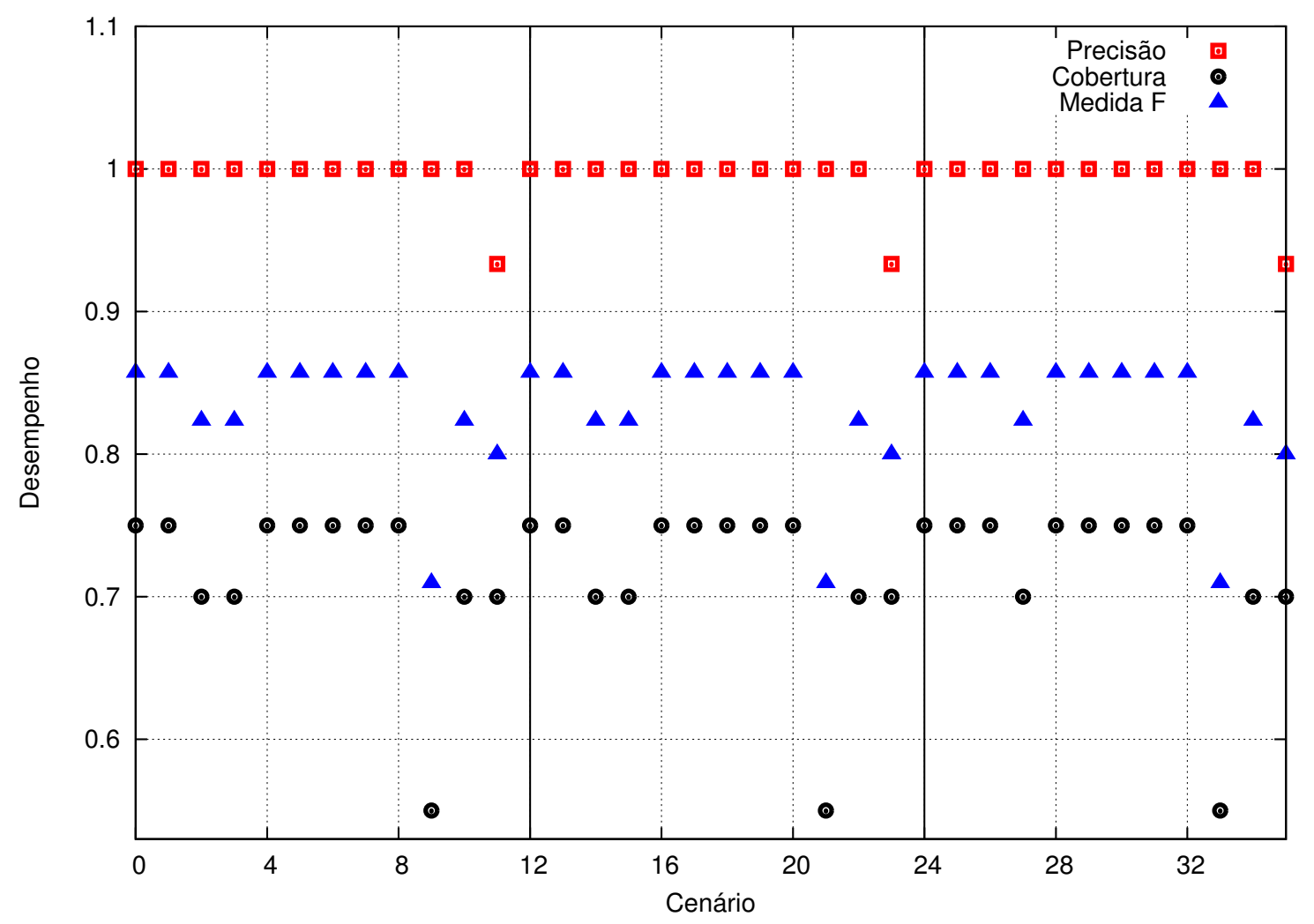

Figura 6.6: Resultado dos 36 cenários de teste efetuados para o nono conjunto de entrada da entidade organização.

são maximais.

\subsection{Análise dos resultados}

Este capítulo tem como objetivo analisar os resultados obtidos durante o treinamento ocorrido no Capítulo 6.1. Neste foram realizadas diversas baterias de testes variando três parâmetros de entrada: janela, corte e iterações. A Tabela 6.1 exibe os parâmetros de entrada para os treinamentos que obtiveram o melhor resultado. Todos os treinamentos individuais alcançaram o melhor resultado utilizando 100 iterações, enquanto o treinamento coletivo atingiu o melhor resultado com 150 iterações. Já o parâmetro janela com valor igual a 2 foi o melhor para todos cenários de treinamento individual exceto pessoa, cujo melhor resultado foi obtido com janela igual a 5. O treinamento coletivo das entidades conseguiu o melhor resultado com janela igual a 3 . O parâmetro corte teve a maior variação de valores, sendo o valor 4 o melhor para as etiquetas: orgazanição, campeonato e estádio; o valor 3 para time e lugar e o valor 5 para a etiqueta pessoa e o treinamento coletivo.

Parte do objetivo ao avaliar esta ampla variedade de cenários de treinamento é concluir que o treinamento coletivo é superior ao treinamento individual das entidades. Neste experimento ambos modelos classificaram todo o córpus utilizado durante o treinamento particionado e a Tabela 6.2 exibe o resultado desta comparação. O treinamento individual 


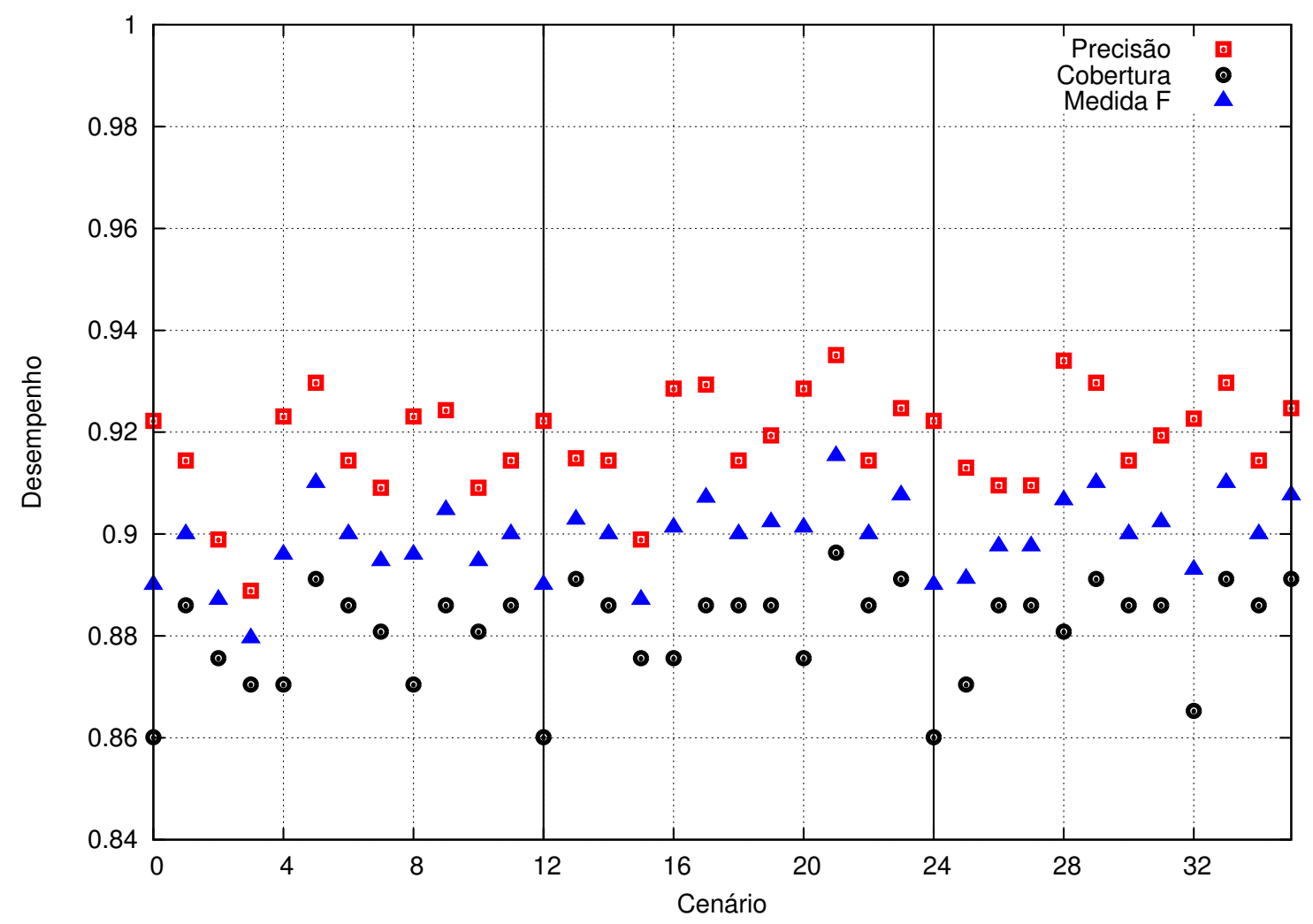

Figura 6.7: Resultado dos 36 cenários de teste efetuados para o oitavo conjunto de entrada para todas as entidades.

\begin{tabular}{l|c|c|c} 
& Janela & Corte & Iterações \\
\hline Pessoa & 5 & 5 & 100 \\
Time & 2 & 3 & 100 \\
Lugar & 2 & 3 & 100 \\
Campeonato & 2 & 4 & 100 \\
Estádio & 2 & 4 & 100 \\
Orgazanição & 2 & 4 & 100 \\
Torcida & - & - & - \\
Todas & 3 & 5 & 150
\end{tabular}

Tabela 6.1: Resultado dos melhores parâmetros de treinamento.

foi extremamente preciso com $99.69 \%$ de sucesso na anotação e classificação, já para a mesma tarefa o treinamento coletivo obteve $91.96 \%$. Porém o treinamento individual só conseguiu anotar $64.55 \%$ das entidades presentes no córpus, enquanto o modelo coletivo anotou $101.97 \%$ das entidades. Mesmo que este modelo conseguisse obter $100 \%$ de precisão ele ainda teria anotado $1.97 \%$ de entidades de forma errada, o que representa aproximadamente 57 entidades. O modelo com treinamento coletivo teve $8.03 \%$ de erros de anotação e classificação e o modelo individual, $0.30 \%$. O indicador cobertura foi $40.90 \%$ melhor no treinamento coletivo, assim como o indicador medida F também foi $16.45 \%$ superior.

Com base nestes dados não existe um modelo vencedor, mas sim um modelo mais apropriado para diferentes cenários, de forma que o treinamento individual é a melhor opção 
quando a anotação ou classificação errada podem gerar grandes prejuízos. Caso seja importante ter uma maior abrangência de classificação, o modelo de treinamento coletivo se mostrou mais eficiente.

\begin{tabular}{l|c|c} 
& Individual & Coletivo \\
\hline Total de entidades & 2930 & 2930 \\
Entidades anotadas & 1950 & 2988 \\
Anotadas com sucesso & 1944 & 2748 \\
Entidades esquecidas & 981 & 92 \\
Entidades classificadas erradas & 5 & 90 \\
Entidades anotadas erradas & 1 & 150 \\
Precisão & 0.99 & 0.91 \\
Cobertura & 0.66 & 0.93 \\
Medida F & 0.79 & 0.92 \\
Tempo (segundos) & 4 & 2
\end{tabular}

Tabela 6.2: Comparação entre os resultados obtidos com o treinamento individual e coletivo utilizando o córpus UOLCP2011.

Para comprovar que estes modelos conseguem realizar a classificação de notícias além das utilizadas no córpus de treinamento, foram classificadas novas 20 notícias esportivas da mesma origem, porém do ano seguinte. Assim foi possível verificar a aplicabilidade do treinamento ao mundo real, pois de um ano para o outro há inversão de times entres a divisões de campeonatos, surgimento de novos jogadores e inclusive a troca dos redatores esportivos com diferentes características textuais. Este córpus será chamado de mini córpus.

As Tabelas 6.3 e 6.4 exibem os resultados detalhados da anotação e classificação deste novo córpus. Desta forma é fácil notar que o modelo de treinamento individual continua extremamente preciso. Nenhum erro de anotação foi detectado e somente três erros de classificação aconteceram, todos em diferentes documentos. A quantidade total de entidades anotadas continua baixa em relação ao modelo de treinamento coletivo. Mas o modelo coletivo continua com número maior de erros de anotação e classificação.

A Tabela 6.5 exibe o resultado resumido desta comparação. O treinamento individual manteve altos índices de precisão com $98.26 \%$ de sucesso na anotação e classificação, enquanto o treinamento coletivo obteve $81.48 \%$ de sucesso. Porém o treinamento individual só conseguiu anotar $35.26 \%$ das entidades presentes, ao passo que o modelo coletivo anotou 98.93\% das entidades. O modelo com treinamento coletivo teve $18.05 \%$ de erros de anotação e classificação e o modelo individual, 1.73\%. O indicador cobertura foi $135.29 \%$ melhor no treinamento coletivo, assim como o indicador medida F também foi $58.82 \%$ superior.

Com os resultados obtidos neste experimento foi possível notar os que modelos preservam as características definidas no primeiro experimento (Tabela 6.2) e que não existe um modelo superior, mas sim um modelo adequado a cada necessidade. 


\begin{tabular}{c|c|c|c|c|c|c} 
Notícia & Total & Anotadas & Sucesso & Esquecidas & Anotadas Erradas & Class. erradas \\
\hline 1 & 15 & 5 & 5 & 10 & 0 & 0 \\
2 & 23 & 3 & 3 & 20 & 0 & 0 \\
3 & 26 & 9 & 9 & 17 & 0 & 0 \\
4 & 31 & 7 & 7 & 24 & 0 & 0 \\
5 & 25 & 11 & 11 & 14 & 0 & 0 \\
\hline 6 & 27 & 4 & 3 & 23 & 0 & 0 \\
7 & 24 & 6 & 6 & 18 & 0 & 0 \\
8 & 32 & 17 & 17 & 15 & 0 & 0 \\
9 & 29 & 8 & 8 & 21 & 0 & 0 \\
10 & 27 & 7 & 7 & 20 & 0 & 0 \\
\hline 11 & 33 & 13 & 13 & 20 & 0 & 0 \\
12 & 36 & 4 & 4 & 32 & 0 & 0 \\
13 & 82 & 19 & 19 & 63 & 0 & 0 \\
14 & 21 & 5 & 5 & 16 & 0 & 0 \\
15 & 49 & 4 & 4 & 45 & 0 & 0 \\
16 & 50 & 7 & 7 & 43 & 0 & 1 \\
17 & 30 & 3 & 2 & 27 & 0 & 0 \\
18 & 30 & 10 & 10 & 20 & 0 & 0 \\
19 & 29 & 14 & 13 & 15 & 0 & 0 \\
20 & 36 & 18 & 18 & 18 & & 0
\end{tabular}

Tabela 6.3: Resultados detalhado da anotação e classificação do modelo individual utilizando o mini córpus.

\begin{tabular}{c|c|c|c|c|c|c} 
Notícia & Total & Anotadas & Sucesso & Esquecidas & Anotadas Erradas & Class. erradas \\
\hline 1 & 15 & 18 & 14 & 0 & 3 & 1 \\
2 & 23 & 24 & 16 & 5 & 6 & 2 \\
3 & 26 & 28 & 24 & 0 & 2 & 2 \\
4 & 31 & 31 & 24 & 2 & 2 & 5 \\
5 & 25 & 28 & 23 & 0 & 3 & 2 \\
\hline 6 & 27 & 21 & 8 & 11 & 5 & 8 \\
7 & 24 & 21 & 20 & 4 & 1 & 0 \\
8 & 32 & 35 & 31 & 0 & 3 & 4 \\
9 & 29 & 26 & 20 & 5 & 2 & 4 \\
10 & 27 & 28 & 21 & 2 & 3 & 5 \\
\hline 11 & 33 & 24 & 18 & 11 & 2 & 3 \\
12 & 36 & 36 & 25 & 6 & 6 & 5 \\
13 & 82 & 87 & 75 & 4 & 9 & 2 \\
14 & 21 & 19 & 13 & 2 & 0 & 4 \\
15 & 49 & 49 & 44 & 0 & 0 & 2 \\
\hline 16 & 50 & 51 & 48 & 0 & 1 & 4 \\
17 & 30 & 30 & 23 & 3 & 3 & 1 \\
18 & 30 & 27 & 23 & 5 & 2 & 2 \\
19 & 29 & 31 & 25 & 0 & 0 & \\
20 & 36 & 34 & 33 & 2 & &
\end{tabular}

Tabela 6.4: Resultados detalhado da anotação e classificação do modelo coletivo utilizando o mini córpus. 


\begin{tabular}{l|c|c} 
& Individual & Coletivo \\
\hline Total de entidades & 655 & 655 \\
Entidades anotadas & 231 & 648 \\
Anotadas com sucesso & 227 & 528 \\
Entidades esquecidas & 425 & 62 \\
Entidades classificadas erradas & 3 & 55 \\
Entidades anotadas erradas & 1 & 62 \\
Precisão & 0.98 & 0.81 \\
Cobertura & 0.34 & 0.80 \\
Medida F & 0.51 & 0.81 \\
Tempo (segundos) & 2 & 1
\end{tabular}

Tabela 6.5: Comparação entre os resultados obtidos com o treinamento individual e coletivo utilizando o mini córpus. 


\section{Capítulo 7}

\section{Índices invertidos}

Este capítulo tem como objetivo exibir o processo de implementação, treinamento e os resultados alcançados através do uso de índices invertidos para a tarefa de anotação e classificação de entidades nomeadas. Os resultados obtidos por este método serão comparados com os resultados alcançados pelo método de maximização de entropia, descritos no Capítulo 6 , na Seção 8.2.

Para realizar as tarefas de indexação e busca nos índices invertidos foi utilizada a biblioteca Lucene $^{1}$. Seu desenvolvimento foi iniciado no ano 2000, sendo hoje a alternativa open source mais robusta e estável disponível.

\subsection{Implementação}

O Lucene, assim como o openNLP, é um projeto mantido pela Apache Software Foundation. Esta biblioteca é escrita em Java e tem duas estruturas principais: indexação e busca de conteúdo. Ambas as funções necessitam de um repositório de dados que deve ser definido pelo usuário, ou seja, não existe um esquema de dados pré definidos. Este repositório é armazenado no sistema de arquivos de forma não volátil e não é permitida a concorrência de escrita entre múltiplos processos.

O esquema de repositório definido para o motor de anotação e classificação de entidades nomeadas tem 3 campos textuais: texto analisado, texto puro e etiquetas. O primeiro campo é o único buscável e os valores armazenados nele passam por um processo de análise e normalização com o objetivo de maximizar os resultados de busca. Foram utilizados os analisadores Whitespace Tokenizer (sepador de palavras por espaços), LowerCaseFilter (transforma o texto todo em letras minúsculas) e ASCIIFoldingFilter (remove todos os acentos).

O campo texto puro contém o texto sem nenhuma etiqueta. O campo etiquetas substitui as palavras anotadas por suas entidades classificadas. No texto "hoje <START:person> Rodrigo <END $>$ será titular", o campo texto puro irá conter " hoje Rodrigo será titular", enquanto o campo etiquetas irá conter " hoje person será titular". Este mecanismo é

\footnotetext{
${ }^{1}$ http://lucene.apache.org/ . Acesso em julho/2012.
} 
interessante pois pode-se adicionar outros campos com mais informações, por exemplo classificação gramatical, assim criando diversas camadas sobre o texto original para melhorar a acertividade do algoritmo.

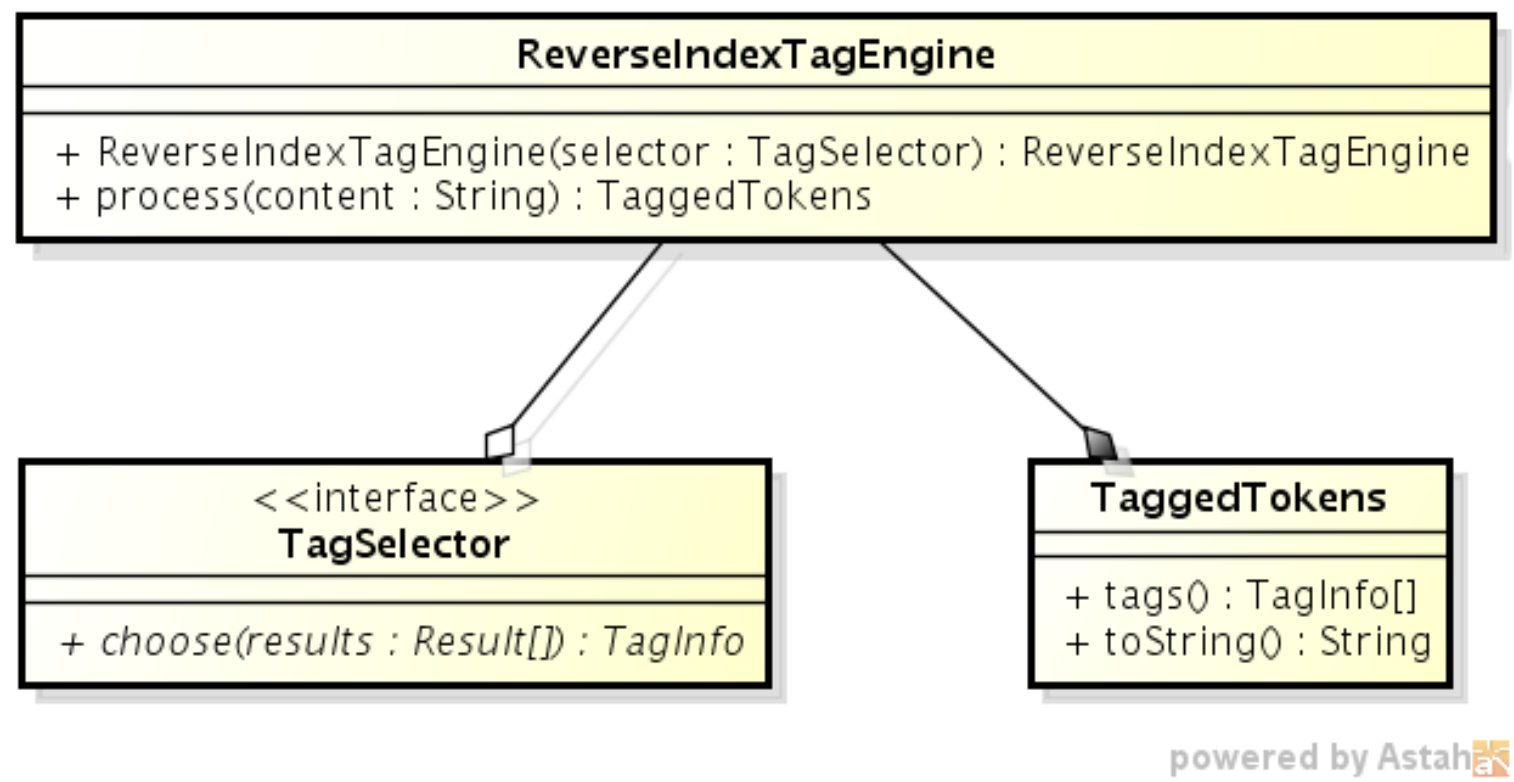

Figura 7.1: Classes do pacote rindex relacionadas ao motor de anotação e classificação.

A Figura 7.1 contém as classes e interfaces utilizadas pelo motor de anotação e classificação. A classe InvertedIndexTagEngine tem como primeira tarefa transformar seu texto de entrada em uma instância da classe Tokens. O próximo passo é realizar buscas utilizando o algoritmo de janela para cada palavra do texto de entrada.

A Tabela 7.1 exibe uma frase e o número de possíveis janelas que podem ser criadas quando o algoritmo utiliza o tamanho máximo igual a 2. As interfaces Tokens e Window estão definidas na Figura 7.2. O método window da interface Tokens necessita de 3 argumentos: pivot, tamanho da janela e direção (esquerda, direita e ambos). A implementação deste método não ignora os caracteres ponto final (.), vírgula(,), interrogação (?), exclamação (!), aspas (") e aspas simples ('); desta forma eles estabelecem barreiras, isolando os contextos.

\begin{tabular}{c|ccccccc|c} 
Linha & Hoje & o & São & Paulo & jogará & no & Morumbi & Núm. Possibilidades \\
\hline 1 & pivot & dir1 & dir2 & & & & & 3 \\
2 & esq1 & pivot & dir1 & dir2 & & & & 4 \\
3 & esq2 & esq1 & pivot & dir1 & dir2 & & & 5 \\
4 & & esq2 & esq1 & pivot & dir1 & dir2 & & 5 \\
5 & & & esq2 & esq1 & pivot & dir1 & dir2 & 5 \\
6 & & & & esq2 & esq1 & pivot & dir1 & 4 \\
7 & & & & & esq2 & esq1 & pivot & 3 \\
\hline & & & & & & & &
\end{tabular}

Tabela 7.1: Exemplo do algoritmo de janelas deslizantes com tamanho máximo igual a 2.

Os resultados de todas as buscas que utilizam o mesmo pivot são repassados para a 
implementação da interface TagSelector, que tem como objetivo avaliá-los e definir se a palavra deve ser anotada e qual a sua classe. Foram implementadas três estratégias para a interface TagSelector: ScoreTagSelector, SimpleTagSelector e ComplexTagSelector. Estas heurísticas serão chamadas de seletor baseado em peso, análise simples e análise completa, respectivamente. A Figura 7.2 exibe as classes envolvidas neste processo de avaliação.

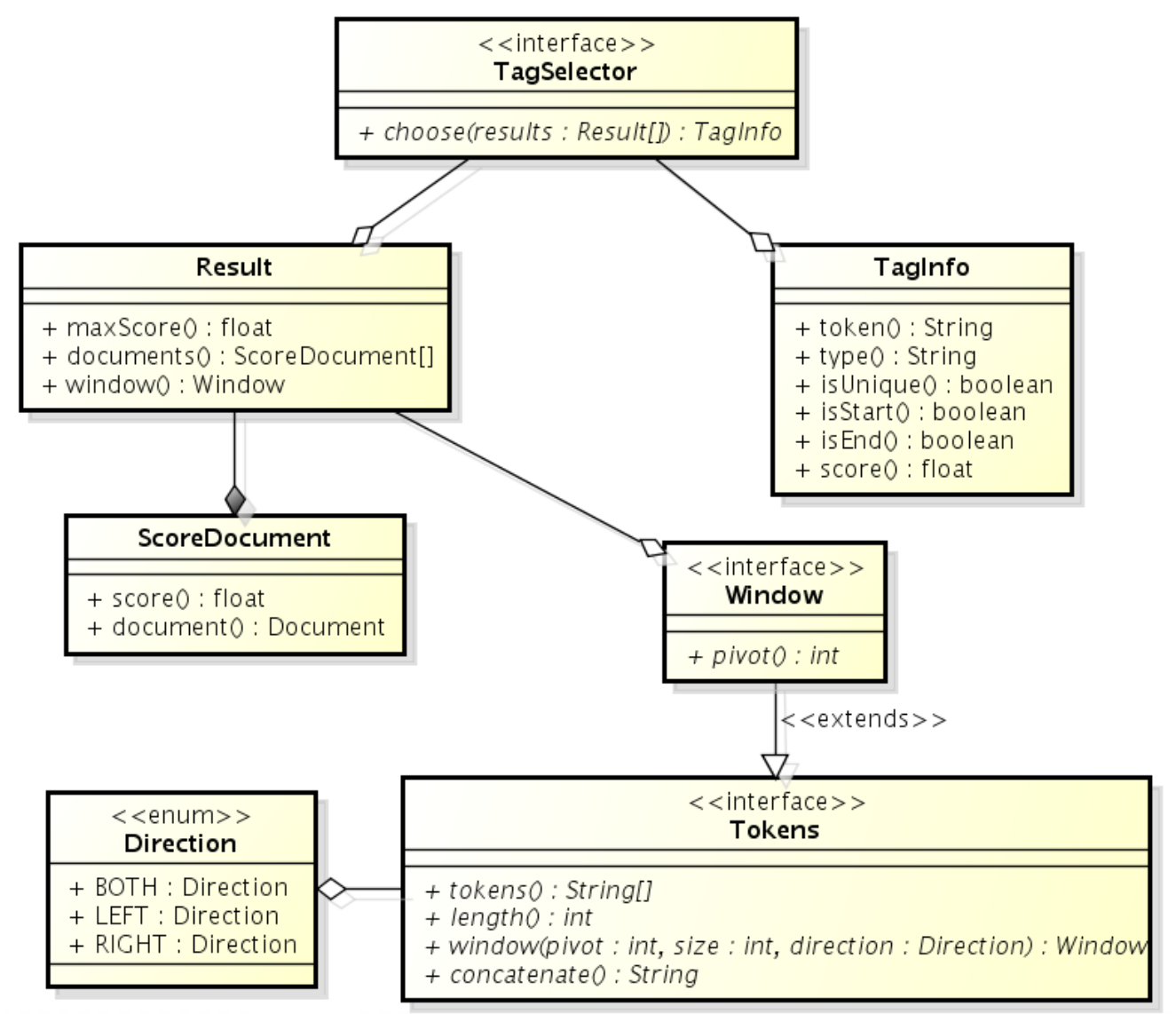

powered by Astahas

Figura 7.2: Classes do pacote rindex relacionadas ao processo de anotação e classificação.

A heurística de seletor baseada em peso escolhe o maior valor calculado pelo algoritmo interno do Lucene. Este leva em consideração a quantidade de repetições da palavra e posicionamento na frase: quanto mais a esquerda, maior o seu valor. Esta é a heurística mais simples implementada e será utilizada para comparação com os demais resultados.

A heurística do seletor de análise simples realiza a ordenação das instâncias de Result de acordo com a janela, de forma que o Result com maior janela é eleito. Em caso de empate a janela em que o pivot estiver mais próximo a posição central ganha. Após esta ordenação é selecionado o primeiro ScoredDocument, que é o documento que tem o maior peso calculado pelo algoritmo interno do Lucene.

A heurística do seletor de análise completa realiza a mesma ordenação do seletor de análise simples, porém, ao invés de pegar o primeiro ScoredDocument, é realizado o processo de contagem entre todos os resultados obtidos nesta busca. Assim a entidade que tiver a maior quantidade de ocorrências é eleita como resposta. 


\subsection{Treinamento}

A fase de treinamento consiste em 15 cenários, sendo estes o cruzamento dos valores para janela (intervalo 1 a 5, inclusive limites) e heurística de seleção (peso, análise simples e análise completa). Foi utilizada a mesma técnica de treinamento particionado apresentada na Seção 6.1, resultando na execução de 150 experimentos. Para a fase de treinamento foi utilizado o córpus UOLCP2011 com o mesmo padrão de anotações utilizados na Seção 6.1 para facilitar as comparações.

O resultado do treinamento é composto por três indicadores: precisão, cobertura e medida F. Todos os indicadores tem seus resultados contidos no intervalo fechado 0 e 1 . A precisão é calculada através da fórmula 7.1, enquanto o cálculo da cobertura é exibido em 7.2. A medida $\mathrm{F}$ é o resultado da razão ilustrada na função 7.3.

$$
\begin{gathered}
\text { precisão(acertos, entidades anotadas })=\frac{\text { acertos }}{\text { entidades anotadas }} \\
\text { cobertura(acertos, entidades esperadas })=\frac{\text { acertos }}{\text { entidades esperadas }} \\
\text { medidaF }(\text { precisão, cobertura })=\frac{2 * \text { precisão } * \text { cobertura }}{\text { precisão }+ \text { cobertura }}
\end{gathered}
$$

Os gráficos 7.3, 7.4 e 7.5 exibem os resultados obtidos durante o treinamento. Cada um destes gráficos contém o resultado de um único indicador em todos os 50 experimentos, cada uma das linhas indica um dos seletores. As linhas verticais posicionadas a cada 10 execuções representam a troca de janela. Assim o intervalo [0-9] utiliza janela com valor igual 1; [10-19] utiliza janela 2; [20-29], janela 3; [30-39], janela 4; [40-49], janela 5.

O gráfico da Figura 7.3 exibe todos os resultados da fase de treinamento para o indicador precisão. Os resultados obtidos foram praticamente os mesmos para as janelas iguais ou maiores que 2. A heurística de análise completa obteve o melhor desempenho em 46 cenários; análise simples ganhou os outros 4 cenários. A heurística de análise completa teve um resultado melhor com janela igual 1, enquanto a análise simples obteve seus melhores resultados com janela igual ou maior a 2 .

O gráfico da Figura 7.4 exibe todos os resultados da fase de treinamento para o indicador cobertura. Os resultados obtidos foram praticamente os mesmos em todas as janelas para as heurísticas de peso e análise completa. Já a heurística de análise simples obteve melhores resultados com janelas iguais ou maiores a 2. A heurística de análise completa obteve o melhor desempenho em 26 cenários; análise simples ganhou os outros 24 cenários.

O gráfico da Figura 7.5 exibe todos os resultados da fase de treinamento para o indicador medida F. Os resultados obtidos foram os mesmos em todas as janelas para a heurística de peso. Já a análise completa e simples tiveram os melhores resultados com janela igual ou maior a 2. A heurística de análise completa obteve o melhor desempenho em 32 cenários; análise simples ganhou os outros 18 cenários. 


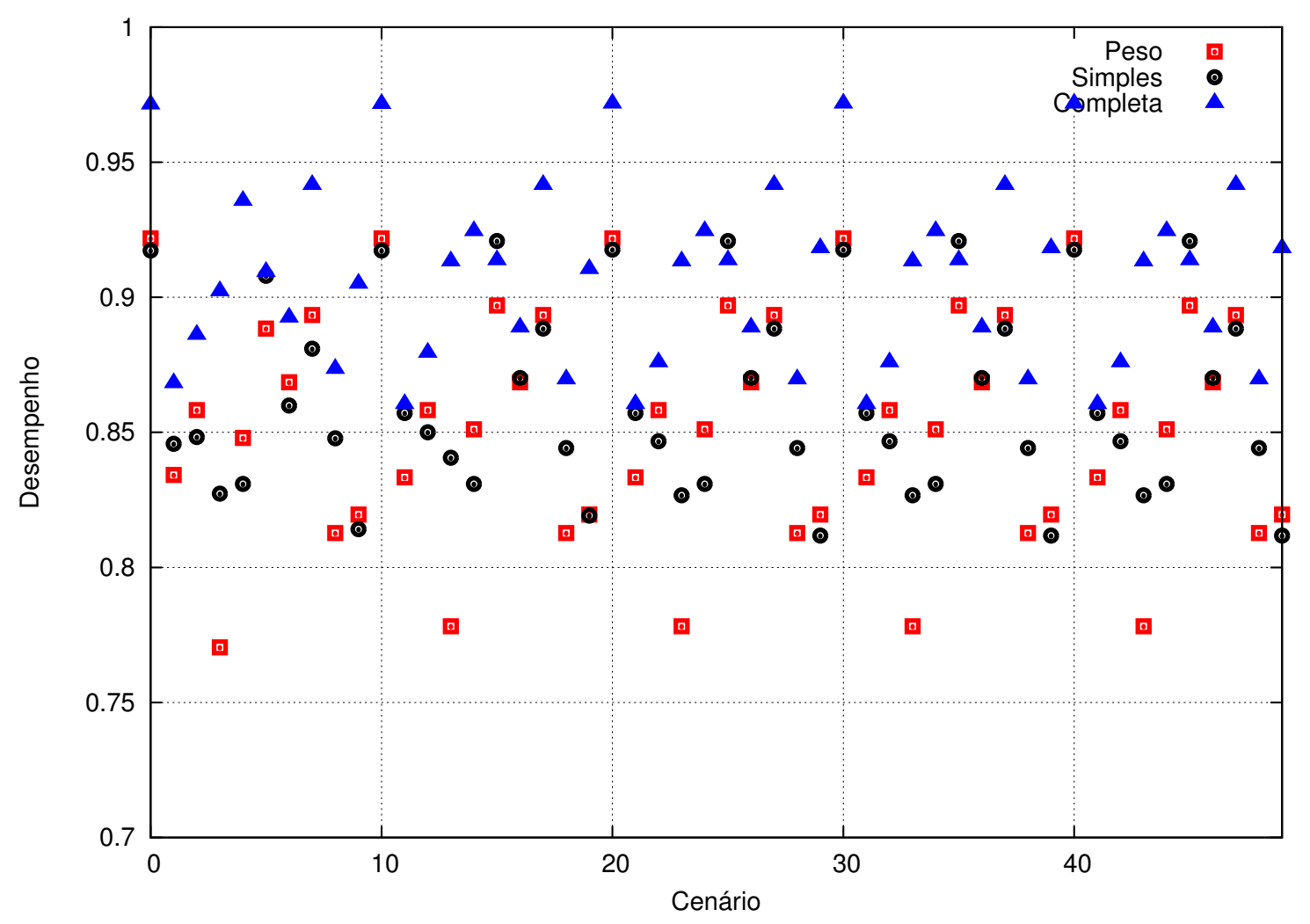

Figura 7.3: Resultado do treinamento para o indicador precisão.

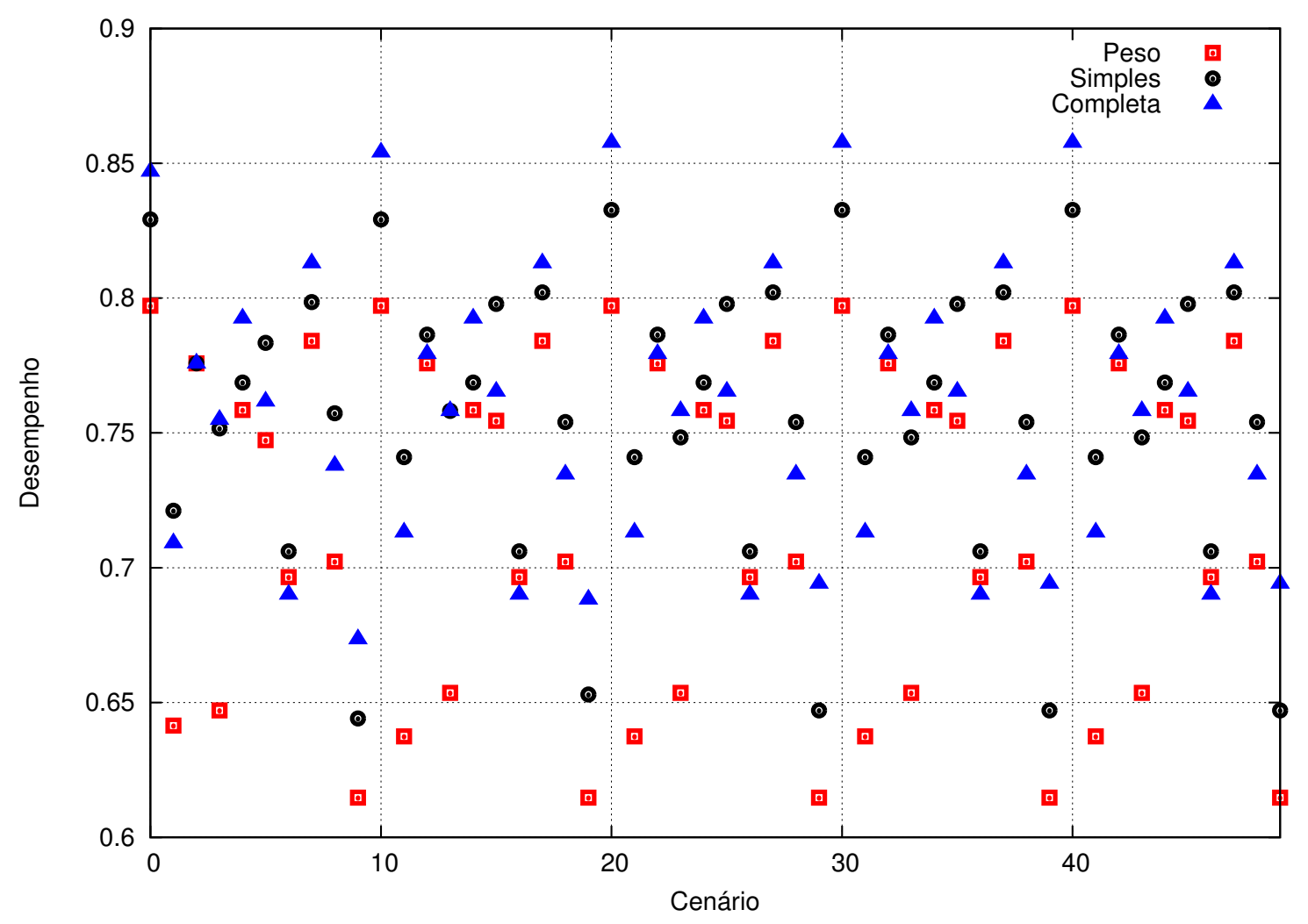

Figura 7.4: Resultado do treinamento para o indicador cobertura. 


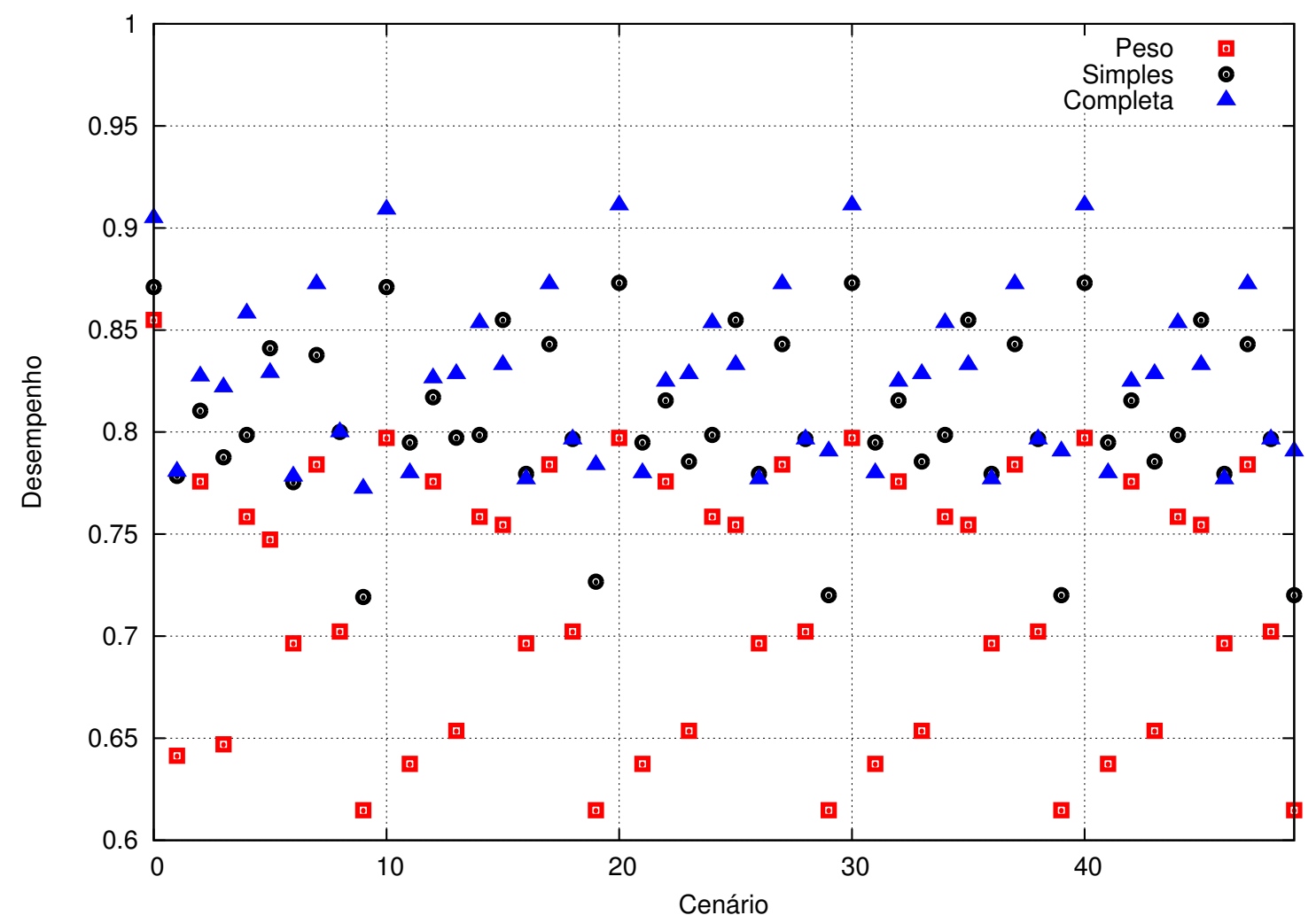

Figura 7.5: Resultado do treinamento para o indicador medida $F$.

\subsection{Análise dos resultados}

Com base no treinamento executado na Seção 7.2 os experimentos realizados com janela igual ou maior 2 obtiveram os melhores resultados no indicador medida F. Assim foi o valor 2 ter a execução mais rápida sem perder a qualidade de anotação e classificação. Os melhores resultados foram obtidos na primeira partição do córpus de treinamento, sendo esta utilizada nas comparações realizadas neste capítulo.

O objetivo deste amplo cruzamento de cenários é determinar qual a implementação do TagSelector é mais eficiente. Assim serão adotados os mesmo cenários de validação utilizados no Capítulo 6.2: avaliação do córpus UOLCP2011 e avaliação do mini córpus de notícias de 2012 .

A Tabela 7.2 exibe os resultados obtidos da anotação e classificação completa do córpus UOLCP2011. A heurística de análise completa foi a que conseguiu os melhores resultados em precisão e cobertura, empatando somente na medida F com a análise simples. A heurística de análise completa teve $0.51 \%$ de erros entre anotação e classificação, enquanto análise simples obteve $1.03 \%$ e peso, $8.83 \%$.

O passo seguinte foi a execução das mesmas heurísticas aplicadas ao mini córpus com novas 20 notícias classificadas manualmente. As Tabelas 7.3, 7.4 e 7.5 exibem os resultados detalhados desta anotação e classificação.

Apesar de alguns indicadores apresentarem valores parecidos, a heurística de análise completa é mais acertiva. No cenário 10, por exemplo, as três heurísticas tiveram 12 entidades 


\begin{tabular}{l|c|c|c} 
& Peso & Simples & Completa \\
\hline Total de entidades & 2930 & 2930 & 2930 \\
Entidades anotadas & 2831 & 2901 & 2895 \\
Anotadas com sucesso & 2581 & 2871 & 2880 \\
Entidades esquecidas & 210 & 42 & 42 \\
Entidades classificadas erradas & 139 & 17 & 8 \\
Entidades anotadas erradas & 111 & 13 & 7 \\
Precisão & 0.91 & 0.98 & 0.99 \\
Cobertura & 0.88 & 0.97 & 0.98 \\
Medida F & 0.89 & 0.98 & 0.98 \\
Tempo (segundos) & 10 & 11 & 14
\end{tabular}

Tabela 7.2: Comparação dos resultados obtidos entre as implementações de TagSelector utilizando o córpus UOLCP2011.

esquecidas. Apesar da quantidade ser a mesma neste quesito, a implementação baseada em peso anotou 18 etiquetas, mas somente 14 estavam corretas, enquanto a análise simples anotou 19 entidades, conseguindo somente 14 com sucesso. Já o heurística de análise completa marcou 15, acertando também 14 entidades.

\begin{tabular}{c|c|c|c|c|c|c} 
Notícia & Total & Anotadas & Sucesso & Esquecidas & Anotadas Erradas & Class. erradas \\
\hline 1 & 15 & 15 & 13 & 2 & 2 & 0 \\
2 & 23 & 19 & 16 & 7 & 3 & 0 \\
3 & 26 & 18 & 14 & 12 & 4 & 0 \\
4 & 31 & 35 & 27 & 1 & 5 & 3 \\
5 & 25 & 22 & 20 & 5 & 2 & 0 \\
\hline 6 & 27 & 17 & 15 & 10 & 0 & 2 \\
7 & 24 & 23 & 20 & 1 & 0 & 3 \\
8 & 32 & 30 & 27 & 4 & 2 & 3 \\
9 & 29 & 29 & 24 & 2 & 2 & 0 \\
10 & 27 & 16 & 15 & 12 & 1 & 2 \\
11 & 33 & 30 & 25 & 4 & 1 & 2 \\
12 & 36 & 29 & 25 & 9 & 2 & 0 \\
13 & 82 & 65 & 63 & 17 & 0 & 2 \\
14 & 21 & 19 & 16 & 5 & 3 & 0 \\
15 & 49 & 29 & 27 & 20 & 0 & 0 \\
\hline 16 & 50 & 36 & 30 & 15 & 1 & 1 \\
17 & 30 & 30 & 27 & 3 & 3 & 2 \\
18 & 30 & 21 & 16 & 14 & 5 & 1 \\
19 & 29 & 20 & 18 & 10 & 3 &
\end{tabular}

Tabela 7.3: Resultados detalhado da anotação e classificação da heurística baseada em peso utilizando o mini córpus.

A Tabela 7.6 exibe os resultados obtidos da anotação e classificação do novo mini córpus classificado manualmente. A heurística de análise completa foi a que conseguiu os melhores resultados em precisão e medida $\mathrm{F}$, perdendo somente na cobertura para a análise simples. A 


\begin{tabular}{c|c|c|c|c|c|c} 
Notícia & Total & Anotadas & Sucesso & Esquecidas & Anotadas Erradas & Class. erradas \\
\hline 1 & 15 & 15 & 13 & 2 & 2 & 0 \\
2 & 23 & 20 & 15 & 6 & 3 & 2 \\
3 & 26 & 19 & 14 & 12 & 5 & 0 \\
4 & 31 & 34 & 27 & 1 & 4 & 3 \\
5 & 25 & 23 & 21 & 4 & 2 & 0 \\
\hline 6 & 27 & 21 & 21 & 6 & 0 & 0 \\
7 & 24 & 25 & 23 & 1 & 2 & 0 \\
8 & 32 & 32 & 27 & 4 & 4 & 1 \\
9 & 29 & 26 & 17 & 6 & 3 & 0 \\
10 & 27 & 20 & 16 & 11 & 4 & 2 \\
\hline 11 & 33 & 30 & 26 & 5 & 2 & 2 \\
12 & 36 & 28 & 25 & 9 & 1 & 0 \\
13 & 82 & 65 & 63 & 17 & 0 & 2 \\
14 & 21 & 21 & 18 & 3 & 3 & 5 \\
15 & 49 & 30 & 28 & 19 & 0 & 0 \\
\hline 16 & 50 & 37 & 31 & 14 & 1 & 4 \\
17 & 30 & 30 & 25 & 4 & 4 & 4 \\
18 & 30 & 22 & 16 & 14 & 6 & 5 \\
19 & 29 & 25 & 16 & 9 & 5 & 3 \\
20 & 36 & 37 & 30 & 2 & &
\end{tabular}

Tabela 7.4: Resultados detalhado da anotação e classificação da heurística de análise simples utilizando o mini córpus.

heurística de análise completa teve $8.80 \%$ de erros entre anotação e classificação, enquanto análise simples obteve $15.71 \%$ e peso, $12.98 \%$. Novamente a heurística de análise completa teve a maior parte dos melhores resultados, sendo considerada a melhor implementação de TagSelector. 


\begin{tabular}{c|c|c|c|c|c|c} 
Notícia & Total & Anotadas & Sucesso & Esquecidas & Anotadas Erradas & Class. erradas \\
\hline 1 & 15 & 12 & 10 & 4 & 1 & 1 \\
2 & 23 & 16 & 14 & 8 & 1 & 1 \\
3 & 26 & 15 & 14 & 12 & 1 & 0 \\
4 & 31 & 32 & 28 & 1 & 2 & 2 \\
5 & 25 & 22 & 21 & 4 & 1 & 0 \\
\hline 6 & 27 & 18 & 16 & 9 & 0 & 2 \\
7 & 24 & 21 & 21 & 3 & 0 & 0 \\
8 & 32 & 28 & 28 & 4 & 0 & 0 \\
9 & 29 & 24 & 18 & 6 & 1 & 0 \\
10 & 27 & 16 & 16 & 11 & 0 & 3 \\
\hline 11 & 33 & 26 & 22 & 8 & 1 & 2 \\
12 & 36 & 28 & 25 & 9 & 1 & 0 \\
13 & 82 & 65 & 63 & 17 & 0 & 2 \\
14 & 21 & 19 & 18 & 3 & 1 & 1 \\
15 & 49 & 30 & 28 & 19 & 0 & 0 \\
\hline 16 & 50 & 37 & 32 & 14 & 1 & 4 \\
17 & 30 & 28 & 25 & 4 & 2 & 0 \\
18 & 30 & 16 & 16 & 14 & 0 & 0 \\
19 & 29 & 20 & 16 & 9 & 0 & 3 \\
20 & 36 & 38 & 35 & 1 & &
\end{tabular}

Tabela 7.5: Resultados detalhado da anotação e classificação da heurística de análise completa utilizando o mini córpus.

\begin{tabular}{l|c|c|c} 
& Peso & Simples & Completa \\
\hline Total de entidades & 655 & 655 & 655 \\
Entidades anotadas & 539 & 560 & 511 \\
Anotadas com sucesso & 469 & 472 & 466 \\
Entidades esquecidas & 156 & 149 & 160 \\
Entidades classificadas erradas & 30 & 34 & 29 \\
Entidades anotadas erradas & 40 & 54 & 16 \\
Precisão & 0.87 & 0.84 & 0.91 \\
Cobertura & 0.71 & 0.72 & 0.71 \\
Medida F & 0.78 & 0.77 & 0.79 \\
Tempo (segundos) & 4 & 5 & 7
\end{tabular}

Tabela 7.6: Comparação dos resultados obtidos entre as implementações de TagSelector utilizando o mini córpus. 


\section{Capítulo 8}

\section{Método de mesclagem ROdIME}

Este capítulo tem a finalidade de descrever o processo de criação do método ROdIME de mesclagem e compará-lo com os resultados obtidos nos Capítulos 6 e 7 . O objetivo deste método é unir da melhor forma possível os resultados dos métodos de maximização de entropia e índices reversos.

\subsection{Implementação}

O processo de desenvolvimento para o método de mesclagem ROdIME foi composto de cinco etapas: prova de conceito, melhorias das informações fornecidas pela biblioteca openNLP, definição da interface BestScore, nota mínima para classificação e utilização de múltiplos modelos treinados com openNLP. A Figura 8.1 exibe a versão final das classes e interfaces utilizadas durante o processo de concepção deste método.

A primeira implementação do método ROdIME de mesclagem foi o desenvolvimento de uma prova de conceito. Foram utilizadas duas entradas, sendo uma o modelo de treinamento coletivo baseado em maximização de entropia (de acordo com os resultados do Capítulo 6.2, este modelo teve uma abrangência maior de classificação) e outra o modelo baseado em índices invertidos (de acordo com os resultados do Capítulo 7.3 foi utilizado o modelo treinado com a primeira partição do córpus de treinamento). Nesta implementação do método de mesclagem, o texto de entrada era submetido às duas instâncias de TagEngine e ambos resultados eram mesclados da seguinte forma: caso ambos anotassem uma entidade com mesma classificação, este valor era utilizado; se a classificação fosse diferente, o resultado escolhido era a entidade anotada pelo motor de maximização de entropia. Caso somente um dos motores de classificação realizasse a anotação, esta também era utilizada.

Esta abordagem teve um bom resultado, mostrando a potencialidade do método, porém este apontava também diversos pontos de melhoria. Neste momento somente a implementação baseada em índices invertidos trazia o campo score da classe TagInfo prenchido corretamente. Para melhorar o algoritmo de mesclagem seria interessante trabalhar com o grau de confiança que cada motor de anotação e classificação tinha em suas entidades mencionadas. 


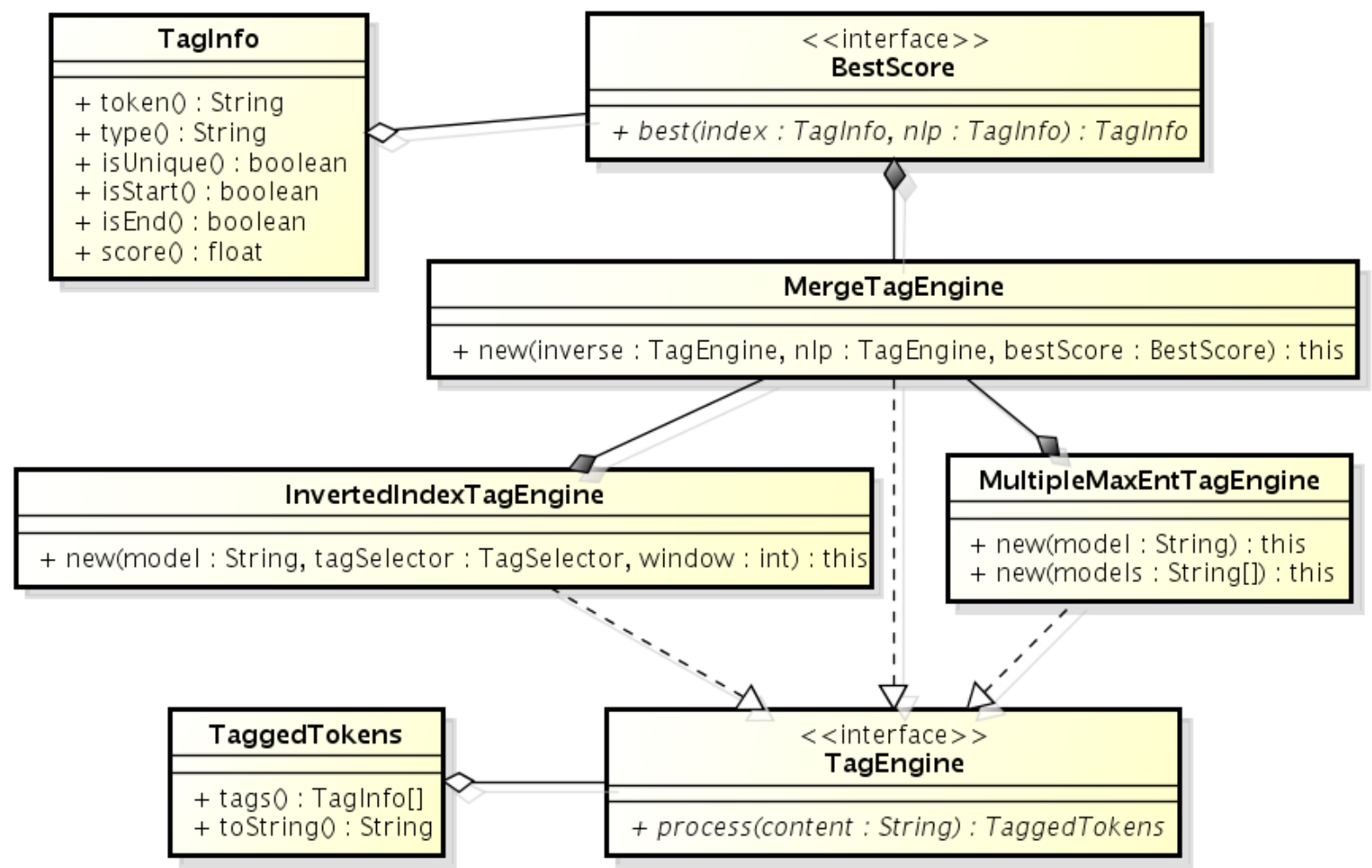

powered by Astahatia

Figura 8.1: Diagrama de classes da implementação do método de mesclagem ROdIME.

A implementação de maximização de entropia baseada em openNLP não trazia nenhum coeficiente para esta finalidade.

Para extrair mais informações do módulo maximização de entropia utilizado pelo openNLP (maxent) foi necessário criar uma extensão da classe NameFinderME chamada ScoreNameFinderME. O próximo passo foi criar uma extensão da classe Span chamada de ScoreSpan que contém um campo adicional do tipo float chamado score. Desta forma o método find foi sobrescrito para devolver instâncias desta nova classe. Assim, para cada entidade anotada o motor que utilizava maximização de entropia passou a devolver o grau de confiança daquela anotação. Mas esta situação ainda não era ideal, pois as palavras não anotadas como entidade não traziam consigo este coeficiente de confiança; então foi implementado um novo método na classe ScoreNameFinderME chamado scoredFind que passou a devolver uma lista de instâncias de TagInfo ao invés de ScoreSpan. Com isso ambas implementações de motor de anotação e classificação passaram a entregar o grau de confiança para todas a palavras contidas no texto de entrada.

O intervalo de valores possíveis para o campo score da implementação de maximização de entropia está contido no intervalo fechado [0-1]. Já os valores para a implementação de índices invertidos utilizam o intervalo fechado [0-5.5]. A Equação 8.1 exibe a regra de atribuição destes valores. Esta função recebe dois argumentos: tamanho da janela e posição 
do pivot.

$$
\text { score }(\text { janela }, \text { pivot })= \begin{cases}\text { janela }- \text { pivot }=\text { janela } / 2, & \text { devolve janela }+0.5 \\ \text { caso contrário } & \text { devolve janela }\end{cases}
$$

Após esta rodada de desenvolvimento foi criada a interface BestScore que tem como objetivo avaliar duas instâncias de TagInfo e devolver a classificação mais adequada. Assim foram realizados diversos testes entre diferentes combinações dos valores do campo score. A Equação 8.2 exibe a melhor combinação de resultados obtidos na primeira rodada de testes.

$$
\text { melhor }(\text { maxent }, \text { invert })= \begin{cases}\text { maxent }>0.95 \mathrm{E} \text { invert }<4 & \text { OU } \\ \text { maxent }>0.85 \mathrm{E} \text { invert }<2 & \text { OU } \\ \text { invert }=0, & \text { devolve maxent } \\ \text { caso contrário } & \text { devolve invert }\end{cases}
$$

Após realizar mais alguns testes outro padrão se mostrou visível: ambos algoritmos classificaram uma entidade, porém ambos com o grau de confiança baixo. Assim foi implementada uma terceira possibilidade: se o valor do TagInfo classificado pelo motor de maximização de entropia fosse menor que um limite pré definido e ao mesmo tempo o valor classificado pelo motor de índices invertidos fosse igual ou menor que 1 não seria aplicada nenhuma classificação a entidade em questão. O valor menor ou igual 1 foi utilizado pois ele indica que a palavra nunca foi vista anteriormente neste contexto, indicando um grau alto de incerteza. A Equação 8.3 ilustra as novas condições do método de escolha do melhor valor. Foram realizados testes com diversos valores para parâmetro limite, sendo 0.5 o que demonstrou os melhores resultados.

$$
\text { melhor }(\text { maxent, invert, limite })= \begin{cases}\text { maxent }>0.95 \mathrm{E} \text { invert }<4, & \text { OU } \\ \text { maxent }>0.85 \mathrm{E} \text { invert }<3, & \text { OU } \\ \text { invert }=0, & \text { devolve maxent } \\ \text { maxent }<\text { limite E } \text { invert }<=1, & \text { devolve vazio } \\ \text { caso contrário } & \text { devolve invert }\end{cases}
$$

O último passo para finalizar a implementação do método de mesclagem ROdIME foi adicionar o suporte a três motores de anotação e classificação. Nesta implementação foram utilizados os dois melhores modelos treinados no Capítulo 6.1: modelo de treinamento indiviual e modelo de treinamento coletivo. Para realizar o suporte ao modelo de treinamento individual foi necessário extender a classe MaxEntTagEngine criando um novo construtor 
que suportasse uma lista de modelos. Foram utilizados 6 modelos: pessoa, time, estádio, local, organização e campeonato. Além do construtor foi necessário implementar um método de mesclagem dos resultados encontrados por cada um dos modelos, a heurística empregada foi selecionar o TagInfo com o maior grau de confiança para cada palavra, pegando a primeira ocorrência em caso de empate.

Ao invés de alterar a interface BestScore para receber três instâncias de TagInfo foi realizada uma implementação mais simples. Caso o motor de anotação e classificação que utiliza o modelo de treinamento individual anotasse uma palavra, esta sugestão era aceita mesmo sem avaliar as demais, caso contrário o processo continua o mesmo. Esta implementação foi realizada desta forma devido ao altísssimo índice de acerto deste treinamento, porém sua cobertura é baixa, como visto no Capítulo 6.2.

\subsection{Análise dos resultados}

A Tabela 8.1 realiza uma comparação dos resultados: treinamento individual e coletivo baseados em maximização de entropia (valores obtidos da Tabela 6.2); heurística de análise completa utilizando índices invertidos (valores retirados da Tabela 7.2); método de mesclagem ROdIME utilizando todas as implementações descritas no Capítulo 8.1. O objetivo desta comparação é descobrir se o método de mesclagem realmente agrega valor em relação aos outros algoritmos discutidos durante este trabalho. Assim foram adotados os mesmos cenários de validação utilizados no Capítulo 6.2: avaliação do córpus UOLCP2011 e avaliação do mini córpus de notícias de 2012.

Com exceção do método de anotação e classificação que utilizou treinamento coletivo todos os demais conseguiram obter 99\% de precisão utilizando o córpus UOLCP2011. Somente dois destes métodos conseguiram obter a cobertura igual a $98 \%$ : índices reversos com heurística de seletor de análise completa e método de mesclagem ROdIME. Somente este último método conseguiu atingir a marca de $99 \%$ no indicador medida F. Este resultado é bastante expressivo e mostra que este método atingiu seu objetivo neste cenário.

O método de mesclagem ROdIME foi o que melhor se aproximou da quantidade de entidades que deveriam ser anotadas, com a maior taxa de sucesso de anotação e classificação. Também foi o método que menos esqueceu de anotar entidades e cometeu a mesma quantidade de erros do método de índices invertidos, no total de 15, entre anotação e classificação.

A Tabela 8.2 exibe o resultado detalhado da anotação e classificação do mini córpus de notícias classificadas manualmente. O método ROdIME obteve o menor valor de entidades anotadas erradas entre todos os resultados expressos nas Tabelas 6.3, 6.4, 7.3, 7.4 e 7.5.

A Tabela 8.3 exibe a comparação dos mesmo métodos utilizados na Tabela 8.1, porém utilizando o mini córpus ao invés do córpus UOLCP2011. O método de mesclagem ROdIME apesar de liderar somente o indicador medida F com 5\% de vantagem sobre o segundo concorrente, conseguiu o segundo lugar em todos os outros indicadores, perdendo para diferentes 


\begin{tabular}{l|c|c|c|c} 
& Individual & Coletivo & Completa & Mesclagem \\
\hline Total de entidades & 2930 & 2930 & 2930 & 2930 \\
Entidades anotadas & 1950 & 2988 & 2895 & 2907 \\
Anotadas com sucesso & 1944 & 2748 & 2880 & 2892 \\
Entidades esquecidas & 981 & 92 & 42 & 30 \\
Entidades classificadas erradas & 5 & 90 & 8 & 8 \\
Entidades anotadas erradas & 1 & 150 & 7 & 7 \\
Precisão & 0.99 & 0.91 & 0.99 & 0.99 \\
Cobertura & 0.66 & 0.93 & 0.98 & 0.98 \\
Medida F & 0.79 & 0.92 & 0.98 & 0.99 \\
Tempo (segundos) & 4 & 2 & 14 & 16
\end{tabular}

Tabela 8.1: Comparação entre os resultados obtidos com o córpus UOLCP2011.

\begin{tabular}{|c|c|c|c|c|c|c|}
\hline Notícia & Total & Anotadas & Sucesso & Esquecidas & Anotadas Erradas & Class. erradas \\
\hline 1 & 15 & 13 & 12 & 2 & 0 & 1 \\
\hline 2 & 23 & 17 & 16 & 6 & 0 & 1 \\
\hline 3 & 26 & 23 & 23 & 3 & 0 & 0 \\
\hline 4 & 31 & 30 & 29 & 1 & 0 & 1 \\
\hline 5 & 25 & 24 & 23 & 1 & 0 & 1 \\
\hline 6 & 27 & 15 & 11 & 12 & 0 & 4 \\
\hline 7 & 24 & 20 & 20 & 4 & 0 & 0 \\
\hline 8 & 32 & 27 & 27 & 5 & 0 & 0 \\
\hline 9 & 29 & 26 & 22 & 3 & 0 & 4 \\
\hline 10 & 27 & 18 & 17 & 9 & 0 & 1 \\
\hline 11 & 33 & 25 & 21 & 9 & 1 & 3 \\
\hline 12 & 36 & 28 & 25 & 9 & 1 & 2 \\
\hline 13 & 82 & 75 & 72 & 7 & 0 & 3 \\
\hline 14 & 21 & 18 & 17 & 3 & 0 & 1 \\
\hline 15 & 49 & 43 & 43 & 6 & 0 & 0 \\
\hline 16 & 50 & 48 & 44 & 2 & 0 & 4 \\
\hline 17 & 30 & 25 & 24 & 5 & 0 & 1 \\
\hline 18 & 30 & 24 & 23 & 6 & 0 & 1 \\
\hline 19 & 29 & 24 & 19 & 5 & 0 & 5 \\
\hline 20 & 36 & 36 & 35 & 1 & 1 & 0 \\
\hline
\end{tabular}

Tabela 8.2: Resultados detalhado da anotação e classificação do método de mesclagem ROdIME utilizando o mini córpus.

algoritmos em cada quesito. O treinamento individual ganhou em: precisão com 98\%, 5\% a mais; quantidade de entidades anotadas erradas, 1 contra 3 do método de mesclagem; e 3 entidades classificadas erradas versus 33 do método ROdIME. Já o treinamento coletivo ganhou nos quesitos: entidades anotadas (648 a 559), anotadas com sucesso (528 a 523), entidades esquecidas (62 a 99) e o indicador cobertura (80\% contra $79 \%$ ). O algoritmo de índices invertidos utilizando o seletor de análise completa não obteve nenhuma vitória sobre o método de mesclagem ROdIME. 


\begin{tabular}{l|c|c|c|c} 
& Individual & Coletivo & Completa & Mesclagem \\
\hline Total de entidades & 655 & 655 & 655 & 655 \\
Entidades anotadas & 231 & 648 & 511 & 559 \\
Anotadas com sucesso & 227 & 528 & 466 & 523 \\
Entidades esquecidas & 425 & 62 & 160 & 99 \\
Entidades classificadas erradas & 3 & 55 & 29 & 33 \\
Entidades anotadas erradas & 1 & 62 & 16 & 3 \\
Precisão & 0.98 & 0.81 & 0.91 & 0.93 \\
Cobertura & 0.34 & 0.80 & 0.71 & 0.79 \\
Medida F & 0.51 & 0.81 & 0.79 & 0.86 \\
Tempo (segundos) & 2 & 1 & 7 & 8
\end{tabular}

Tabela 8.3: Comparação entre os resultados obtidos com o mini córpus.

\subsection{Comparação com método Carvalho'12}

Com o intuito de validar a eficiência do método de mesclagem ROdIME, este seção irá compará-lo com os resultados do método apresentado por Carvalho (2012), atualmente o quinto melhor método na classificação geral do $\mathrm{HAREM}^{1}$, sendo este o melhor resultado alcançado por métodos completamente automatizados de anotação e classificação de entidades nomeadas. A implementação deste método é baseada em maximização de entropia e uso de dicionários, levando também em consideração a classificação gramatical das palavras.

Para que o resultado desta comparação tenha validade os métodos propostos por Carvalho (2012) foram treinados utilizando o córpus UOLCP2011 da mesma forma que os algoritmos apresentados neste trabalho, mais detalhes sobre o treinamento particionado na Seção 6.1.

Em Carvalho (2012) foram propostos dois métodos de anotação e classificação de entidades nomeadas: MTodas e MSinergia. Após realizar diversos testes preliminares, o modelo MSinergia foi descartado, pois este precisa de um volume muito grande de informações durante o treinamento para ser eficiente. O modelo MTodas será utilizado para as comparações a seguir. Este modelo pode ter seu resultado melhorado através do uso de um filtro de sentenças, implementação descrita em Carvalho (2012) no Capítulo 7.4.2; o resultado obtido neste método também fez parte desta comparação.

A Tabela 8.4 exibe os resultados obtidos na comparação do método de mesclagem ROdIME e os métodos descritos em Carvalho (2012) utilizando o córpus UOLCP2011. Assim como nos outros resultados obtidos das implementações baseadas em openNLP neste trabalho, os métodos MTodas anotaram e acertaram mais entidades, porém o índice de acerto foi menor. Por anotar mais entidades, os métodos MTodas, obtiveram uma quantidade menor de entidades esquecidas, porém a quantidade de erros de anotação foi maior. O indicador cobertura teve o melhor resultado utilizando o método MTodas com filtro, enquanto o modelo MTodas teve o mesmo desempenho do método de mesclagem ROdIME. Já no indicador medida F o método de mesclagem ROdIME teve um desempenho superior a todas as im-

\footnotetext{
${ }^{1}$ http://www.linguateca.pt/HAREM/ . Acesso em julho/2012.
} 
plementações descritas em Carvalho (2012).

\begin{tabular}{l|c|c|c} 
& ROdIME & MTodas & MTodas com filtro \\
\hline Total de entidades & 2930 & 2930 & 2930 \\
Entidades anotadas & 2907 & 2976 & 3005 \\
Anotadas com sucesso & 2892 & 2898 & 2903 \\
Entidades esquecidas & 30 & 15 & 11 \\
Entidades classificadas erradas & 8 & 17 & 16 \\
Entidades anotadas erradas & 7 & 61 & 88 \\
Precisão & 0.99 & 0.97 & 0.96 \\
Cobertura & 0.98 & 0.98 & 0.99 \\
Medida F & 0.99 & 0.98 & 0.97
\end{tabular}

Tabela 8.4: Comparação entre método de mesclagem ROdIME e Carvalho'12 para anotação e classificação do córpus UOLCP2011.

A Tabela 8.5 exibe os resultados obtidos na comparação do método de mesclagem ROdIME e os métodos descritos em Carvalho (2012) utilizando o mini córpus. Assim como nos outros resultados obtidos das implementações baseadas em openNLP neste trabalho, os métodos MTodas anotaram e acertaram mais entidades, porém o índice de acerto foi menor, ambos com a precisão na casa dos 88\%, enquanto o método ROdIME obteve $93.55 \%$. Por anotar mais entidades, os métodos MTodas, obtiveram uma quantidade menor de entidades esquecidas, porém a quantidade de erros de anotação foi maior, ambos superiores ou iguais 70 erros contra 36 do método ROdIME. O indicador cobertura teve melhores resultados utilizando o métodos MTodas. Já no indicador medida F o método de mesclagem ROdIME teve um desempenho superior a todas as implementações descritas em Carvalho (2012).

\begin{tabular}{l|c|c|c} 
& ROdIME & MTodas & MTodas com filtro \\
\hline Total de entidades & 655 & 655 & 655 \\
Entidades anotadas & 559 & 605 & 616 \\
Anotadas com sucesso & 523 & 535 & 545 \\
Entidades esquecidas & 99 & 67 & 59 \\
Entidades classificadas erradas & 33 & 53 & 51 \\
Entidades anotadas erradas & 3 & 17 & 20 \\
Precisão & 0.93 & 0.88 & 0.88 \\
Cobertura & 0.79 & 0.81 & 0.83 \\
Medida F & 0.86 & 0.84 & 0.85
\end{tabular}

Tabela 8.5: Comparação entre método de mesclagem ROdIME e Carvalho'12 para anotação e classificação do mini córpus. 


\section{Capítulo 9}

\section{Conclusão}

O principal objetivo deste trabalho foi a construção de uma plataforma para anotação e classificação automática de entidades nomeadas em notícias esportivas escritas em português do Brasil. Para atingir este objetivo foram desenvolvidos três artefatos principais: interface rica web para a classificação de documentos, o córpus anotado UOLCP2011 e a avaliação e comparação entre três diferentes estratégias para a classificação automática de entidades nomeadas.

Tanto o código fonte da interface de anotação e classificação de documentos quanto o córpus UOLCP2011 estão disponíveis para download no GitHub¹ sob a licença MIT.

Após realizar a implementação dos métodos de maximização de entropia e outra usando índices invertidos foi proposta uma nova solução, esta baseada na mesclagem dos resultados destes dois métodos. Os resultados deste novo método foram muito satisfatórios, de forma a absorver as melhores características de cada um, gerando um resultado mais preciso e com menor índice de erros em relação a quantidade de entidades anotadas.

Para avaliar se o método de mesclagem ROdIME realmente era eficiente foi importante realizar a comparação com outros métodos já propostos no meio acadêmico. Assim o algoritmo definido por Carvalho (2012) foi utilizado como referência. Atualmente este detem o quinto melhor resultado na classificação geral do HAREM, sendo este o melhor resultado alcançado por métodos completamente automatizados de anotação e classificação de entidades nomeadas.

Os resultados alcançados pelo método de mesclagem ROdIME se mostraram superiores ao método Carvalho'12, validando-o como uma boa alternativa para anotação e classificação de entidades nomeadas em português do Brasil.

\footnotetext{
${ }^{1}$ https://github.com/rodzac/webcorpus/ e https://github.com/rodzac/UOLCP2011/, respectivamente.
} 


\subsection{Trabalhos futuros}

Após a implementação da plataforma de anotação e classificação automática de entidades nomeadas existem alguns pontos que podem ser melhores explorados, a seguir uma breve lista dos principais:

- Adicionar tratamentos de expiração e edição concorrente na ferramenta na interface WebCorpus;

- Criar perfil de usuário para realizar histórico das mudanças de anotação e classificação;

- Criar uma área administrativa na ferramenta WebCorpus para realizar a gestão das etiquetas;

- Adicionar suporte a multiplos córpus em uma única instância da ferramenta WebCorpus;

- Realizar testes com técnicas de aprendizado infinito utilizando a abordagem de índices invertidos;

- Avaliar a inserção de outros métodos automáticos de anotação e classificação no algoritmo de mesclagem;

- Realizar o treinamento do algoritmo ROdIME utilizando o córpus do HAREM. 


\section{Referências Bibliográficas}

Bick (2000) Eckhard Bick. The parsing system "palavras": Automatic grammatical analysis of portuguese in a constraint grammar framework. Citado na pág. 8

Brill (1992) E. Brill. A simple rule-based part of speech tagger. Em Proceedings of the Third Conference on Applied Natural Language Process, Trento, Italy. Association for Computational Linguistics. Citado na pág. 13

Candido Jr. (2008) Arnaldo Candido Jr. Criação de um ambiente para processamento de córpus de Português Histórico. Citado na pág. 5

Carvalho (2012) Wesley Seidel Carvalho. Reconhecimento de entidades mencionadas em português utilizando aprendizado de máquina. Citado na pág. 3, 66, 67, 69

Cho et al. (1998) Junghoo Cho, Hector G. Molina e Lawrence Page. Efficient crawling through url ordering. Computer Networks and ISDN Systems, 30. Citado na pág. 10

Fowler (2004) Martin Fowler. Inversion of control containers and the dependency injection pattern, 01 2004. Citado na pág. 17, 26

Gasperin e de Lima (2001) Caroline Varaschin Gasperin e Vera Lúcia Strube de Lima. Fundamentos do processamento estatístico da linguagem natural. Relatório técnico, PUCRS. Citado na pág. 1

Giouli e Piperidis (2007) Voula Giouli e Stelios Piperidis. Corpora and hlt: Current trends in corpus processing and annotation. Citado na pág. 30

Heydon e Najork (1999) Allan Heydon e Marc Najork. Mercator: A scalable, extensible web crawler. World Wide Web, 2. Citado na pág. 10

Knuth (1998) Donald Knuth. Sorting and Searching, Second Edition. Addison-Wesley. Citado na pág. 12

Manning e Schütze (1999) Christopher Manning e Hinrich Schütze. Foundations of Statistical Natural Language Processing. The MIT Press. Citado na pág. 1, 11, 32

McEnery e Wilson (1996) Tony McEnery e Andrew Wilson. Corpus Linguistics. Edinburgh University Press, 1st ed. ISBN 0748611657. Citado na pág. 6 
Michalski et al. (1985) Ryszard S. Michalski, Jaime G. Carbonell e Tom M. Mitchell. Machine Learning: An Artificial Intelligence Approach. Morgan Kaufmann. Citado na pág. 10

Milidíu et al. (2006) Ruy Luiz Milidíu, Julio Cesar Duarte e Roberto Cavalcante. Machine learning algorithms for portuguese named entity recognition. Citado na pág. 13, 14

Ratnaparkhi (1998) Adwait Ratnaparkhi. Maximum entropy models for natural language ambiguity resolution. Relatório técnico, Univerty of Pennsylvania. Citado na pág. 11

Russell e Norvig (1995) Stuart Russell e Peter Norvig. Artificial Intelligence: A Modern Approach. Prentice Hall. Citado na pág. 10

Sardinha (2004) Tony Berber Sardinha. Linguística de Corpus. Manole. Citado na pág. 5, 30 Vapnik (1998) V. Vapnik. Statistical Learning Theory. Wiley, New York, NY. Citado na pág. 14

Zobel e Moffat (2006) Justin Zobel e Alistair Moffat. Inverted files for text search engines. ACM Computing Surveys, 38. Citado na pág. 12 